BNL- -52324

DE92 016756

\title{
RAPID QUENCHING OF MOLTEN LITHIUM-ALUMINUM JETS IN WATER UNDER LOSS-OF-CONTROL-ROD-COOLING CONDITIONS
}

*G.A. Greene, C.C. Finfrock, C.E. Schwarz, ${ }^{\star \star M}$ M.L. Hyder, and D.K. Allison

January 1992

*EXPERIMENTAL HEAT TRANSFER AND FLUID DYNAMICS GROUP DEPARTMENT OF NUCLEAR ENERGY

BROOKHAVEN NATIONAL LABORATORY, ASSOCIATED UNIVERSITIES, INC.

UPTON, LONG ISLAND, NEW YORK 11973

**SAFETY ANALYSIS GROUP

SAVANNAH RIVER LABORATORY

WESTINGHOUSE SAVANNAH RIVER COMPANY

AIKEN, SOUTH CAROLINA 29808

and

UNDER CONTRACT NO. DE-ACO2-76CHOOO16 WITH THE UNITED STATES DEPARTMENT OF ENERGY 


\section{DISCLAIMER}

This report was prepared as an account of work sponsored by an agency of the L'nited States Government. Neither the United States Government nor any agency thereof. nor any of their employees, nor any of their contractors. subcontractors, or their employees, makes any warranty, express or implied, or assumes any legal liability or responsibility for the accuracy, cornpleteness, or usefulness of any information. apparatus, product, or process disclosed, or represents that its use would not infinge privately owned rights. Reference herein to any specific commercial product. process. i) service by trade name, trademark, manufacturer. or otherwise, does not necessanly constitute or imply its endorsement, recommendation, or favoring by the United States Government or any agency, contractor or subcontractor thereot. The views and opinions of authors expressed herein do not necessanly state or retlect those of the United States Government or any agency, contractor or subcontractor thereot.

Printed in the United States of America

Available from

National Technical Information Service

U.S. Department of Commerce

5285 Port Royal Road

Springfield, VA 22161

NTIS price codes

Printed Copy: A05: Microfiche Copy: A01 


\begin{abstract}
A series of fifteen tests were performed to investigate the thermal interactions between molten LiAl control rod material and water under conditions prototypic of the loss-of-controlrod-cooling (LCRC) accident scenario. The experimental parameters such as melt mass, stream diameter, melt temperature and flowrate, water depth and water temperature were controlled or varied to agree with analytically determined conditions, thus insuring prototypicality of the experiments and applicability of the results. Experiments were performed in an actual Qseptifoil with web insert; the test section was one meter tall. Natural triggers were in restigated in selected tests, to evaluate the self-triggering potential of this system. The self-triggering mechanisms that were investigated were thermal stratification of the water pool, two-phase flow in the water pool, and simultaneous drop of a control rod in a parallel channel. Only benign interactions were observed during these tests with some evidence of pressurization in the tests with deepest and hottest water pools. There was no evidence of any explosive interactions in any of the tests, even those with natural triggers. The molten LiAl jet was found to undergo jet breakup and fragmentation; in some cases the debris hung up in the web, in other cases the debris settled into a loose debris bed at the bottom of the septiloil. It is concluded from these tests that molten lithium-aluminum alloy injected into water under conditions prototypic of LCRC conditions will not self-trigger to a steam explosion nor can it be triggered by naturally occurring triggers. The mode of interaction is benign jet breakup and fragmentation, followed by debris solidification. Explosive events did not occur and may not even be possible under these conditions. As a result, the LCRC accident cannot propagate damage and should not be a power-limiting concern in the K-reactor.
\end{abstract}




\section{EXECUTIVE SUMMARY}

Recently, restart activities for the WSRC K-reactor have begun to consider phenomena in the design basis suggestive of severe accident conditions in addition to the traditional thermalhydraulics considerations. The accident of most concern for the restart of the K-reactor which could result in some melting of non-fuel components involves loss of forced cooling to one of the sixty control rod assemblies due to failure to seat the housing properly on its end fitting. This accident is known as the Loss-of-Control-Rod-Cooling/Septifoil Mis-seat Accident (LCRC mis-seat). The concern in the LCRC accident is that, due to loss of forced cooling, the lithiumaluminum control rods would rapidly heat up and begin to melt. If the control rod material were to melt, it would drain down the intact portion of the rod and enter the water, possibly as a gravity-driven jet. There have been concerns raised that the molten jet of lithium-aluminum alloy could engage in a high efficiency thermal-chemical steam explosion with the water in the lower portion of the septifoil, causing significant local mechanical damage to the septifoil and surrounding fuel assemblies. The objectives of this program are to experimentally investigate the interactions between molten lithium-aluminum control rod material and water under conditions as close to prototypic as possible of the K-reactor LCRC accident case. The specific objectives of these tests are to create jets of molten lithium-aluminum control rod material of small diameter to simulate the melt-water contact mode expected under LCRC conditions and to look for melt-water explosive events and the parameters and conditions that promote these interactions.

An apparatus was constructed specifically for the performance of these tests. The apparatus combines the ability to withstand severe explosive loads with the ability for precision measurements and rapid experimental turn-around. It consists of three major functional components, the cylindrical explosion-proof vessel in which the septifoil is housed, the melt crucible and heater assembly, and the pneumatic injector. The blast vessel consists of a six-inch, schedule 120, 304 stainless steel pipe which is 36 inches long and has a $150 \mathrm{lb}$. slip-on flange welded at each end. The bottom is fitted with a $150 \mathrm{lb}$. blind end flange with a penetration for the liquid-filled dip leg for the pressure transducer and another penetration for gas injection. The top end is also fitted with a $150 \mathrm{lb}$. blind end flange. This top flange has several penetrations and all the experimental hardware is mounted on this flange. The melt crucible, all of its fixtures, and the crucible heater reside on top of and are physically bolted to the top flange of the blast vessel. The melt crucible is constructed out of four inch long, two inch diameter stainless steel tubing which is welded at one end to a two inch diameter solid stainless steel cylindrical slug which forms the crucible base. The steel slug is milled on the inside face to a concave conical profile and necks down to a $1 / 4$ inch clearance hole through which the melt is injected into the blast vessel. The mechanical rod which seals the hole in the bottom of the crucible is connected to a pneumatic, spring-loaded cylindrical piston. The piston is normally closed and must be electrically live and pressurized to lift off and, thus, initiate melt injection into the blast vessel. 
A series of fifteen experiments were executed to examine the quenching behavior of molten lithium-aluminum control rod material in water in a Q-type septifoil under conditions prototypic of the loss-of-control-rod-coolin: $\tilde{s}$ accident. Of primary interest was the possibility of energetic steam explosions as the molten control rod material is injected into the water in the confined space of the septifoil. In addition, the effects of natural trigger mechanisms were tested to determine the self-triggering potential of the system. Natural occurring triggers that were investigated were thermal stratification of the water pool, two-phase flow in the septifoil, and the simultaneous drop of a control rod in a parallel channel.

No lithium-aluminum/water explosive interactions were recorded in any of these tests. Other tests with molten aluminum jets at comparable temperatures and flow rates have been performed with the same results. Three methods to naturally trigger a steam explosion were attempted in seven of the fifteen tests. These involved injection of melt into thermally stratified water, into a two-phase flow pool, and with a simultaneous rod drop in a parallel channel. None was successful in initiating a steam explosion. In several of the tests, minor steam spikes were measured. They ranged in amplitude from several psi to as much as $18 \mathrm{psig}$ in one case. There was no damage to the septifoil or web in any test. After some of the tests, a significant quantity of white powder was found in the water. It is believed to be $\mathrm{LiOH}$ from the oxidation of the lithium; tests which resulted in this fine white powder also had a very high $\mathrm{pH}$ in the water, approaching 10 or 11 . The debris from the melt injection and breakup process were found to be concentrated in rather large particle sizes. No debris was found in any of the tests smaller than $50 \mu \mathrm{m}$. Most debris was $3 \mathrm{~mm}$ or larger. Calculations indicate that the jets of melt injected into water in these tests should have undergone jet breakup within $5-10 \mathrm{~cm}$ of the water surface. This breakup and quench of the jet leading edge severely limits the amount of melt that can reside in the water in a molten form and be available for a steam explosion. It is estimated that no more than $1-2 \mathrm{~cm}^{3}$ of melt would mix with the water in these tests and be available to participate in a steam explosion. The rest would be fragmented and frozen. This same mixing limitation applies to the prototypic case. It is concluded that energetic steam explosions are not possible under conditions prototypic of LCRC accident conditions. The mode of melt-water interaction would be hydrodynamic fragmentation of the jet, resulting in a severe limitation on melt-water mixing and particle sizes concentrated in the range of $3 \mathrm{~mm}$ and larger. 


\section{TABLE OF CONTENTS}

Page

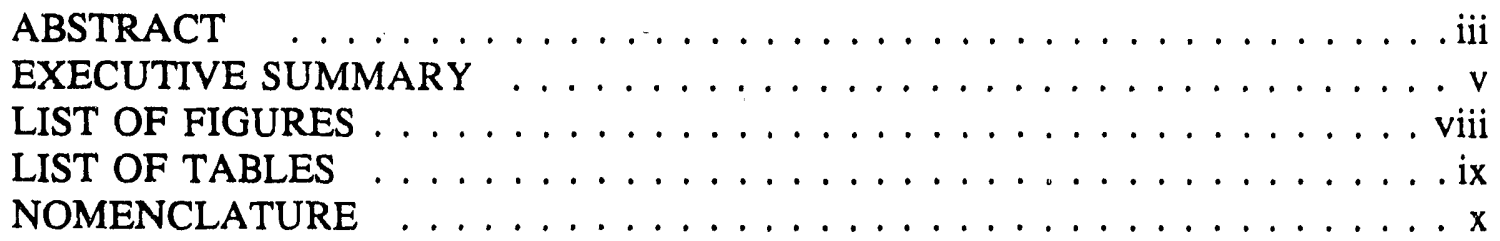

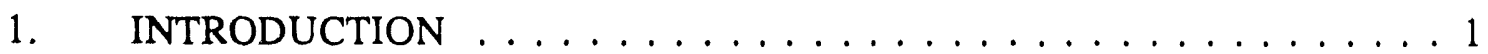

1.1 Background $\ldots \ldots \ldots \ldots \ldots \ldots \ldots \ldots \ldots$

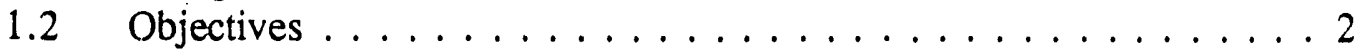

2. EXPERIMENTAL APPARATUS AND PROCEDURES . . . . . . . 5

2.1 General Description of Apparatus $\ldots \ldots \ldots \ldots \ldots \ldots$

2.2 Blast Vessel ....................... 5

2.3 Melt Crucible and Heater Assembly . . . . . . . . . . . 5

2.4 Pneumatic Injector $\ldots \ldots \ldots \ldots \ldots \ldots \ldots$

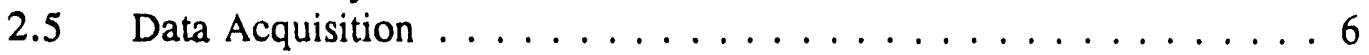

2.6 Experimental Procedures . . . . . . . . . . . . 7

3. EXPERIMENTAL TEST RESULTS $\ldots \ldots \ldots \ldots \ldots \ldots \ldots$

3.1 Series 100 Tests $\ldots \ldots \ldots \ldots \ldots \ldots \ldots \ldots$

3.2 Series 200 Tests $\ldots \ldots \ldots \ldots \ldots \ldots \ldots \ldots \ldots$

3.3 Series 300 Tests . . . . . . . . . . . . . . . . . . 19

3.4 Effect of Thermal Stratification in Water . . . . . . . . . 22

3.5 Effect of Two-Phase Flow in Septifoil . . . . . . . . . . . . 23

3.6 Effect of Rod Drop In a Parallel Channel . . . . . . . . . . . 23

3.7 Molten Lithium-Aluminum Jet Breakup Length . . . . . . . . . 25

4. CONCLUSIONS ..................... 27

Appendix A: Water Temperature, Melt Temperature, Pool

Pressure Figures . ................... A1

Appendix B: REFLEX Spreadsheet Listing of Experimental

Parameters and Measurements . . . . . . . . . . B1 


\section{LIST OF FIGURES}

$\begin{array}{ll}\text { Figure } & \text { Page }\end{array}$

1 Schematic Diagram of Experimental Blast Facility $\ldots \ldots \ldots . .9$

$2 \quad$ Top View of Blast Vessel $\ldots \ldots \ldots \ldots \ldots$

3 Schematic Diagram of Top Flange, Melt Crucible, and Heater Assembly . . . . . . . . . . . . . . . 11 


\section{LIST OF TABLES}

Table

Page

1

WSRC Li/Al- $\mathrm{H}_{2} \mathrm{O}$ Test Parameters . . . . . . . . . . . . . . 8

2

Rod Drop and Melt Jet Timing . . . . . . . . . . . . . . . 24 


\section{NOMENCLATURE}

$\begin{array}{ll}\text { We } & \text { Weber number } \\ L^{*} & \text { Dimensionless Jet Breakup Length } \\ \mathrm{L}_{\text {break }} & \text { Dimensional Jet Breakup Length } \\ \mathrm{d}_{\mathrm{j}} & \text { Jet Diameter } \\ \rho_{\mathrm{w}} & \text { Water Density } \\ \rho_{\mathrm{j}} & \text { Melt Jet Density } \\ \mathrm{u}_{\mathrm{j}} & \text { Jet Velocity at Water Pool Surface } \\ \sigma & \text { Melt Jet-Water Surface Tension }\end{array}$




\section{INTRODUCTION}

\subsection{Background}

There have been many years of work, both experimental and analytical, in the general area of thermal interactions between high temperature molten metals and water. Among the many areas of research interest in high temperature melt-water interactions are boiling on molten metal surfaces and on droplets, jet breakup behavior, formation of debris beds by hydrodynamic fragmentation, transient spreading of metallic melts under water, natural convective and bubbling-enhanced heat transfer in molten metal pools, and explosive interactions between molten metals and water. Although all of the subjects just mentioned are interesting and fertile areas for research and development and each can be the mode of interaction when high temperature melts are poured into water, safety needs of the metallurgical and nuclear industries have dictated that attention and resources be concentrated on systems that do not interact benignly. As a result, the emphasis in studying high temperature melt-water interactions has been placed on explosive interactions between molten metals and water, at the expense of the more benign modes of contact, since it is these explosive interactions that present the greatest damage potential and, hence, the greatest threat to facilities and personnel.

Most experimental studies in melt-water explosive interactions (aka. steam explosions, vapor explosions, FCI's) have been so-called triggered tests; in these circumstances, an explosive shock is delivered to the melt-water mixture to precondition the mixture and artificially initiate the FCI by accelerating the fragmentation and mixing processes, and causing the vapor layer on the melt droplets to collapse. By artificially triggering the explosive interaction, the experimenter is able to synchronize high speed data acquisition and high speed photography which would not otherwise be possible. Although such studies may be useful for understanding the maximum work potential that may be encountered in the event of an FCI and may in fact be somewhat prototypic of LWR systems, these sorts of experiments have been fundamental by nature and are of limited applicability when extrapolated directly to reactor accident conditions. Due to the unique design of HWR core components, these sorts of experiments are neither prototypic of HWR geometry nor representative of anticipated HWR melt-down behavior. As a result, extrapolation of results of such FCI studies to HWR systems, in which a mass of melt is dumped into water and then explosively triggered, may result in misleading or even erroneous conclusions concerning HWR safety under core-melt conditions. The two aspects of these sorts of tests just described that would most seriously affect the applicability of the results to HWR systems are the mode of melt-water contact and the effects of the artificial trigger.

Recently, restart activities for the WSRC K-reactor have begun to consider phenomena in the design basis suggestive of severe accident conditions in addition to the more traditional thermal-hydraulics considerations. This, of course, is a direct result of the fact that the $\mathrm{K}$ reactor core is composed of aluminum and aluminum alloys ( $\mathrm{UAl}$ and $\mathrm{LiAl}$ ) that will melt at temperatures in the range $615-650^{\circ} \mathrm{C}$, more than $1000 \mathrm{~K}$ lower than the temperature required to melt LWR steel structures and more than $2000 \mathrm{~K}$ lower than the temperature required to melt 
LWR fuel. As a result, whereas melting of core components in a LWR during a design basis accident is considered by many to be incredible and is ruled out of the design basis, some melting of core components in the $\mathrm{K}$-reactor must be considered for some accidents in the design basis due to the low melting point of these materials. Fortunately, the consideration of melting during a DBA is limited to non-fuel components; the fuel is insured to be protected.

The accident of most concern for the restart of the $\mathrm{K}$-reactor which could result in some melting of non-fuel components involves loss of forced cooling to one of the sixty control rod assemblies due to failure to seat the housing properly on its end fitting. This accident is known as the Loss-of-Control-Rod-Cooling/Septifoil Mis-seat Accident (LCRC mis-seat). Presently, this accident is estimated to have a frequency of $2.4 \times 10^{-6}$ per reactor operating year. The concern in the LCRC accident is that, due to loss of forced cooling, the lithium-aluminum control rods would rapidly heat up and begin to melt. If the control rod material were to melt, it would drain down the intact portion of the rod and enter the water, possibly as a gravitydriven jet. There have been concerns raised that the molten jet of lithium-aluminum alloy could engage in a high efficiency thermal-chemical steam explosion with the water in the lower portion of the septifoil, causing significant local mechanical damage to the septifoil and surrounding fuel assemblies, as well as propagating across the core to potentially result in full core involvement, loss of core coolability, and eventually a core-melt situation. These concerns have been the result of extrapolating a limited data base of generic, high temperature, triggered aluminumwater steam explosion data to specific HWR accident conditions without proper consideration of prototypicality or applicability.

The hypothetical accident scenarios in the K-reactor (HWR) which have been postulated to result in overheating and melting of fuel and control materials, are well-documented and constitute a well-characterized system. The thermal-hydraulic conditions that may exist in a septifoil under LCRC conditions have been well-defined and their range can be well-predicted by existing, state-of-the-art analytical tools. Among sucn variables for LCRC are the control rod heating rate $(\sim 10 \mathrm{~kW} / \mathrm{ft})$, mass of molten material (several hundreds of grams), melt stream size (less than one inch), melt flow rate $(100-200 \mathrm{gm} / \mathrm{s})$, and melt superheat (less than $30^{\circ} \mathrm{C}$ ). The geometry is unique and readily reproduced; as a result, actual reactor structures (septifoil and web) and reactor materials (lithium-aluminum alloy) can be used to simulate the LCRC accident. Full scale, prototypic experiments can be conducted which require no extrapolation and whose performance is exactly representative of the reactor component under investigation.

\subsection{Objectives}

The objectives of this program are to experimentally investigate the interactions between molten lithium-aluminum control rod material and water under conditions as close to prototypic as possible of the K-reactor LCRC accident case. All efforts will be made to insure prototypicality of the experimental results and validity of direct extrapolation to the reactor accident conditions. Parameters of the tests which are representative or prototypic of expected LCRC conditions or bound those conditions are listed below: 
melt mass:

melt temperature:

melt flowrate:

water temperature:

water depth:

test article:

$$
\begin{aligned}
& 50-150 \mathrm{gm} \\
& 645-670^{\circ} \mathrm{C} \\
& 100-200 \mathrm{gm} / \mathrm{s} \\
& 25-100^{\circ} \mathrm{C} \\
& 30-100 \mathrm{~cm} \\
& \text { Q-type septifoil }
\end{aligned}
$$

The specific objectives of these tests are to create jets of molten lithium-aluminum control rod material of small diameter (nominal jet diameter $=0.25$ inch) to simulate the melt-water contact mode expected under LCRC conditions. A prime objective is to look for melt-water explosive events and the parameters and conditions that promote these interactions. A selected number of tests will be performed to investigate the effect of narurally occurring triggering events such as thermal stratification of the water pool. two-phase flow in the water pool, and the simultaneous drop of a control rod in a parallel channel. Explosive triggers will not be considered. Primary measurements to be made are pressure and temperature. Debris size distributions will be constructed to aid in evaluating debris fragmentation and interaction modes, as well as to guide the evaluation of debris mobility and transportability. Other observations will be made and recorded as appropriate.

It is anticipated that these results will assist in a reliable and technically structured resolution of the potential for energetic explosive interactions between melt and water under LCRC conditions which will be based upon a prototypic data base and which will insure compliance with all applicable safety goals for restart of the K-reactor. 


\section{EXPERIMENTAL APPARATUS AND PROCEUURES}

\subsection{General Description of Apparatus}

An apparatus has been designed and constructed specifically for the performance of these tests. The apparatus is unique insofar as it combines the ability to withstand severe explosive loads with the ability for precision measurements and rapid experimental turn-around. It consists of three major functional components, the cylindrical explosion-proof vessel in which the septifoil is h'sused, the melt crucible and heater assembly, and the pneumatic injector. These components will be discussed below in more detail.

\subsection{Blast Vessel}

The blast vessel consists of a six-inch, schedule 120,304 stainless steel pipe which is 36 inches long and has a $150 \mathrm{lb}$. slip-on flange welded ai each end (see Figures 1-2). The bottorn is fitted with a $150 \mathrm{lb}$. blind end flange with a peneliation for the liquid-filled dip leg for the pressure transducer and another penetration for gas injection. The top end is also fitted with a $150 \mathrm{lb}$. blind end flange. This top flange has several penetrations and all the experimental hardware is mounted on this flange. Two cylindrical band heaters are installed on the outside of the blast vessel for heating the water and controlling its temperature. They can be moved axially up and down in response to changes in the water depth. The blast vessel is fully insulated with four inches of fiberglass wool pipe insulation to minimize heat losses. The septifoil insert is three feet long and $3 \frac{1}{4}$ inches in diameter. It has been fitted with three riveted tabs at two axial locations to insure axial alignment of the center channel of the septifoil with the melt injector when installed in the blast vessel. The septifoil has severai holes to allow the water level inside the septifoil to equilibrate with the water depth in the blast vessal. The top flange acts as a blast shield but does not function as a pressure boundary. The top flange has five penetrations for access into the blast vessel. Two penetrations are connected to lines which vent steam and deflect the steam downward into a water reservoir for condensation purposes. One penetration is for a gas bubbler to the:mally mix the water in the blast vessel prior to melt injection. A fourth penetration allows for installation of three thermocouples into the blast vessel for the measurement of the water pool temperature. Their location is dependant upon testspecific conditions, such as water pool depth, pool stratification, and two-phase flow by gas injection. The fifth penetration is a centered clearance hole, $1 / 2$ inch in diameter, for injection of the molten lithium-aluminum from the melt crucible directly through the top flange and into the center channel of the septifoil.

\subsection{Melt Crucible and Heater Assembly}

The melt crucible, all of its fixtures, and the crucible heater reside on top of and are physically bolted to the top flange of the blast vessel (see Figure 3). The melt crucible is constructed out of four inch long, two inch diameter stainless steel tubing which is welded at one end to a two inch diameter solid stainless steel cylindrical slug which forms the crucible base. 
The steel slug is milled on the inside face to a concave conical profile and necks down to a $1 / 4$ inch clearance hole through which the melt is injected into the blast vessel. Once welded together, the conical profile forms the bottom-inside face of the melt crucible. The crucible sits on a piece of one inch thick ceramic fiberboard insulation on top of the top flange of the blast vessel. The crucible rests inside a cylindrical, ceramic clamshell heater which supplies heat to the walls of the crucible to melt the lithium-aluminum alloy charge. The crucible has a $1 / 4$ inch thick stainless steel cover plate to seal the lithium-aluminum charge. The cover plate has a circular groove to fit exactly over the crucible and is fitted with four penetrations. One penetration allows installation of a thermocouple for measurement and control of the melt temperature. Two penetrations allow for argon gas purge and venting in order to inert the crucible. When the vent line is closed, the crucible can be pressurized for melt ejection. The fourth penetration allows for the installation and sealing of the mechanical piston rod which seals the bottom hole in the crucible until melt injection. It is aligned along the central vertical axis of the pneumatic injector, crucible, and blast vessel-septifoil assembly. It is well established that molten aluminum and lithium-aluminum alloy dissolve stainless steel at temperatures above the solidus. Other work at BNL has quantified the erosion rate as a function of carrier fluid temperature and velocity. It is also known that oxidation of the steel surface retards the erosion rate. In order to prevent dissolution of the stainless steel melt crucible by the lithium-aluminum melt, the crucible and mechanical piston rod were placed inside a tube furnace and baked at $800^{\circ} \mathrm{C}$ for 24 hours in slightly forced air to heavily oxidize these vulnerable components and prevent erosion and, eventually, failure by dissolution. The success of this technique permitted the construction of these components from 300-series stainless steel, thus saving money, time, and ensuring reliable performance of the facility.

\subsection{Pneumatic Injector}

The mechanical rod which seals the hole in the bottom of the crucible is connected to a pneumatic, spring-loaded cylindrical piston. The piston is normally closed and must be electrically live and pressurized to lift off and, thus, initiate melt injection into the blast vessel. The piston resides above and is bolted to the same mounting bolts that align and hold the melt crucible. The piston has a microswitch on its shaft as an event marker for melt injection. The output of this event marker is indicated on all of the data graphs for all the tests as a reference point. Once the entire facility is assembled, two stainless steel shims are positioned across the path of melt injection, between the clearance hole in the top flange and the ceramic fiberboard. These shims, which must be removed prior to melt injection, eliminate radiative and convective heat losses from the bottom of the crucible to the cold environment of the blast vessel during the heat-up phase of the tests. Failure to remove these shims in Test 203 resulted in failure of that test.

\subsection{Data Acquisition}

An electrical control package has been constructed to service this apparatus. The package provides for control of voltages and setpoint temperatures to the lithium-aluminum melt crucible heater and to the band heaters on the outside of the blast vessel. Digital temperature indicators 
are provided to facilitate on-the-spot observation of the various component temperatures during the heat-up phase of the execution of the tests.

Various signals are monitored during the heatup phase of each test using our in-house data acquisition facility. Water pool temperature and melt crucible temperature are constantly monitored to insure that set-point parameters are achieved, and to monitor time-at-target for the crucible to ensure the melt charge is completely melted. Monitored signals are continuously displayed on a video monitor for observation.

During execution of the tests, the water pool temperatures, melt temperature, and water pool pressure are recorded at a rate of $100 \mathrm{~Hz}$ by the HP1000 data acquisition computer. Temperature signals are locally referenced to a $\mathrm{HyCal} 150^{\circ} \mathrm{F}$ reference junction, and all signals are conditioned (filtered and amplified) and measured by the Neff multichannel multiplexer. Data is then transferred to magnetic tape for storage and retrieval. Each run is recorded visually in VHS video format by a Panasonic industrial video system. The debris that results from the injection of the melt into water is segregated according to its location and is photographed in black and white $4 \times 5$ inch prints using Polaroid 55 negative-positive film.

\subsection{Experimental Procedures}

The procedure for conducting these tests is roughly divided into three major stages: pretest assembly, test execution, and post-run measurements and debris recovery. Written procedures are executed and verified in accordance with published QA, safety, and test protocol requirements and will not be elaborated upon further in this section. Table 1 lists the actual test parameters that were achieved for each test, in addition to identifying special test parameters under the heading of "Trigger Method." The actual execution and findings of each of the three series of tests will be discussed in the next section. 
Table 1

WSRC Li/Al- $\mathrm{H}_{2} \mathrm{O}$ Test Parameters

\begin{tabular}{|c|c|c|c|c|c|}
\hline Test & $\begin{array}{l}\text { Injected } \\
\text { Melt Mass } \\
\text { (g) }\end{array}$ & $\begin{array}{c}\text { Melt } \\
\text { Temperature } \\
\left({ }^{\circ} \mathrm{C}\right)\end{array}$ & $\begin{array}{l}\text { Water } \\
\text { Depth } \\
(\mathrm{cm})\end{array}$ & $\begin{array}{c}\text { Water } \\
\text { Temperature } \\
\left({ }^{\circ} \mathrm{C}\right)\end{array}$ & $\begin{array}{l}\text { Trigger } \\
\text { Method }\end{array}$ \\
\hline 101 & 36.2 & 647.8 & 91 & 100 & -- \\
\hline 102 & 76.5 & 671.8 & 86.4 & 80 & -- \\
\hline 103 & 74.9 & 664.0 & 86.4 & 61 & -- \\
\hline 104 & 57.7 & 660.6 & 86.4 & 42 & -- \\
\hline 105 & 80.7 & 656.5 & 86.4 & 33 & -- \\
\hline 201 & 98.8 & 662.0 & 30.5 & 62 & Obstacle \\
\hline 202 & 71.8 & 654.9 & 30.5 & 60.5 & - \\
\hline 204 & 102.1 & 658.0 & 30.5 & 60.5 & Rod Drop \\
\hline 205 & 110.3 & 658.4 & 30.5 & 60.3 & Rod Drop \\
\hline 206 & 109.0 & 660.4 & 30.5 & 60.2 & Rod Drop \\
\hline 207 & 76.5 & 656.5 & 30.5 & 62.0 & Rod Drop \\
\hline 301 & 98.4 & 662.1 & 91.4 & 25 to 73 & $\begin{array}{c}\text { Stratified } \\
\text { Water }\end{array}$ \\
\hline 302 & 23.0 & 658.6 & 61.0 & 99.6 & $\begin{array}{c}\text { Gas } \\
\text { Injection }\end{array}$ \\
\hline 303 & 57.6 & 670.4 & 30.5 & 100 & $\begin{array}{c}\text { Gas } \\
\text { Injection }\end{array}$ \\
\hline 304 & 91.4 & 664.6 & 30.5 & 81.5 & Rod Drop \\
\hline
\end{tabular}




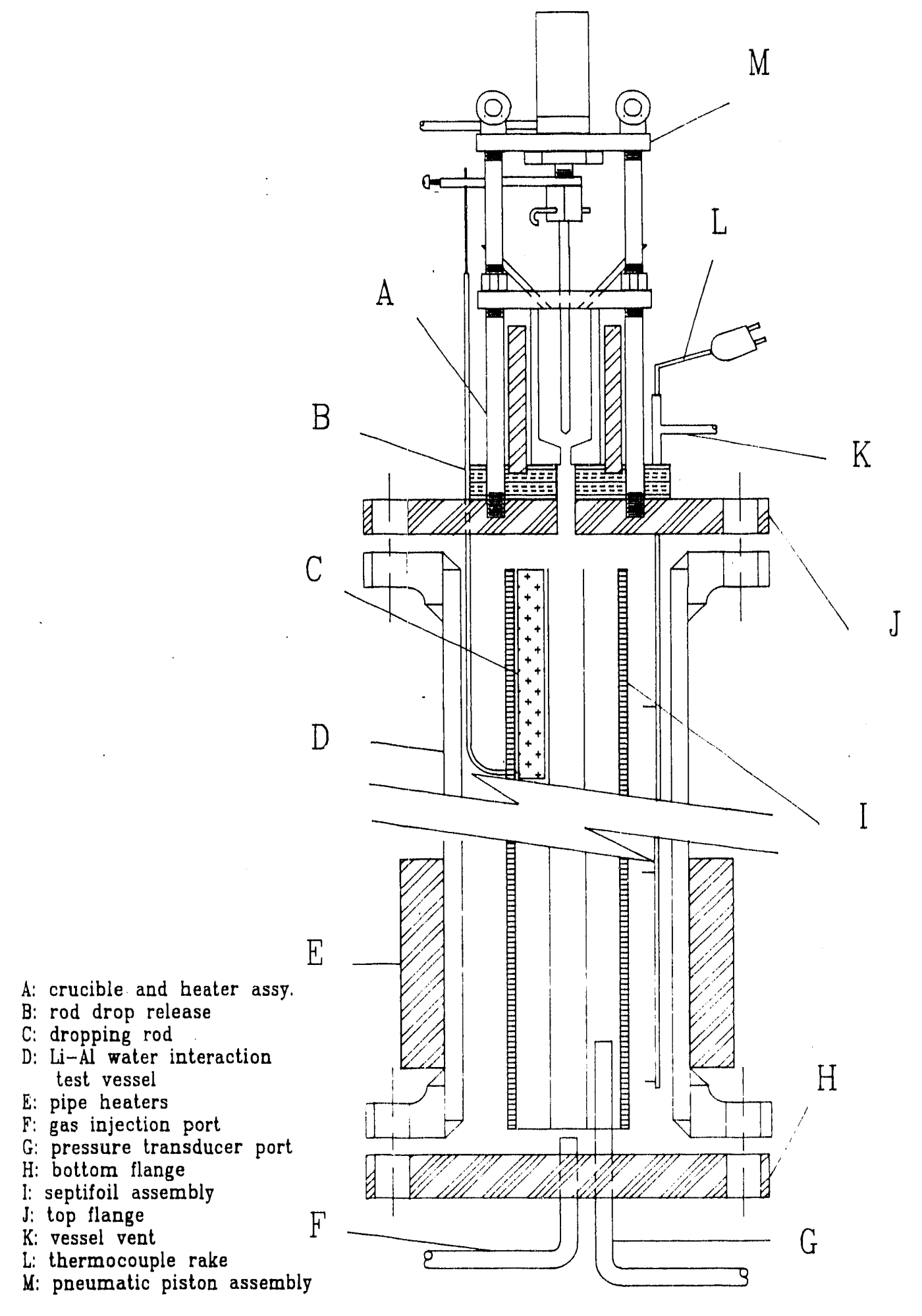

Figure 1. Schematic Diagram of Experimental Blast Facility. 


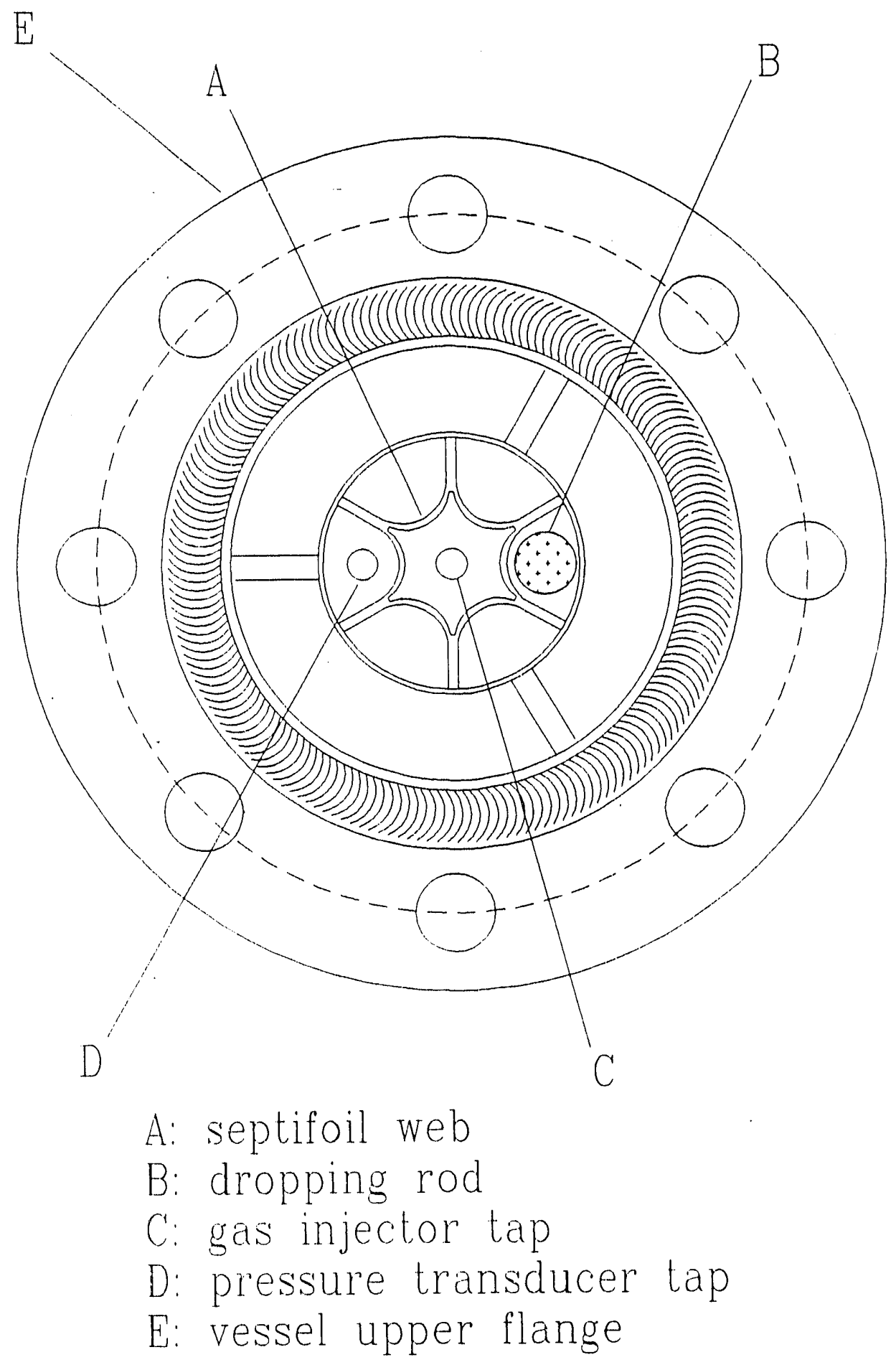

Figure 2. Top View of Blast Vessel. 

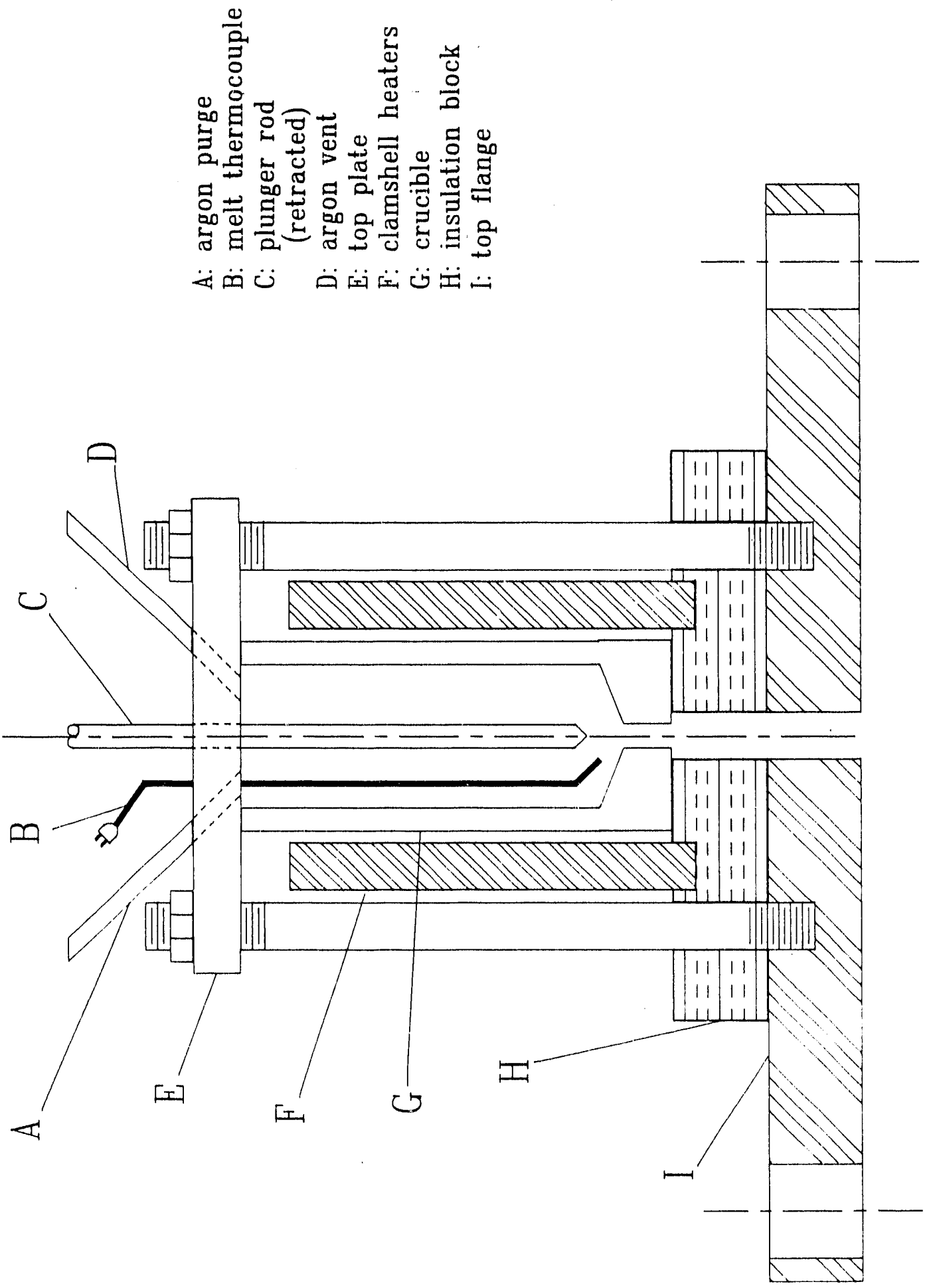

ํ. 


\section{EXPERIMENTAL TEST RESULTS}

A total of fifteen experiments were performed in this experimental program in three series. The Series 100 tests were conducted with deep water with the primary objective to investigate the effect of water pool temperature on melt-water interactions. The Series 200 tests were conducted with shallow water at $60^{\circ} \mathrm{C}$ with the primary objective to investigate the effect of a rod drop on melt-water interactions. The Series 300 tests were conducted to examine the effect of three specific natural triggering events in more detail at the request of the RSG review panel: water pool thermal stratification, two-phase flow in the septifoil, and precisely-timed rod drop in a channel parallel to the melt injection channel.

\subsection{Series 100 Tests}

The first series of tests with molten lithium/aluminum alloy and water were WSRC-Li/Al Series 1. There were five tests in this series. In this test series, the melt mass and temperature are fixed at nominal values of 100 grams and $660^{\circ} \mathrm{C}$, the molten jet diameter is $0.25 \mathrm{inch}$, the melt driving cover pressure is $2 \mathrm{psi}$, and the water pool depth is 1 meter. The water pool temperature in Tests $101,102,103,104$, and 105 was $100^{\circ} \mathrm{C}, 80^{\circ} \mathrm{C}, 60^{\circ} \mathrm{C}, 40^{\circ} \mathrm{C}$, and $33^{\circ} \mathrm{C}$ respectively. The objectives of this test series, in addition to the obvious objective of recording the occurrence of energetic events under prototypic conditions in a reactor septifoil with a web insert, were to shake-down the test facility, make modifications to the facility and instrumentation as determined necessary, and verify all test procedures. There were no observable energetic events recorded in WSRC-Li/Al 101-105. In Test 101 which had a water pool temperature of $100^{\circ} \mathrm{C}$, vigorous steam generation was observed, resulting in a 2 psi pressure rise in the water pool; no pressure spikes were measured. In Test 102 which had a water pool temperature of $80^{\circ} \mathrm{C}$, less steam generation was observed; there was however a 2 psi pressure rise in the water pool with 4 pressure spikes superimposed which ranged in amplitude from 6-10 psi. There was no damage to the septifoil or web from the pressure spikes. In Test 103 which had a water pool temperature of $60^{\circ} \mathrm{C}$, almost no steam generation was observed. One pressure spike was measured with an amplitude of $18 \mathrm{psi}$. There was no damage to the septifoil or web from the pressure spike. The water pool temperatures in Tests 104 and 105 were $40^{\circ} \mathrm{C}$ and $33^{\circ} \mathrm{C}$, respectively. In neither test were any pressure spikes or pressurization observed. There was little oxidation of the melt and the resulting debris was very large, in the centimeter size range. One interesting event was that in both these tests, nearly all the debris was found to be frozen and suspended up in the web structure, $20-45 \mathrm{~cm}$ below the water surface, never having made it to the bottom of the septifoil. This configuration enhances debris coolability and suggests that benign jet breakup is the mode of $\mathrm{Li} / \mathrm{Al}$ melt-water interactions.

Run 101

The specific objective of Run 101 was to evaluate the quenching behavior of molten lithium-aluminum control rod material in deep water at $100^{\circ} \mathrm{C}$ in a typical septifoil. The initial test conditions that were established for Run 101 are as follows. A water depth of 91 
centimeters was established in the test vessel. This depth represents the maximum depth which the test vessel was designed to contain. Water temperature was maintained at $100^{\circ} \mathrm{C}$. A mass of $102.7 \mathrm{gm}$ of lithium-aluminum alloy was loaded into the melt crucible. The crucible was continuously purged with a stream of argon to prevent sample oxidation. Crucible temperature was adjusted to facilitate sample melting. When the initial test conditions were satisfied, the plunger rod sealing the crucible exit nozzle was remotely retracted and the melt was delivered to the test pool. Of the original $102.7 \mathrm{gm}$ alloy inventory, $36.2 \mathrm{gm}$ was injected into the test section at a temperature of $647.8^{\circ} \mathrm{C}$. The balance of the alloy was retained in the crucible. Post-run inspection revealed that much of the remaining alloy did not melt. Subsequent runs were allowed to have more "soak" time at temperature to attempt to insure complete melting of the alloy. Immediately following injection, steam was observed vigorously venting through the two half-inch diameter vent tubes. Analysis of the pressure history recorded by the data acquisition system from the transducer connected to the pool revealed a gradual pressurization event about eight seconds in length coincident with the observation of steam venting. The maximum pressure achieved was 1.55 psig. Post run disassembly and debris recovery revealed variation in size and location of the injected alloy. Most of the debris was roughly spherical in shape. Most of the debris was collected in the end cap placed on the bottom of the septifoil. A small amount of the smaller debris was apparently ejected out of the top of the septifoil and recovered from the bottom of the test vessel. Several very small grains were also ejected from the test vessel along with the steam that exited through the steam vents. Particle size distribution for the debris from this and subsequent runs will be discussed quantitatively in a separate section.

Run 102

Run 102 was intended to provide us with information on the quenching behavior of molten lithium-aluminum alloy in slightly subcooled, deep water. Some changes to the initial test conditions were made based on experience gained from the previous run. The water depth in Run 102 was reduced by about four centimeters to 86.4 centimeters to allow a little more headspace in the test vessel. The water temperature was specified at $80^{\circ} \mathrm{C}$. A $1 / 4$ " diameter dip tube was installed through the top flange to extend almost to the bottom of the test vessel. Nitrogen is passed through this tube to stir the water. By agitating the water in this manner, temperature stratification under subcooled conditions was eliminated. The alloy loading procedure was changed for this run in an attempt to ensure more complete melting of the charge. A mass of $100.5 \mathrm{gm}$ was loosely arranged in the crucible as long thin sticks, stood on end, surrounding the centrally located plunger rod. Again, the crucible was continuously purged with argon to preclude oxidation. The target temperature for the alloy was increased to $660^{\circ} \mathrm{C}$ to provide some superheat in the melt, again in an attempt to ensure complete melting. When the test parameters delineated above were nominally achieved, the test was initiated remotely and observed via video camera. Of the initial $100.5 \mathrm{gm}$ loaded into the crucible, all but $24 \mathrm{gm}$ was ejected into the apparatus. The melt temperature reported by the data acquisition system immediately prior to melt-water interaction was $671.8^{\circ} \mathrm{C}$. Visually, the run proceeded similarly to the previous run, evolving steam vigorously through the steam vents. The pressure history recorded from the transducer shows a slow rise and fall, spanning about four seconds, to a 
pressure of 1.7 psig. Superimposed on that rise, during the first second of the run, are four pressure spikes, ranging between six and ten psig. Post-run disassembly revealed debris distributed throughout the apparatus. Fine screen traps were placed on the steam vents for this and subsequent runs, and $4.2 \mathrm{gm}$ of debris was collected from these. The septifoil end cap contained the bulk of the debris, $47.4 \mathrm{gm}$. As in the previous run, a quantity of debris was found outside the septifoil. It is not clear whether this debris is exiting from the top of the septifoil or finding its way through the small drain holes located near the bottom of the septifoil. Almost $7 \mathrm{gm}$ of material was also recovered from the area between the bottom of the crucible and the top of the top vessel flange. It is unknown whether the material was deposited here by the jet during its entry to the blast vessel or by ejection from the blast vessel during the pressure events.

Run 103

Run 103 was intended to provide information on molten lithium-aluminum quenching behavior in deep water with slightly more subcooling. In this run, we had established a water depth identical to the previous run, $86.4 \mathrm{~cm}$. "The water temperature was lowered another $20^{\circ} \mathrm{C}$ relative to the previous run, bringing us to $60^{\circ} \mathrm{C}$. Loading of the lithium-aluminum alloy into the crucible was conducted as in the previous run, $104.2 \mathrm{gm}$ of sticks placed on end surrounding the plunger rod. The melt temperature was also intended to be as in the previous run, $660^{\circ} \mathrm{C}$. This run proceeded in a routine manner, and when the target conditions were nominally achieved, the run was executed. The alloy mass actually injected into the rest vessel was 74.9 $\mathrm{gm}$ at a temperature of $664^{\circ} \mathrm{C}$. At this level of subcooling (water temperature of $61^{\circ} \mathrm{C}$ ), less steam was observed to exit the steam vents. The slow pressurization seen in the previous two runs was also absent. One pressure pulse was observed reaching 18 psig, during the melt-water interaction. Post-run disassembly and debris recovery revealed a distribution pattern throughout the apparatus similar to the previous run. The bulk of the melt, $51.2 \mathrm{gm}$, was recovered from the septifoil end cap, while $21.1 \mathrm{gm}$ was recovered outside the septifoil. Some moderately fine debris, $2.6 \mathrm{gm}$, was recovered from the steam vent screens, and $1.2 \mathrm{gm}$ was removed from the area between the crucible bottom and the top flange. About $23 \mathrm{gm}$ of alloy was not discharged from the crucible.

\section{Run 104}

Run 104 provided us with another look at lithium-aluminum quenching behavior in deep water at an even greater subcooling. Again, as in previous runs, water depth was fixed at 86.4 $\mathrm{cm}$ and the target water temperature reduced another $20^{\circ} \mathrm{C}$, to $40^{\circ} \mathrm{C}$. The charge of alloy, $101.5 \mathrm{gm}$, was loaded as before, and its temperature targeted for $660^{\circ} \mathrm{C}$. Upon attainment of the desired initial conditions, the test was initiated remotely. A total of $57.7 \mathrm{gm}$ of alloy was injected at a temperature of $660.6^{\circ} \mathrm{C}$ into the pool of water at $42^{\circ} \mathrm{C}$. During the melt injection, no visible steam was vented, and no outward sign of activity was discernable. Examination of the pressure trace revealed only minor oscillatory disturbance during melt entry of less than 1 psig in magnitude. No pressurization of the vessel, or spikes were observed. Debris distribution through the apparatus was slightly different than in previous runs. No debris was 
transported to the steam vent screens, because no steam was liberated from the apparatus. When the septifoil webbing was removed from the septifoil assembly, $38.1 \mathrm{gm}$ of melt was found distributed along its length, trapped on the perforations of the web. The balance of the delivered mass was found either in the septifoil end cap, or on the floor of the test vessel, near the water drain holes. The larger debris appeared more irregular in shape than in previous runs. Many of the pieces were irregular in shape and had long thin spindles attached.

\section{Run 105}

This was the final test in the deep water series, using deep water at ambient summer temperature. The initial temperature for the water was established by hot summer weather at $33^{\circ} \mathrm{C}$ and its depth is again $86.4 \mathrm{~cm}$. A charge of lithium-aluminum alloy was prepared at 100.1 $\mathrm{gm}$ and the target alloy temperature established at $660^{\circ} \mathrm{C}$. A routine heatup preceded an uneventful execution during which no external activity could be perceived. The injected melt mass was $80.7 \mathrm{gm}$ at a temperature of $656.5^{\circ} \mathrm{C}$. Review of the data taken from the pressure transducer revealed only oscillatory fluctuations of several tenths of a psig during melt entry and no other activity. Upon disassembly of the test vessel, $66.8 \mathrm{gm}$ of melt was found trapped on the septifoil webbing. Most of the trapped melt was firmly entwined in the septifoil web perforations at about $25 \mathrm{~cm}$ below the water surface. The balance of the injected debris was collected from the septifoil end cap and the floor of the test vessel and amounted to about 14 gm.

\subsection{Series 200 Tests}

There were seven tests in WSRC-Li/Al Series 2. For all tests in this series, the water pool was lowered to a depth of $30 \mathrm{~cm}$, and the water pool temperature was fixed at $60^{\circ} \mathrm{C}$. Melt mass, temperature, flow rate, and jet diameter were nominally the same as in Series 1 . Several parameters were investigated in this series. Test 201 included an above-water physical obstacle to the melt jet. Test 202 was the base case run for this series. Test 203 failed in execution. Tests 204 and 205 investigated the triggering effect of a control rod drop in an adjacent channel simultaneously with the melt injection. In none of these tests was any pressurization or pressure spikes observed. Little oxidation of the melt was found; the debris consisted mostly of mm-cm size chunks. There was no fine debris generated in these tests. In Tests 204 and 205, the debris was found to have been trapped and suspended in the web of the septifoil, about $10 \mathrm{~cm}$ below the water line. This result is very similar to the results from Tests 104 and 105. It appears that the effect of the rod drop was to cause the jet to fragment as it fell through the water pool, thus becoming suspended in the web, in much the same fashion as the effect of the cold water pool. The final two tests in WSRC Li/Al Series 2 were Tests 206 and 207. In both of these tests, the primary parameter of interest that was being investigated was the drop of a control rod simultaneously with injection of molten lithium-aluminum alloy into the water-flooded septifoil. In both Tests 206 and 207, the water pool was at $60^{\circ} \mathrm{C}$ and $30 \mathrm{~cm}$ deep. The timing of the rod drop in Test 207 was slightly later after the melt injection than in Tests 204-206 since the melt jet had to cut the monofilament approximately one foot lower than in the cases where it was suspended from above. The time differential for cutting the monofilament (top vs. bottom) is 
estimated to be no more than 0.10 second. As in the previous rod drop tests, no explosive interactions were encountered. The debris formed small clumps, no small debris was found. An appreciable amount was found suspended in the webbing in the septifoil, approximately 10$15 \mathrm{~cm}$ below the water surface; the remainder was found at the bottom of the septifoil.

Run 201

The objective of Run 201 was to provide us with alloy-water interaction data for shallow water conditions. For Run 201, and the balance of the 200 series tests, the water depth in the test vessel was reduced from the $86.4 \mathrm{~cm}$ depth of the 100 series, to $30.5 \mathrm{~cm}$. The length of the septifoil is still about $91 \mathrm{~cm}$, and therefore the melt is delivered through about $61 \mathrm{~cm}$ of free fall in air inside the septifoil prior to contacting the water. The target water temperature for this run was $60^{\circ} \mathrm{C}$. An increase in the mass of alloy loaded into the crucible from $100 \mathrm{gm}$ to 120 $\mathrm{gm}$ was introduced in this run to offset the holdover of material experienced in the 100 series runs. The intended temperature for the alloy is $660^{\circ} \mathrm{C}$. When the prescribed run conditions were achieved, the plunger rod was remotely actuated, and the melt was injected. The injected mass was $98.8 \mathrm{gm}$, much closer to the design injection of $100 \mathrm{gm}$, and its temperature during injection was $6 \epsilon 2^{\circ} \mathrm{C}$. The test proceeded routinely, without any external sign of activity. The pressure history revealed only small disturbances on the order of $0.75 \mathrm{psig}$. Upon disassembly, it was founc that the pressure transducer dip leg, which enters into a septifoil side channel through the test vessel top flange, had inadvertently crossed through the perforations into the center channel. This obstruction to the melt jet was located about $15 \mathrm{~cm}$ above the water surface. The vast majority of the alloy injected was collected as loose rubble in the septifoil end cap. Only $0.5 \mathrm{gm}$ remained on the exposed obstacle, and $4.7 \mathrm{gm}$ was collected from the test vessel floor.

Run 202

This run is a repeat of Run 201 to provide baseline alloy-water interaction data for comparison to other 200 series runs intended to have various interaction precipitating triggers. This run was assembled and intended to provide these initial conditions: $30.5 \mathrm{~cm}$ of water at $60^{\circ} \mathrm{C}$. Some procedural changes were implemented to prevent the misplacement of the pressure transducer dip leg. When the previously stated conditions were met, the test was executed. During the run, $71.8 \mathrm{gm}$ of alloy was injected at a temperature of $654.9^{\circ} \mathrm{C}$ into $30.5 \mathrm{~cm}$ of water at $60.5^{\circ} \mathrm{C}$. No visible interactions were observed during the operation of the test. The pressure transducer data contained no evidence of pressurization outside of some small oscillatory behavior ( $\sim 0.2 \mathrm{psig}$ ). Debris recovery from Run 202 proceeded routinely. The septifoil end cap contained $71.8 \mathrm{gm}$ of loose debris, the larger particles of which are roughly spherical. No debris was found in the steam vent screens, or on the floor of the test vessel.

Run 204

The objective of Run 204 was to investigate the effect of potential explosive triggering events which may occur in a septifoil. For this test, a lithium-aluminum alloy rod $2.22 \mathrm{~cm}$ in 
diameter by $26.7 \mathrm{~cm}$ long was suspended in one of the outer channels formed by the septifoil webbing. The rod was suspended with a piece of monofilament nylon fishing line which was anchored to the top of the rod and secured across the top of the septifoil. The monofilament was routed so as to intersect with the intended path of the melt jet. During melt discharge, the alloy jet would melt the monofilament and allow the rod to drop under gravitational acceleration to impact on the water interface and then the vessel bottom. Run 204 was established with 30.5 $\mathrm{cm}$ of water installed in the blast vessel. The water temperature, as in the previous 200 series tests, was targeted for $60^{\circ} \mathrm{C}$. The intended melt delivery conditions were $100 \mathrm{gm}$ of alloy at a temperature of $660^{\circ} \mathrm{C}$. To achieve this goal, a $20 \mathrm{gm}$ overload of alloy was placed in the crucible for a total crucible load of $120.9 \mathrm{gm}$. The heat soak time was again lengthened in an effort to avoid the low injected melt yield obtained in the last test. After attainment of the desired run conditions and a prolonged heat soak of the crucible and its contents, the run was executed without incident. We were able to deliver $102.1 \mathrm{gm}$ of melt to the blast vessel at a temperature of $658.0^{\circ} \mathrm{C}$ into $30.5 \mathrm{~cm}$ of water at $60.5^{\circ} \mathrm{C}$. The trace of the pressure transducer shows an increase in oscillatory noise coincident with the disturbances is in the range of \pm 0.5 psig. No pressure pulses were observed. Upon disassembly and debris recovery, the rod was found at the bottom of its channel and the ends of the monofilament were severely melted. A substantial amount of the injected melt, $63.8 \mathrm{gm}$, deposited itself in the septifoil webbing $16 \mathrm{~cm}$ above the floor. This debris was interlocked with the septifoil webbing perforations and required some mechanical manipulation to remove. The balance of the injected melt was collected as loose debris in the septifoil end cap.

\section{Run 205}

This run was a repeat of Run 204 with special emphasis placed on reducing the noise observed in the data acquired from the pressure transducer. The intended conditions for this run are $30.5 \mathrm{~cm}$ of water at $60^{\circ} \mathrm{C}$ and $100 \mathrm{gm}$ of alloy injected at $660^{\circ} \mathrm{C}$. Preparations for the run were made in the usual manner, $120.6 \mathrm{gm}$ of lithium-aluminum alloy being loaded into the crucible. The crucible and water were heated to their respective target temperatures, and the run was conducted without incident. The mass of alloy injected into the blast vessel was 110.3 $\mathrm{gm}$ and its temperature at injection was $658.4^{\circ} \mathrm{C}$. The water depth was, as in previous runs. $30.5 \mathrm{~cm}$ and its temperature during injection was $60.3^{\circ} \mathrm{C}$. The noise seen in the pressure trace from the last few runs was eliminated by thoroughly purging the transducer dip leg with about $200 \mathrm{~cm}^{3}$ of cool water immediately prior to run execution. The only observable action in the pressure trace is what is assumed to be the water surface disturbance caused by the rod drop. The magnitude of the largest measured disturbance is about $0.25 \mathrm{psig}$. Upon disassembly, it was found that the rod had dropped as expected. Most of the melt that was injected was distributed along the septifoil webbing penetrations as in the previous run. The balance was collected as loose debris in the septifoil end cap.

Run 206

Run 206 was intended to reproduce the previous run, with a change made regarding the location of the pressure transducer dip leg. It was decided to relocate the dip leg because there 
appeared to be boiling occurring in it where it passed in close proximity to the crucible. Provisions were made to allow the dip leg to enter the blast vessel and the septifoil assembly through the bottom flange thereby avoiding the hot crucible area. The initial conditions desired for this run are $100 \mathrm{gm}$ of melt delivery at $660^{\circ} \mathrm{C}$ into $30.5 \mathrm{~cm}$ of water at $60^{\circ} \mathrm{C}$ accompanied by a rod drop trigger. Upon attainment of the desired run conditions, the plunger rod was remotely actuated, delivering melt into the blast vessel. The run proceeded, as before, without incident. The injected melt mass was $109.0 \mathrm{gm}$ and it was injected at a temperature of $660.4^{\circ} \mathrm{C}$. The water depth remained at $30.5 \mathrm{~cm}$ and its temperature was $60.2^{\circ} \mathrm{C}$. The pressure history shows a quieter baseline which exhibits an increase in noise coincident with the initiation of the injection. The magnitude of the noise on the pressure trace during the injection is about 0.25 psig. No other pressure events were observed. Post-run debris recovery revealed 67.0 gm of melt trapped on the septifoil. This debris was trapped in the webbing perforations near the bottom and also about $16 \mathrm{~cm}$ above the bottom. Another $42.0 \mathrm{gm}$ of loose debris was recovered from the septifoil end cap. The rod was recovered from the bottom of the channel in which it was suspended, as in the previous two tests.

Run 207

The objective of Run 207 was to provide us with a run comparable to the previous 200 series tests, differing only in timing of the rod drop. In this test, the monofilament nylon fishing line which supports the rod prior to the melt injection was relocated from the top of the rod to the bottom. The monofilament was passed through the septifoil and webbing assembly across the diameter at a distance of about $30 \mathrm{~cm}$ down from the top of the septifoil. The dropping rod was then allowed to rest on top of this line in its side channel. In this manner, the rod still falls from about the same elevation, but the melt must travel almost $30 \mathrm{~cm}$ further down before the rod begins to fall. The initial conditions desired for this test are as follows: $100 \mathrm{gm}$ of melt at $660^{\circ} \mathrm{C}$ injected into $30.5 \mathrm{~cm}$ of water at $60^{\circ} \mathrm{C}$ with a rod drop trigger. Once these conditions were met, the test was conducted in a manner consistent with previous tests, and proceeded uneventfully. The as-conducted test parameters were, $76.5 \mathrm{gm}$ of alloy at $656.5^{\circ} \mathrm{C}$ injected into $30.5 \mathrm{~cm}$ of water at $62.0^{\circ} \mathrm{C}$. No activity outside the blast vessel was observed. The pressure history showed a small amount of noise immediately following the injection. The maximum amplitude of this noise is about $0.2 \mathrm{psig}$. No other pressure events were observed. Upori disassembly, most of the debris was found loosely piled in the septifoil end cap. A small amount, about $20 \mathrm{gm}$, was distributed along the septifoil webbing perforations. The rod was once again recovered from the bottom of its side channel.

\subsection{Series 300 Tests}

WSRC-Li/Al Series 3 consisted of four tests. Test 301 had a water pool depth of $1 \mathrm{~m}$ and was intended to investigate the effect of thermal stratification. Tests 302 and 303 had a water pool depth of 60 and $30 \mathrm{~cm}$, respectively. The water pool was at saturation and had gas injection from below to simulate the turbulence from boiling. Test 304 had a water pool $30 \mathrm{~cm}$ deep at $60^{\circ} \mathrm{C}$ with a precisely timed rod drop. In none of these tests were any explosive events recorded, nor were any pressure spikes measured. The debris in Tests 301 and 304 was found 
suspended in the web while the debris in Tests 302 and 303 was found loose at the bottom of the sentifoil. It is the conclusion from these tests that molten lithium-aluminum alloy injected into water under conditions representative of prototypic LCRC conditions will not self-trigger to a steam explosion, nor can it be triggered by normally occurring triggers such as pool stratification (this would cause vapor film collapse), two-phase flow (this simulates a boiling environment in the septifoil), or dropping of a rod in a parallel channel. The mode of interaction observed during the course of this study was hydrodynamic jet fragmentation and debris solidification.

Run 301

The objective of Run 301 was to study the behavior of lithium-aluminum melt quenching in a deep pool of water with a stratified temperature gradient. The major change in the initial conditions for this iest is the intentional stratification of the $91.4 \mathrm{~cm}$ deep water pool, providing a gradient of $47.7^{\circ} \mathrm{C}$ through which the melt would fall. The nitrogen bubbler, normally used before run execution to avoid stratification in the water, was not installed during the apparatus assembly. Again, it is desired to inject $100 \mathrm{gm}$ of alloy at $660^{\circ} \mathrm{C}$, and to this end, we loaded $121.7 \mathrm{gm}$ into the crucible. It was found, during heatup, that the water temperature gradient established appeared to be more of a stepwise change instead of a gradual gradient. It was suspected that this step occurred near the bottom edge of the band heater clamped around the top of the blast vessel. When the melt and water temperatures were observed to be correct, the run was executed and, roceeded normally. A mass of $98.4 \mathrm{gm}$ of alloy was injected into the blast vessel at $662.1^{\circ} \mathrm{C}$. At a depth of about $10 \mathrm{~cm}$ from the top flange, the water temperalure was $73^{\circ} \mathrm{C}$. At a depth of about $46 \mathrm{~cm}$, the water temperature was $31^{\circ} \mathrm{C}$, and finally, at a depth of about $86 \mathrm{~cm}$, the temperature was $25^{\circ} \mathrm{C}$. Review of the pressure trace showed random noise coincident with melt injection of about $0.2 \mathrm{psig}$ in magnitude. No pressure events were observed. Upon disassembly, some unusual debris distribution was observed. Only $17 \mathrm{gm}$ of loose debris was recovered from the septifoil end cap. The balance, $81.4 \mathrm{gm}$, was interwoven with the septifoil webbing perforations at an elevation of 50 to $75 \mathrm{~cm}$ above the bottom of the blast vessel. The center channel was completely occluded from 61 to $75 \mathrm{~cm}$ elevation. At the $50 \mathrm{~cm}$ elevation, a large blockage had formed in a peripheral channel, apparently directed there by the central channel blockage above. The position of this blockage is close to the lower edge of the blast vessel heater and presumably close to the suspected stepwise water temperature change.

Run 302

The objective of Run 302 was to observe the lithium-aluminum melt quenching behavior in a pool of saturated water with a simulated boiling heat flux. To simulate this boiling flux, nitrogen was injected into the center channel of the septifoil assembly from below during melt injection. The superficial gas velocity averaged over the cross sectional area of the septifoil was $15.9 \mathrm{~cm} / \mathrm{sec}$. The water temperature was specified at $100^{\circ} \mathrm{C}$. The water depth, without gas injection, was specified at $61 \mathrm{~cm}$. The specifications for the alloy were $100 \mathrm{gm}$ injected at $660^{\circ} \mathrm{C}$. Once the specified conditions were achieved, the nitrogen injector was activated and 
the melt was discharged to the blast vessel. No activity was observed during melt injection other than the venting of the nitrogen and steam. The data from the pressure transducer shows very random noise of about 0.5 psig caused by the turbulence of the nitrogen injection. No pressure events other than the noise were observed. Only $23.0 \mathrm{gm}$ of debris was recovered from the septifoil end cap. The balance of the melt never left the crucible. It was suspected that the turbulence and splashing caused by the vigorous gas injection may have cooled the bottom of the crucible enough to freeze the melt in the nozzle.

Run 303

This test was intended to provide us with information on molten lithium-aluminum alloy quenching behavior in a pool or saturated water with a boiling heat flux. The principal difference between this run and Run 302 is that the water depth was decreased from $61 \mathrm{~cm}$ to $30.5 \mathrm{~cm}$ in an effort to prevent the splashing of water from freezing the melt in the crucible exit nozzle. The nitrogen superficial gas velocity, used to simulate the boiling flux, averaged across the s'stifoil cross-sectional area is again $15.9 \mathrm{~cm} / \mathrm{sec}$. The water temperature is intended to be $100^{\circ} \mathrm{C}$. The desired alloy parameters are to inject $100 \mathrm{gm}$ of molten alloy at $670^{\circ} \mathrm{C}$. The melt temperature has been increased $10^{\circ} \mathrm{C}$ relative to previous runs in an effort to circumvent the melt freezing problem experienced in Run 302 which prevented proper melt delivery. Pre run heatup proceeded normally, and upon attainment of desired initial conditions, the run was executed with the following procedural modification. The nitrogen injector, used to simulate the boiling vapor flux, was not activated until 2.5 seconds prior to melt injection. The primary reason for this was to minimize the possibility of the injected nitrogen or transported steam from freezing the melt in the nozzle prior to injection. Even with these precautions, we were only able to inject $57.6 \mathrm{gm}$ of molten alloy at a temperature (in the crucible) of $670.4^{\circ} \mathrm{C}$. The only observable external event was the vigorous venting of the nitrogen and steam. The only information discernable from the pressure history is the effect of nitrogen injection on pool conditions. When injection of nitrogen commenced, the pressure trace changed from a quiet, steady baseline value of about $0.22 \mathrm{psig}$, to an agitated, noisy signal at about $0.55 \mathrm{psig} \pm 0.2$ psig. No indication of any pressure activity related to melt injection is present. Upon disassembly, all of the injected debris was recovered from the septifoil end cap. Its appearance was mostly spherical in shape and variable in size.

Run 304

A new method of rod dropping was implemented for Run 304. A braided steel cable approximately $1 / 16^{\prime \prime}$ diameter was threaded through a piece of $1 / 4 "$ stainless steel tubing. This piece of tubing terminated through the side of the septifoil at an elevation slightly above the bottom edge of the rod in the pre-drop position. A hole was drilled perpendicular to the long axis of the rod into which one end of the cable protruded. The stainless steel tube sheath guided the cable up through the top flange, and terminated in free space just below the crucible top plate. An arm was connected to the air piston rod which projected laterally so as to pick up the other end of the cable. When the piston retracts to deliver melt, it also withdraws the cable from the hole in the rod, thereby releasing the rod to be accelerated from rest. The initial 
conditions specified for this run are similar to the previous rod drop runs except for water temperature. A temperature of $80^{\circ} \mathrm{C}$ was specified with the usual $30.5 \mathrm{~cm}$ depth. The molten alloy delivery was specified to be $100 \mathrm{gm}$ at $665^{\circ} \mathrm{C}$. The apparatus was assembled routinely and pre-run heatup proceeded normally. Of the $122.2 \mathrm{gm}$ of lithium-aluminum alloy loaded into the crucible, $91.4 \mathrm{gm}$ was delivered to the blast vessel at a temperature of $664.6^{\circ} \mathrm{C}$. At the time of run execution, the vessel contained water at a depth of $30.5 \mathrm{~cm}$ and a temperature of $81.5^{\circ} \mathrm{C}$. The run executed routinely. There is a clear increase in the activity on the pressure transducer trace coincident with run execution. The maximum noise observed is $\pm 0.2 \mathrm{psig}$. No evidence of pressure spikes are present. Upon disassembly, the entire inventory of melt was found in the septifoil end cap. The debris had formed a loose pile of rubble most of which was roughly spherical in shape. The rod was recovered from the bottom of its channel and appeared to have dropped routinely.

\subsection{Effect of Thermal Stratification in Water}

Run 301 was conducted under conditions of thermal stratification in the water pool in the septifoil. The question to be addressed was "would a severe spatial temperature gradient in the water cause the steam vapor blanket on the injected melt to condense and result in an energetic steam explosion?" In order to address this question, only one band heater was installed on the blast vessel and it was moved up as high as possible to just under the top flange. A water pool $91 \mathrm{~cm}$ deep was formed, and three thermocouples were installed in the water at various depths to record the temperature profile. The top-most thermocouple (\#12) was submerged just below the surface of the water at the same elevation as the shell heater. The middle thermocouple (not recorded on the water pool temperature plot) was essentially at midplane of the water. The bottom thermocouple (\#13) was located ten centimeters above the pool bottom. At the time of melt injection, TC12 was at $73^{\circ} \mathrm{C}$, the middle thermocouple was at $31^{\circ} \mathrm{C}$, and $\mathrm{TC} 13$ was at $24^{\circ} \mathrm{C}$. It is suspected that there existed a severe, stepwise change in water temperature just below the heated zone where the temperature gradient is estimated to have been approximately $10^{\circ} \mathrm{C} / \mathrm{cm}$. It is considered unlikely that a more severe thermal gradient could occur in a septifoil under LCRC conditions. It is also considered unlikely that thermal stratification could occur with the top layer of water any hotter than $75^{\circ} \mathrm{C}$; if the pool got hotter, it would approach saturation and become isothermal. As a result, the conditions in Run 301 are deemed to be as severe as prototypically possible.

Post-test observations revealed that nearly all the injected melt became hung up in the web inside the septifoil at an elevation that coincided with the bottom of the heated zone of water. This is the region, just below the shell heater, where the thermal gradient is estimated to have been most severe. The debris was found to be quite large, over $90 \%$ of the recovered debris was greater than one centimeter in size. No pressurization ev?nts were recorded and no oxidation was found to have occurred. It was concluded that severe thermal gradients in the water would not trigger a steam explosion, but would instead suddenly quench the flow of melt and arrest it in a coolable geometry in the web. 


\subsection{Effect of Two-Phase Flow in Septifoil}

Runs 302 and 303 were conducted under conditions of two-phase flow in the septifoil to simulate the void fraction and turbulence that could exist if a control rod had fallen into saturated water in the septifoil bottom and boiling was occurring on its surface. In order for the boiling to create such a two-phase flow environment, the pool would have to be at saturation; as a result, the water in the blast vessel was maintained at saturation in both these tests. The question to be addressed was "would a high void fraction, two-phase flow environment cause the injected melt stream to fragment and induce an energetic steam explosion?" In order to address this question, a non-condensable gas was injected through a penetration in the bottom flange into the septifoil, resulting in a superficial gas velocity based upon the entire unobstructed cross-sectional area of the septifoil of $15.9 \mathrm{~cm} / \mathrm{s}$. Run 302 had a water pool $61.0 \mathrm{~cm}$ deep and Run 303 had a water pool $30.5 \mathrm{~cm}$ deep; the resulting average void fractions in these two tests were measured to be 0.21 and 0.27 , respectively. It was judged to be unlikely that a two-phase boiling pool could exist in a septifoil more severe than the conditions established in these tests for two reasons. First, an actual septifoil would be submerged in a pool of reactor moderator at no more than $40^{\circ} \mathrm{C}$ which would act as an efficient heat sink and reduce if not suppress boiling entirely. Secondly, the data for void fraction in channels by gas injection shows that void fraction does not increase significantly with an increase in superficial gas velocity beyond the injection velocity used in these two tests. As a result, the conditions in Runs 302 and 303 are deemed to be as severe as prototypically possible for LCRC conditions.

Post-test observations revealed that none of the injected melt became hung up in the web inside the septifoil. All the recovered debris was collected from the end cap at the bottom of the septifoil in the form of loose nuggets. The debris from both runs was found to be almost all in the 3.35-9.5 mm range. No pressurization events were recorded in these two tests. It was concluded that the effect of two-phase flow induced turbulence in the water would not be to trigger a steam explosion, but would instead solidify the debris in the form of a loose, porous debris bed.

\subsection{Effect of Rod Drop in a Parallel Channel}

Several runs were conducted to investigate the effect of a simultaneous rod drop in a channel parallel to the center target channel for melt injection. The intent was to simulate the mechanical disturbance that would be generated if a solid piece of control rod were to fall into the septifoil at the same time that molten control rod material was streaming into the water. The question to be addressed was "would the mechanical shock of a physical rod drop be sufficient to trigger an energetic steam explosion between molten lithium-aluminum and water?" In order to address this question, four tests were conducted in which a cylindrical length of control rod was suspended in a septifoil channel and released to free fall into the water below at the time of melt ejection from the crucible. In Runs 204-206, the rod was suspended from its upper end by a piece of monofilament nylon line stretched across the top of the septifoil insert. The nylon line crossed over the melt injection channel with the intent that the leading edge of the melt jet would impinge upon the monofiiament, cutting it and releasing the rod to fall simultaneously with 
Table 2

Rod Drop and Melt Jet Timing

\begin{tabular}{||c|c|c|c|c|c|c||}
\hline \hline \multirow{2}{*}{ Run } & \multicolumn{2}{|c|}{ Rod Arrival Timing (s) } & \multicolumn{4}{|c|}{ Melt Jet Arrival Timing (s) } \\
\cline { 2 - 7 } & Water Top & Water Bottom & Water Top & Water Bottom & $\begin{array}{l}\text { Jet } \\
\text { Duration } \\
\text { Length } \\
\text { (cm) }\end{array}$ \\
\hline \hline 204 & 0.32 & 0.42 & 0.23 & 0.30 & 0.63 & 281 \\
\hline 205 & 0.32 & 0.42 & 0.23 & 0.30 & 0.68 & 303 \\
\hline 206 & 0.32 & 0.42 & 0.23 & 0.30 & 0.67 & 299 \\
\hline 207 & 0.41 & 0.51 & 0.23 & 0.30 & 0.47 & 210 \\
\hline 304 & 0.32 & 0.42 & 0.23 & 0.30 & 0.56 & 250 \\
\hline
\end{tabular}

the melt injection. Since the melt would already be moving with some appreciable velocity, the rod which accelerated from rest would be assured of arriving at the water just after the melt. This timing was critical to the issue of rod drop triggering. In Run 207, the rod was suspended from its lowest end; the rod essentially sat on the taut monofilament line. The line was once again stretched across the melt injection channel with the intent that the leading edge of the melt jet would cut the line and drop the rod. In this case, the rod would arrive at the water pool surface about $1 / 10$ th second later than in Runs 204-206. In this manner, the effect of a slight shift in timing of the rod drop could be investigated. The fourth rod drop test was Run 304. It was decided that in this test, the rod would be held and released by a cable release mechanism. A rigid cable was attached to the melt injection plunger and the other end was fed through the upper flange, through a guide tube, and through the side of the septifoil, pinning the control rod in position. Upon actuation of the Bimba pneumatic piston, the cable would be pulled out of the rod simultaneously with the melt injection plunger lift-off. This technique gave us assurance that the rod was being dropped with the intended timing, a concern that we had not been able to completely satisfy ourselves of in Runs 204-207. A summary of the timings of the rod arrival at the water pool surface and the pool bottom, along with similar timings for the melt jet, is given in Table 2. Also listed in Table 2 are the jet duration and length of the jet at the water surface. Note that the jet always penetrated to the water pool bottom prior to the rod hitting the water surface. Also, the jet continued to stream into the water even after the rod had hit the water pool bottom. This ensures that the jet extended throughout the pool at the times of both rod impacts, water top and bottom. 
No energetic interactions were recorded during these four tests, nor were any pressure spikes observed. Post-test observations revealed that most of the debris from the injected melt became hung-up in the web of the septifoil, at an elevation about ten centimeters below the level of the upper surface of the water pool. This is about the distance that has been calculated for the jet breakup length for these tests. It appears that the rod impact, most likely with the water surface, enhanced the jet fragmentation process and that the debris immediately froze in place in the perforated web. It was concluded that the rod drop as simulated in these tests would not trigger an energetic steam explosion in the septifoil, but would instead enhance jet breakup and arrest the debris in a coolable geometry in the web.

\subsection{Moiten Lithium-Aluminum Jet Breakup Length}

The jet breakup length was calculated for each run by the relationship below, ${ }^{1}$

$$
\mathrm{L}^{*}=200 \cdot \mathrm{We}-0.6
$$

where

$$
\begin{aligned}
& L^{*}=\left(\frac{L_{\text {break }}}{d_{j}}\right)\left(\frac{\rho_{w}}{\rho_{j}}\right)^{0.5} \\
& W e=\rho_{j} d_{j} u_{j}^{2} / \sigma
\end{aligned}
$$

and $L_{\text {break }}$ is the jet breakup length, $d_{j}$ is the jet diameter, $u_{j}$ is the jet velocity, $\rho_{j}$ is the jet density, $\rho_{w}$ is the water density, and $c$ is the jet-water surface tension. Under the conditions of the tests just reported, the jet breakup lengths were calculated to be in the range $5-10 \mathrm{~cm}$ in length. At the melt jet diameters investigated in these tests $(0.5 \mathrm{~cm})$, it is calculated that only $1-2 \mathrm{~cm}^{3}$ of lithium-aluminum melt could remain in a coherent jet form; the rest of the melt jet would have broken into droplets and frozen. Therefore, only $1-2 \mathrm{~cm}^{3}$ of melt can be molten in the water at any time. This severe limitation on the extent of melt-water mixing imposed by the rapid hydrodynamic jet fragmentation and quenching process essentially rules out of consideration the accumulation of melt under the water and any threat of a sizable steam explosion.

\footnotetext{
${ }^{1}$ Marshall, B. W., Beck, D. F., and Berman, M., "Mixing of Isothermal and Boiling Molten-Core Jets With Water: The Initial Conditions for Energetic FCl's," Proceedings of the International ENS/ANS Conference on Thermal Reactor Safety, Avignon, France, 1988.
} 


\section{CONCLUSIONS}

A series of fifteen experiments were executed in this series of tests to examine the quenching behavior of molten lithium-aluminum control rod material in water in a Q-type septifoil under conditions prototypic of the loss-of-control-rod-cooling accident. Of primary interest was the possibility of energetic steam explosions as the molten control rod material is injected into the water in the confined space of the septifoil. In addition, the effects of natural trigger mechanisms were tested to determine the self-triggering potential of the system. Naturally occurring triggers that were investigated were thermal stratification of the water pool, two-phase flow in the septifoil, and the simultaneous drop of a control rod in a parallel channel. The following observations and conclusions were made during the course of these investigations:

1. No hthium-aluminum/water explosive interactions were recorded in any of these tests. Other tests with molten aluminum jets at comparable temperatures and flow rates have been performed with the same results.

2. It appears that the mode of melt-water contact is critical in determining if an energetic steam explosion will occur. These tests employed the jet-entry mode exclusively.

3. Three methods to naturally trigger a steam explosion were attempted in seven of the fifteen tests. These involved injection of melt into thermally stratified water, into a two-phase flow pool, and with a simultaneous rod drop in a parallel channel. None was successful in initiating a steam explosion.

4. In several of the tests, minor steam spikes were measured. They ranged in amplitude from several psi to as much as 18 psig in one case. There was no damage to the septifoil or web in any test.

5. After some of the tests, a significant quantity of white powder was found in the water. It is believed to be $\mathrm{LiOH}$ from the oxidation of the lithium; tests which resulted in this fine white powder also had a very high $\mathrm{pH}$ in the water, approaching 10 or 11 .

6. The dtoris from the melt injection and breakup process were found to be concentrated in rather large particle sizes. No debris was found in any of the tests smaller than $50 \mu \mathrm{m}$. Most debris was $3 \mathrm{~mm}$ or larger.

7. Calculations indicate that the jets of melt injected into water in these tests should have undergone jet breakup within $5-10 \mathrm{~cm}$ of the water surface. This breakup and quench of the jet leading edge severely limits the amount of melt that can reside in the water in a molten form and be available for a steam explosion. It is estimated that no more than $1-2 \mathrm{~cm}^{3}$ of melt would mix with the water in these 
tests and be available to participate in a steam explosion. The rest would be fragmented and irozen. This same mixing limitation applies to the prototypic case.

8. It is concluded that energetic steam explosions are not possible under conditions prototypic of LCRC accident conditions. The mode of melt-water interaction would be hydrodynamic fragmentation of the jet, resulting in a severe limitation on melt-water mixing and particle sizes concentrated in the range of $3 \mathrm{~mm}$ and larger. The pressurization events that have occurred were minor and caused no damage. 


\section{APPENDIX A}

\section{Water T'emperature, Melt Temperature and Pool Pressure Figures}

For each experiment, three plots have been created to indicate the water pool temperature, melt crucible temperature, and water pool pressurization. The time duration of each plot is ten seconds, which includes a short baseline period preceding melt injection. Each plot includes the output of the event marker which recorded the crucible plunger motion to indicate the onset of melt injection. The event marker output is a vertical line, sometimes going off scale or terminating with a spike and going horizontal. The first plot in each series is the water pool temperature: channels 12 and 13 are thermocouples submerged in the test chamber water pool. The second plot is the temperature in the melt crucible. The output of this thermocouple is indicated by channel.11. The third plot is the pressure in the water pool and is indicated by channel 10. The ordinates of the pressure plots are in units of voltage; the conversion to units of psig are listed below:

\begin{tabular}{|c|c|}
\hline RUN & PRESSURE RANGE (psig) \\
\hline \hline 101 & 0 to 5 \\
102 & 0 to 15 \\
103 & 0 to 20 \\
104 & 0 to 2 \\
105 & -1 to 1 \\
& -2 to 3 \\
$201-205$ & -1 to 1 \\
$206-207$ & 0 to 2 \\
$301-304$ & \\
\hline
\end{tabular}

The baseline has been shifted for convenience of presentation. 


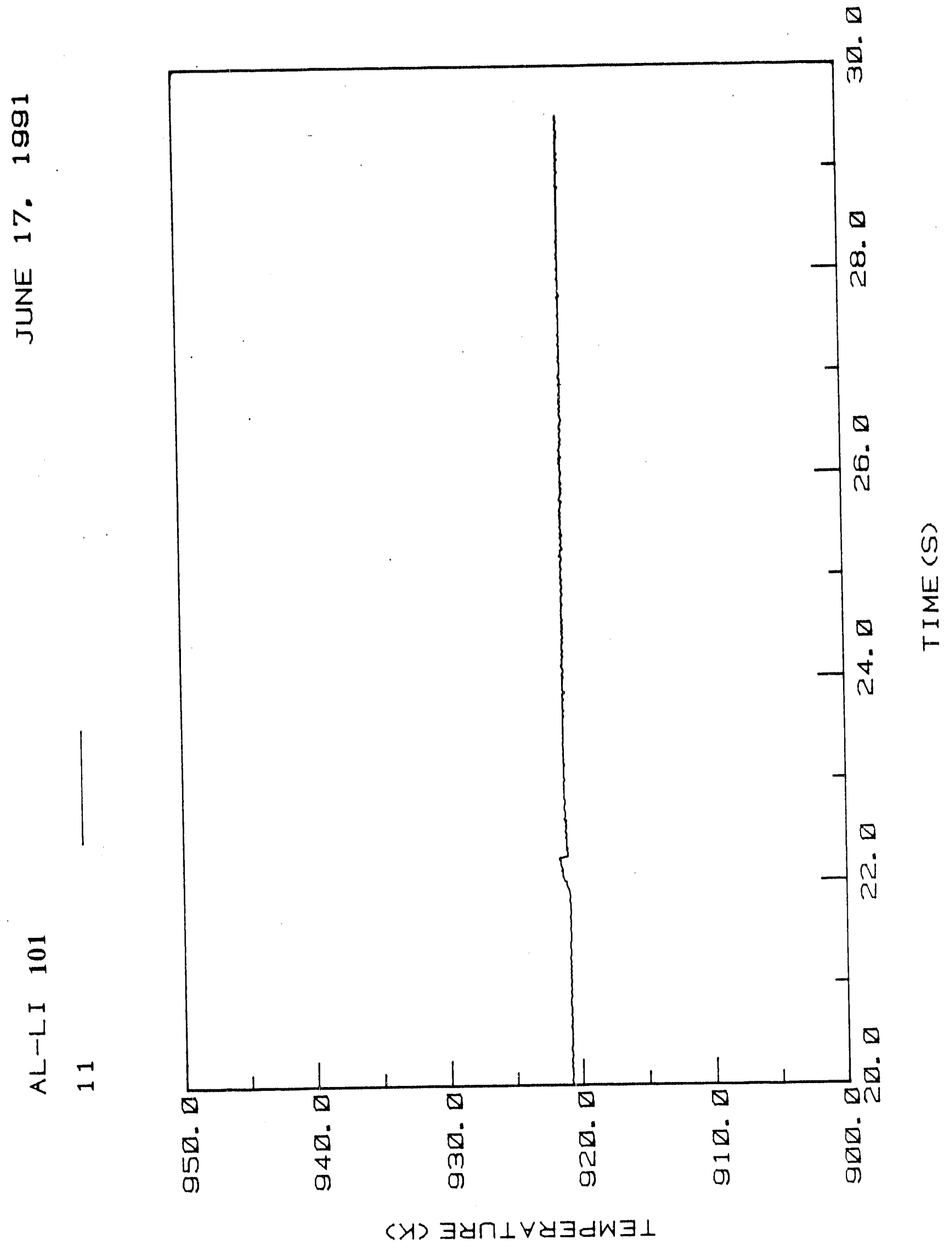




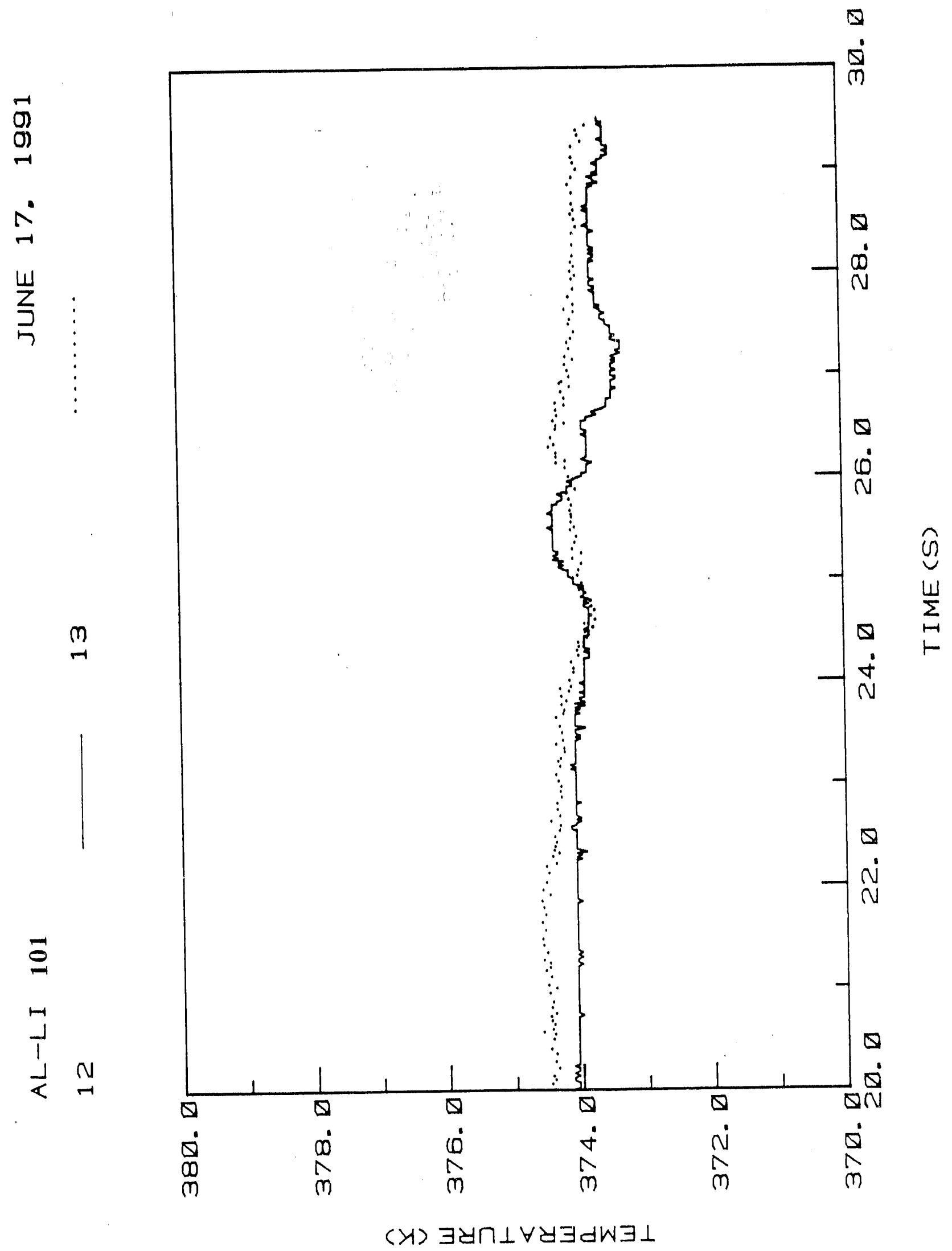




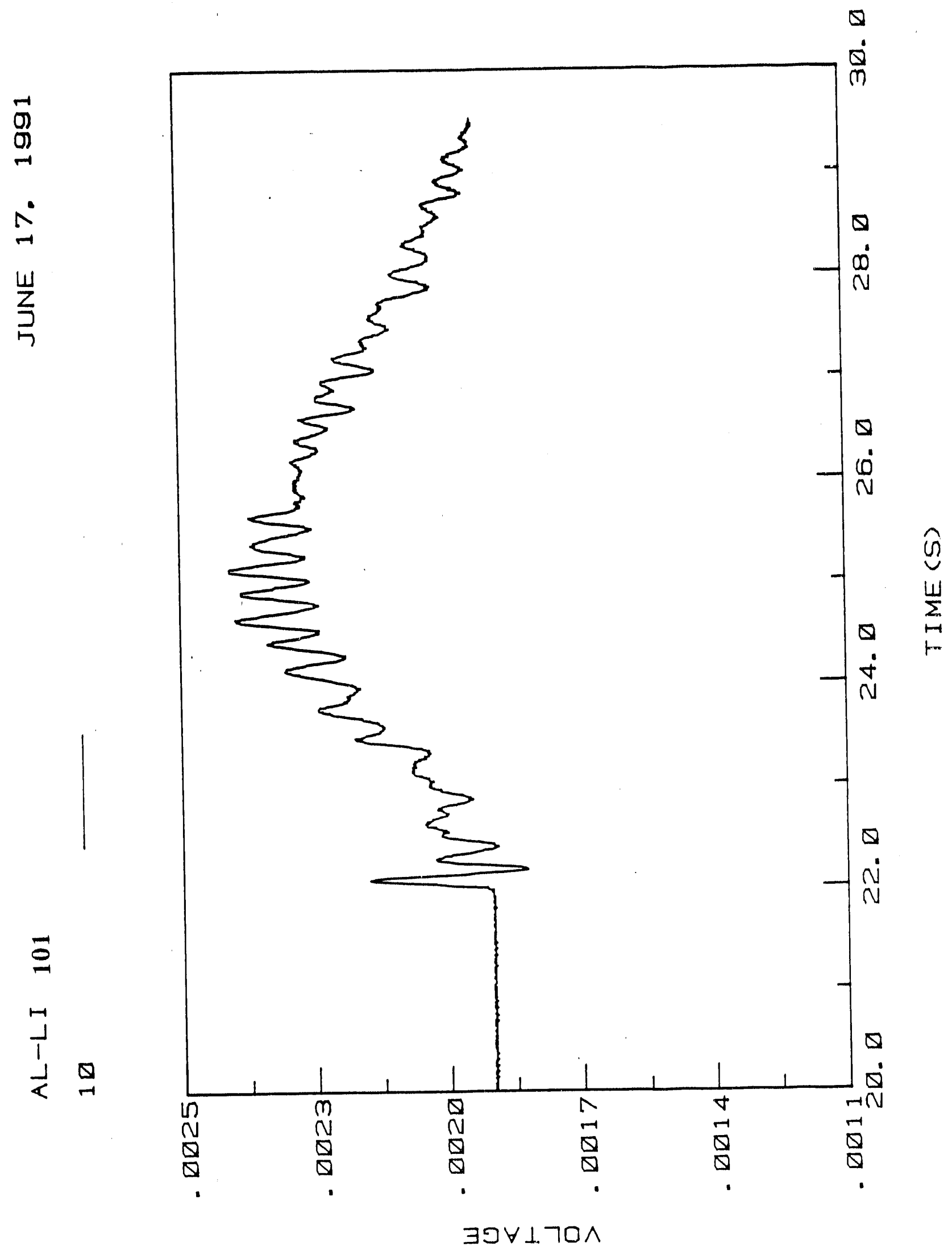




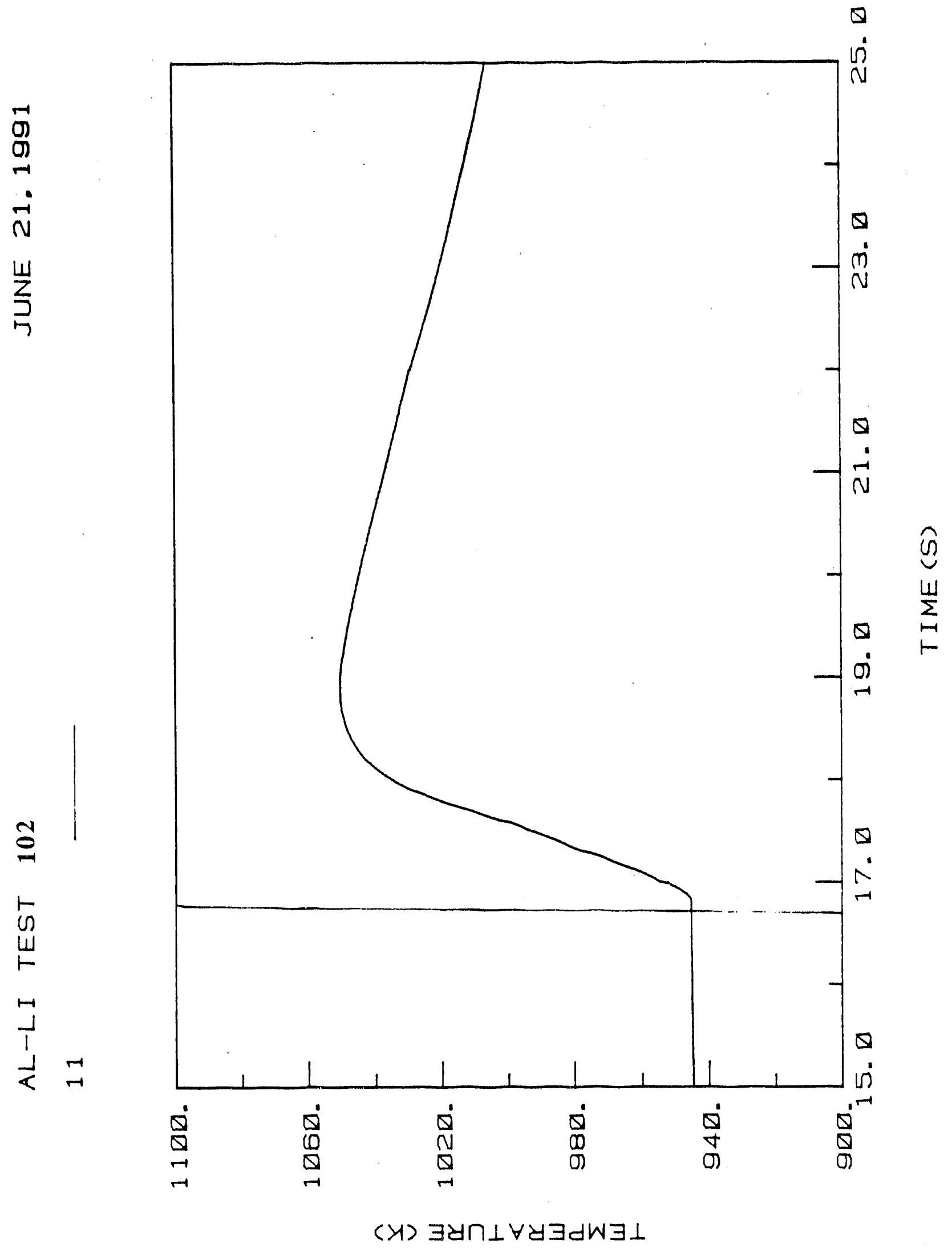




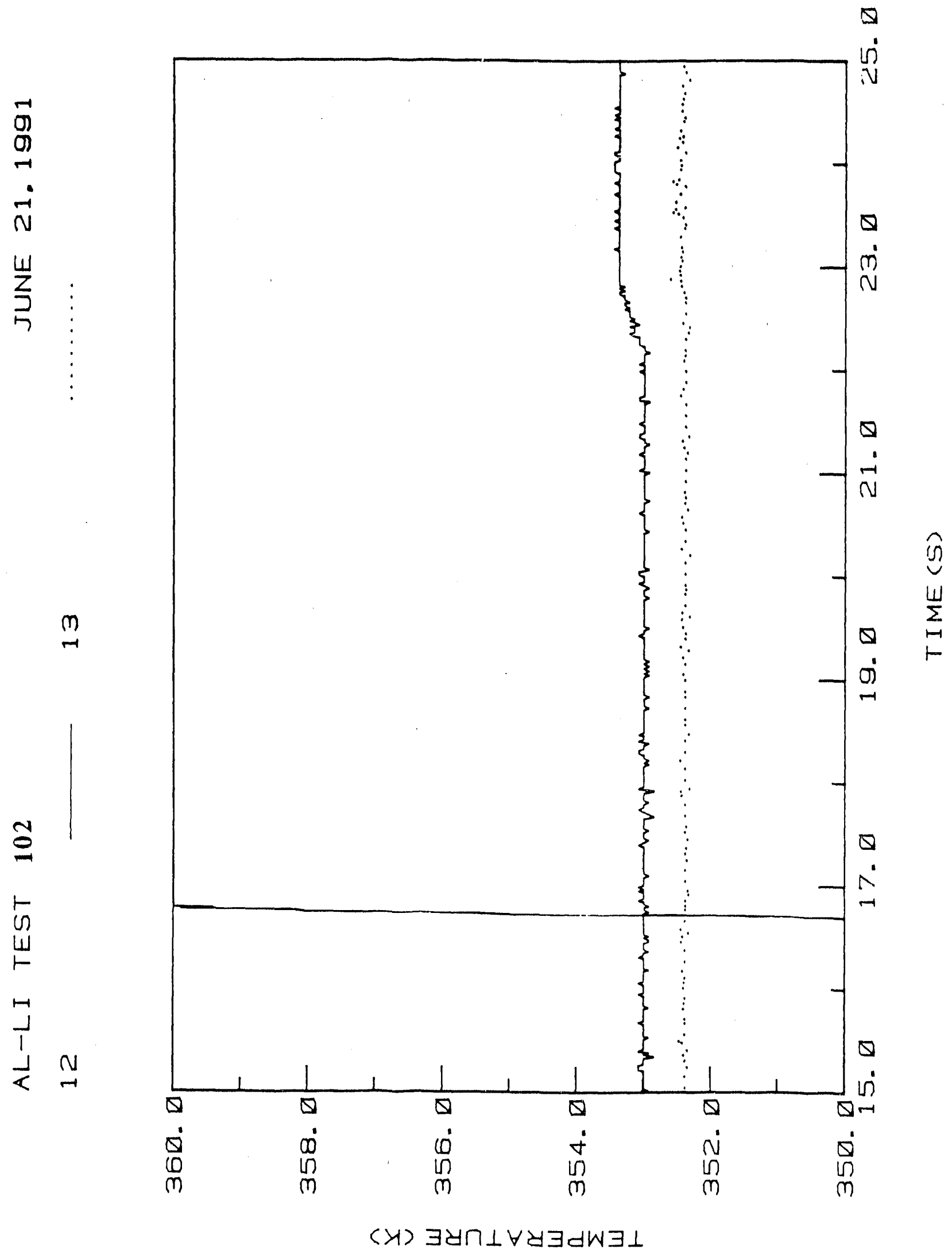




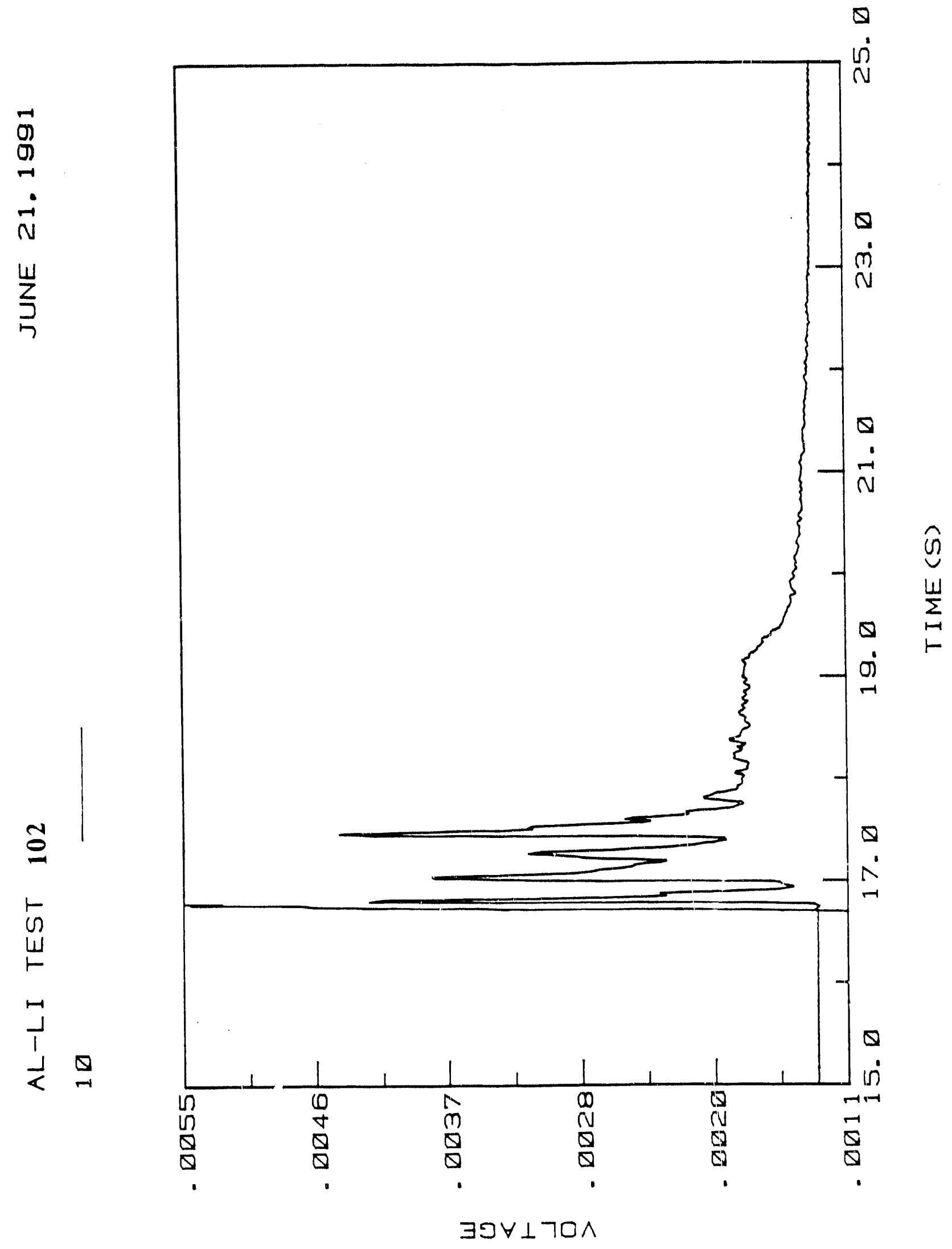




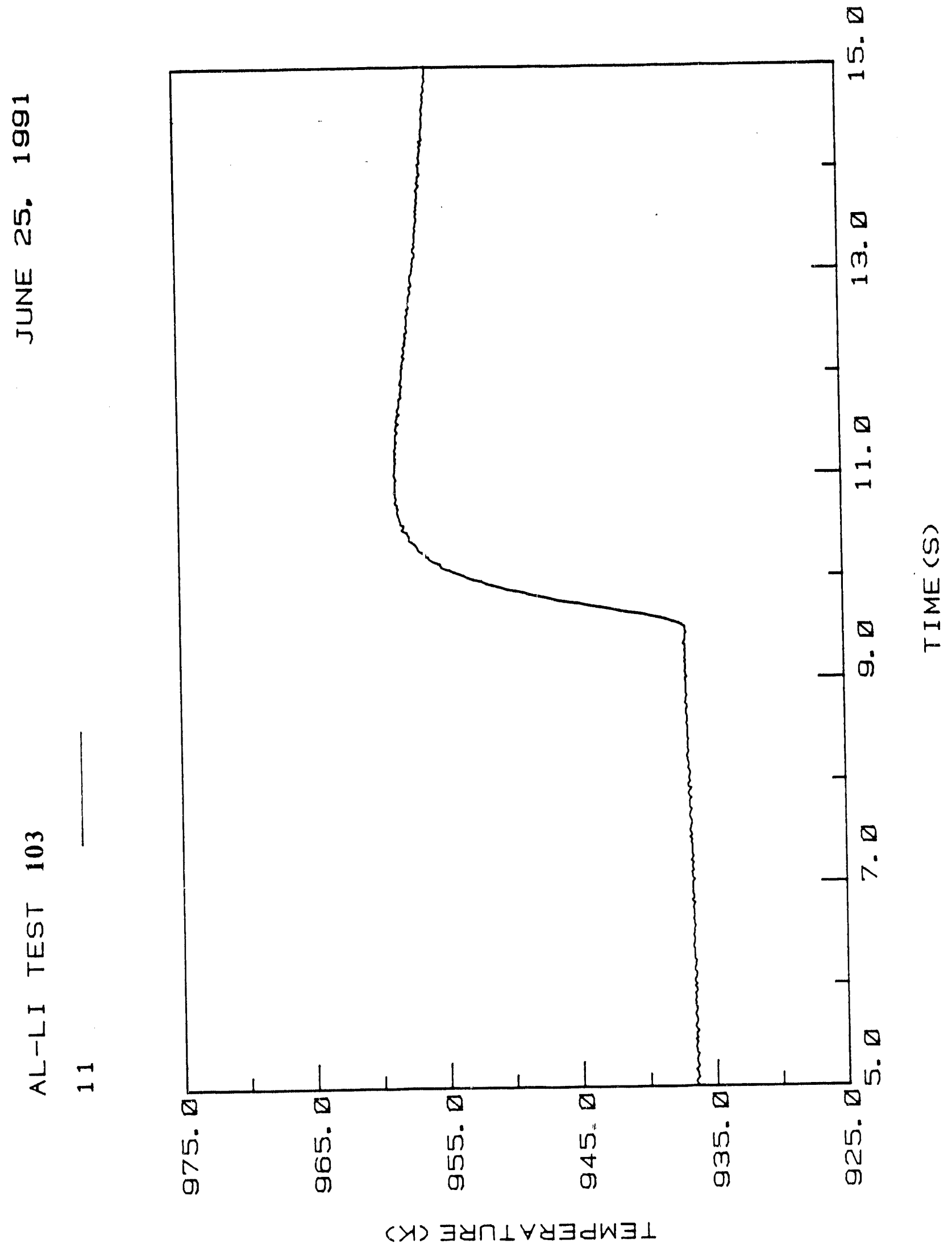




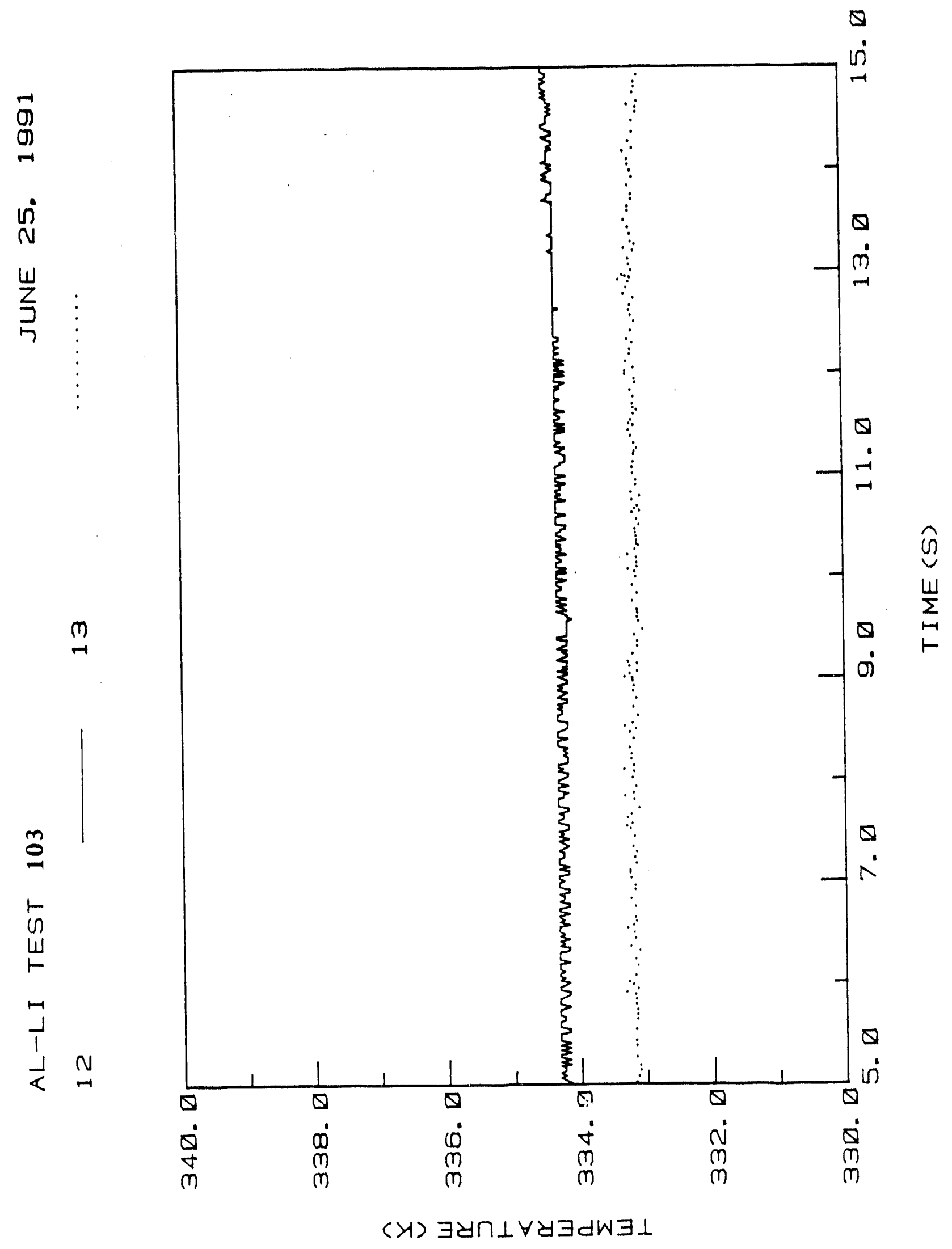




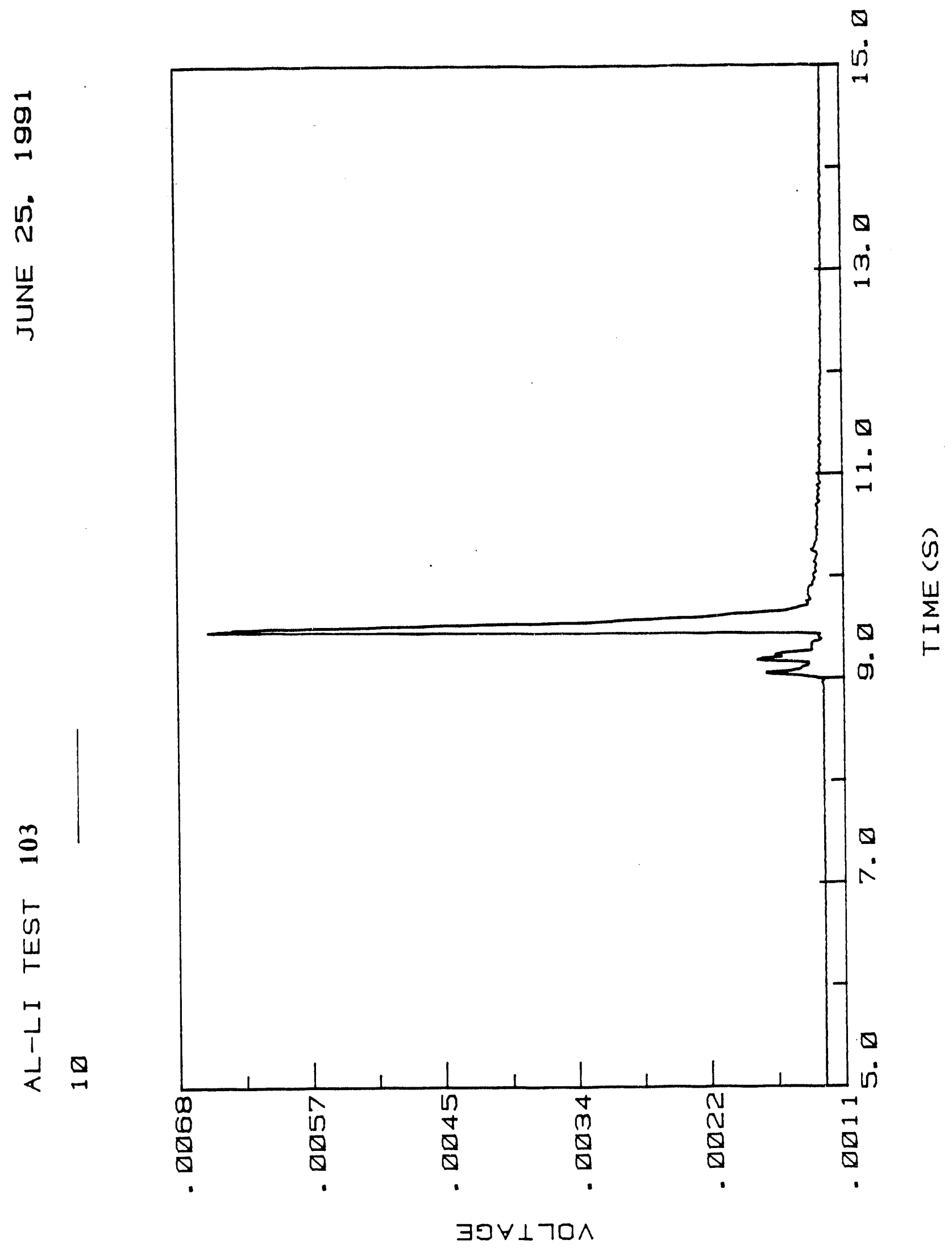




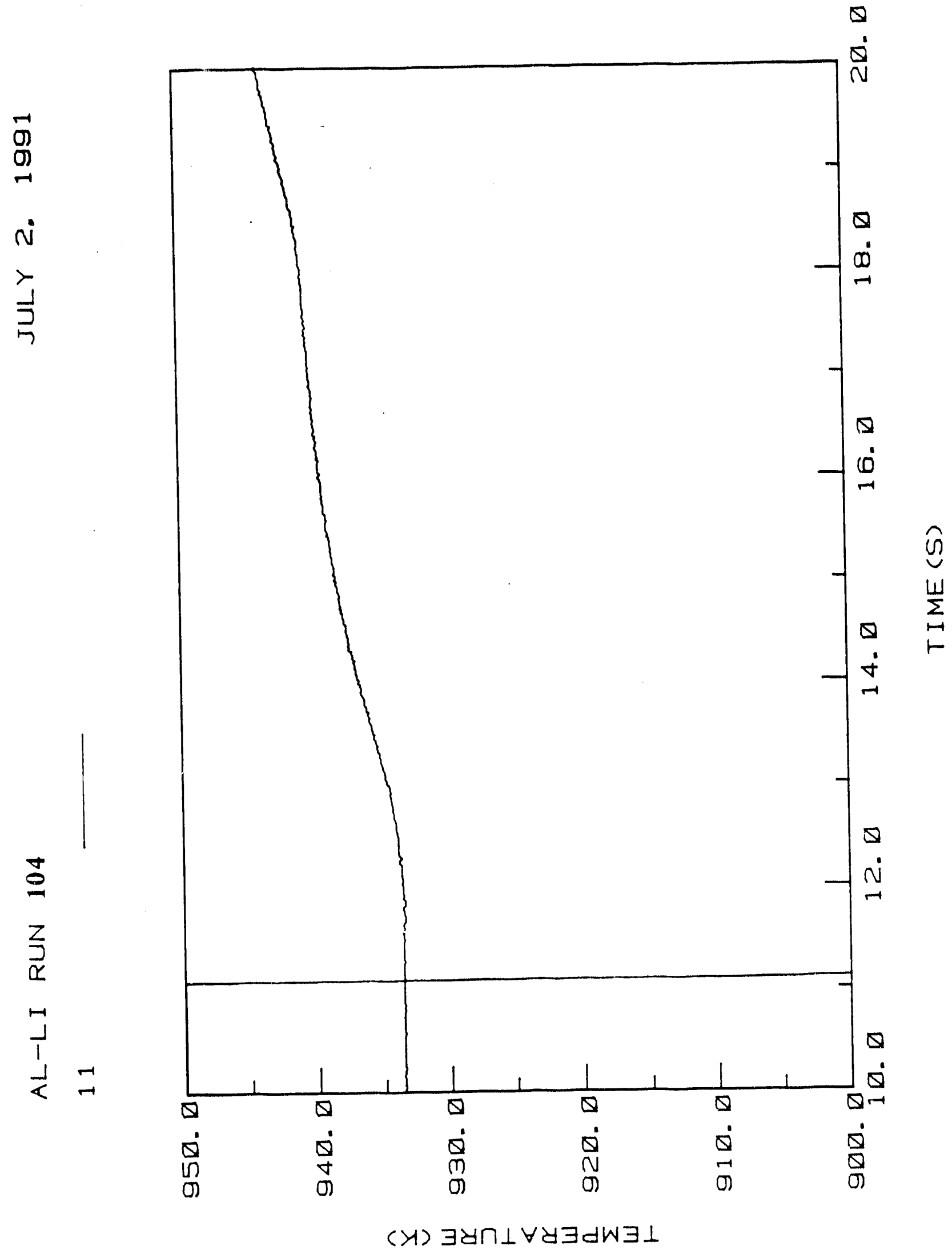




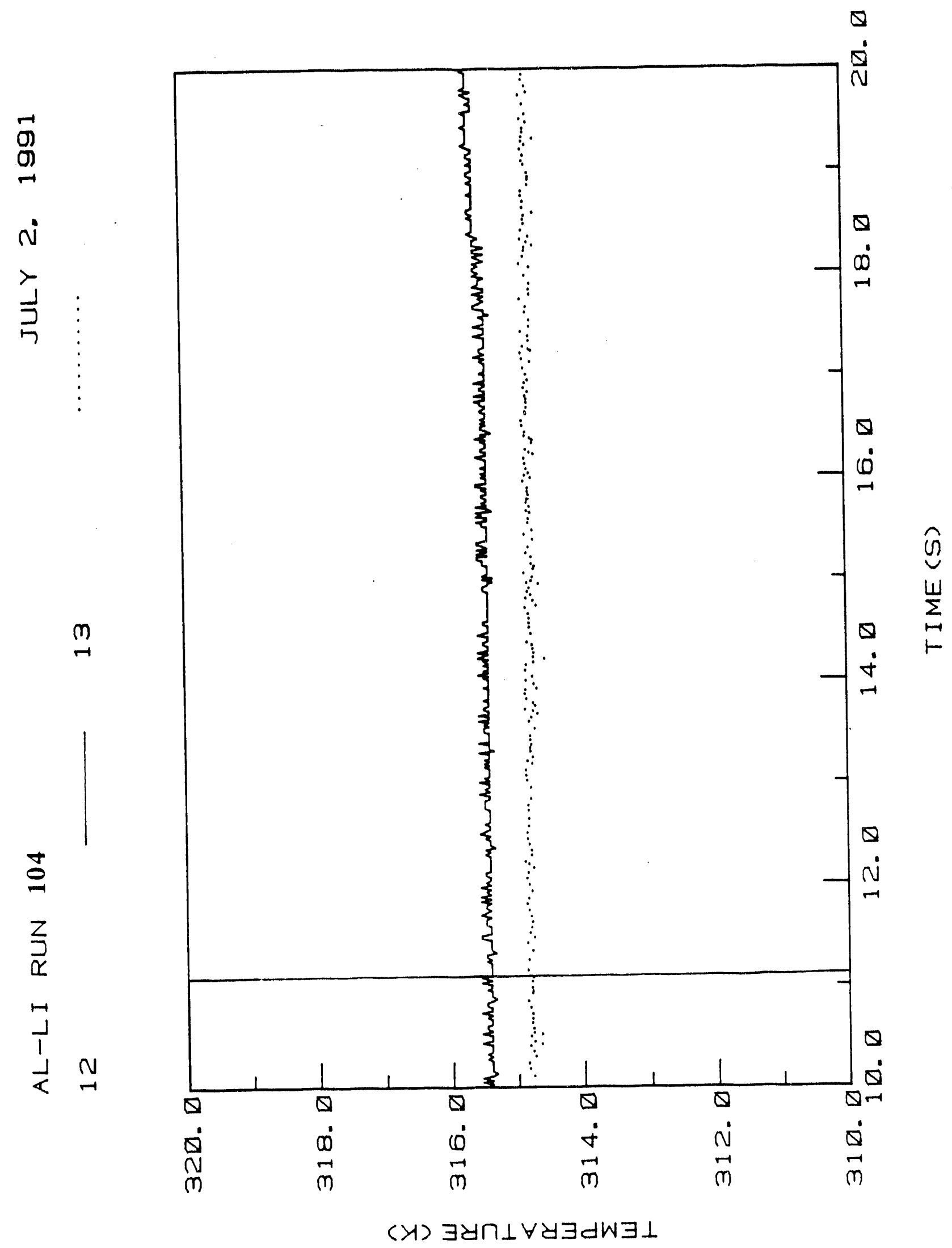




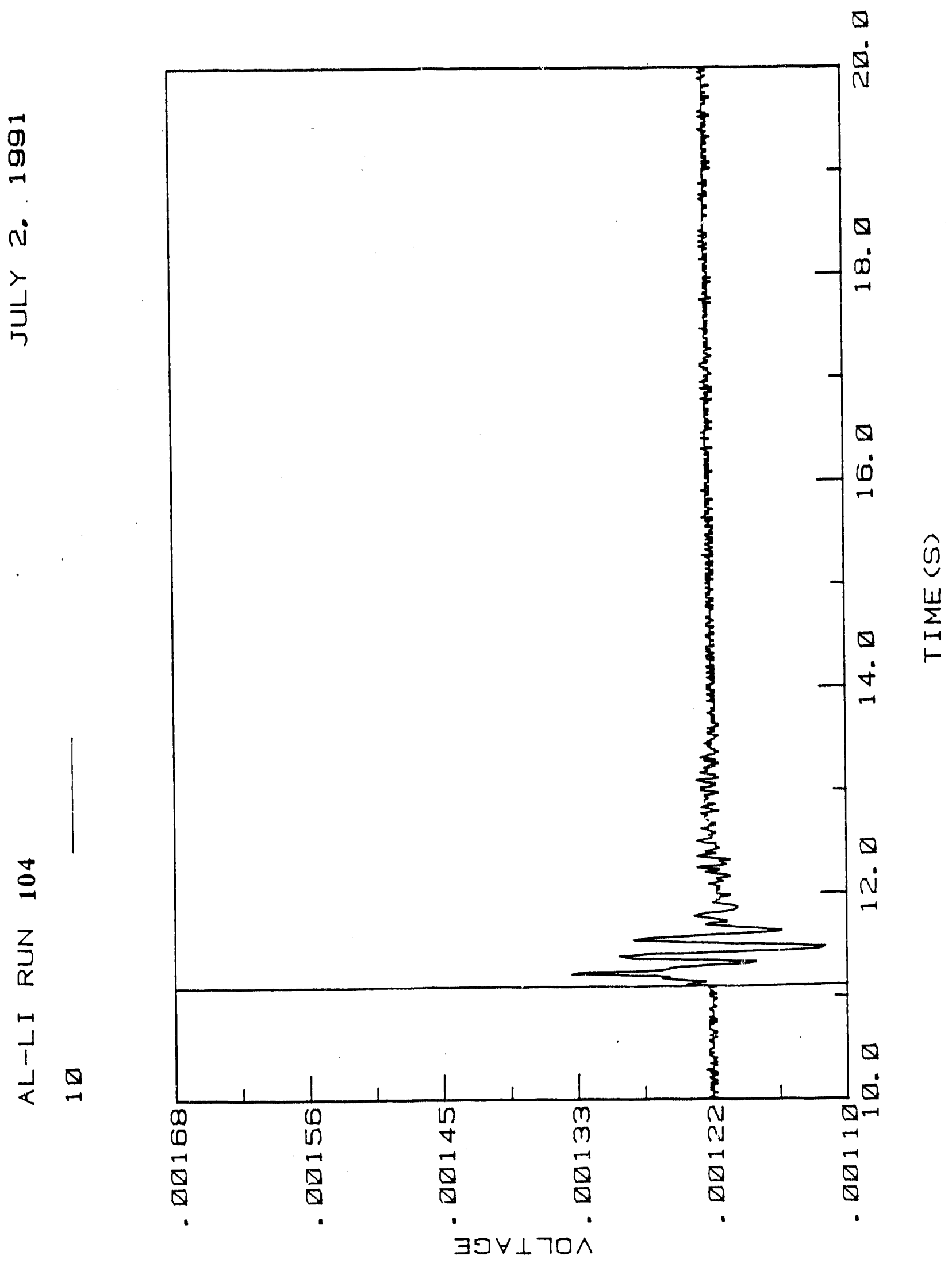




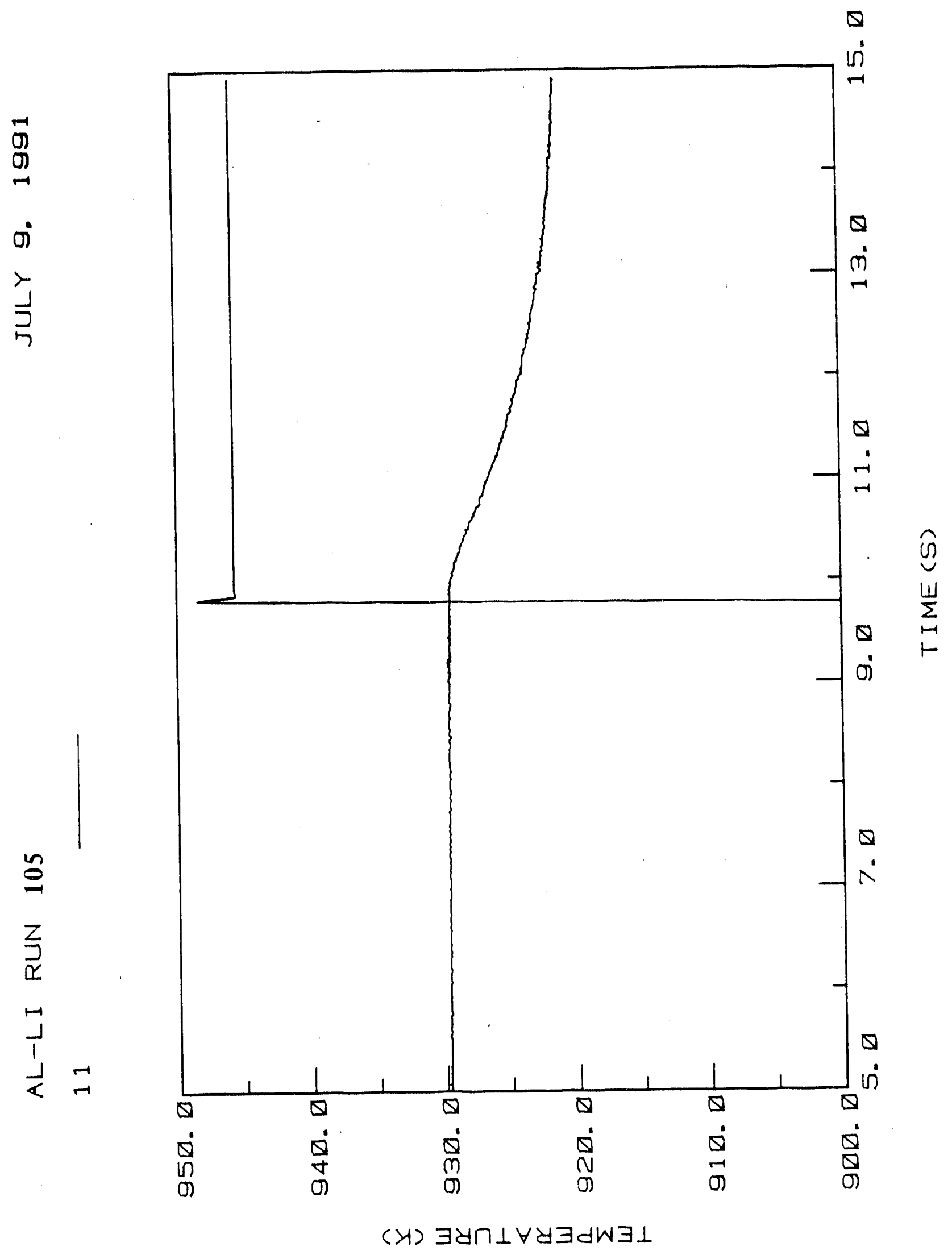




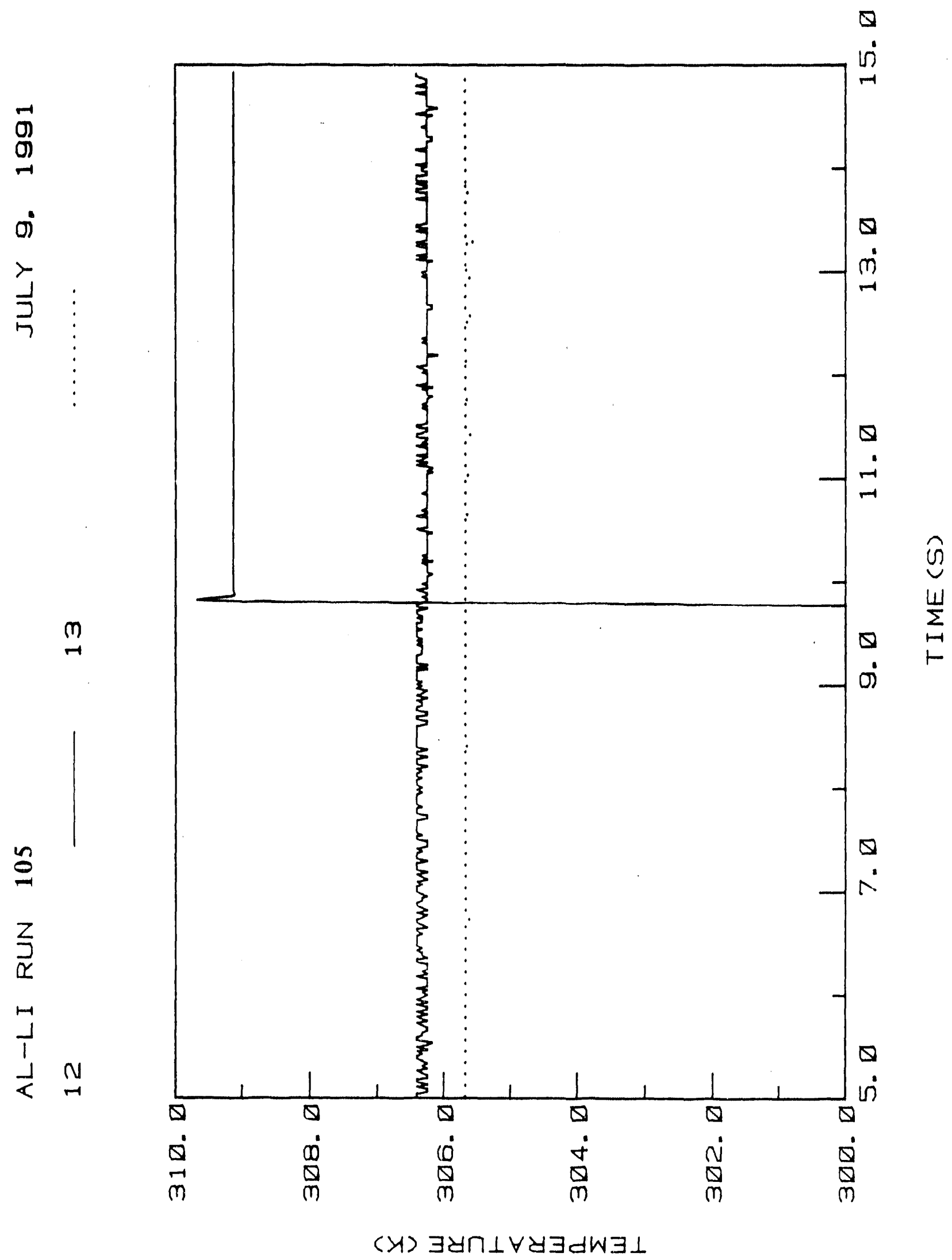




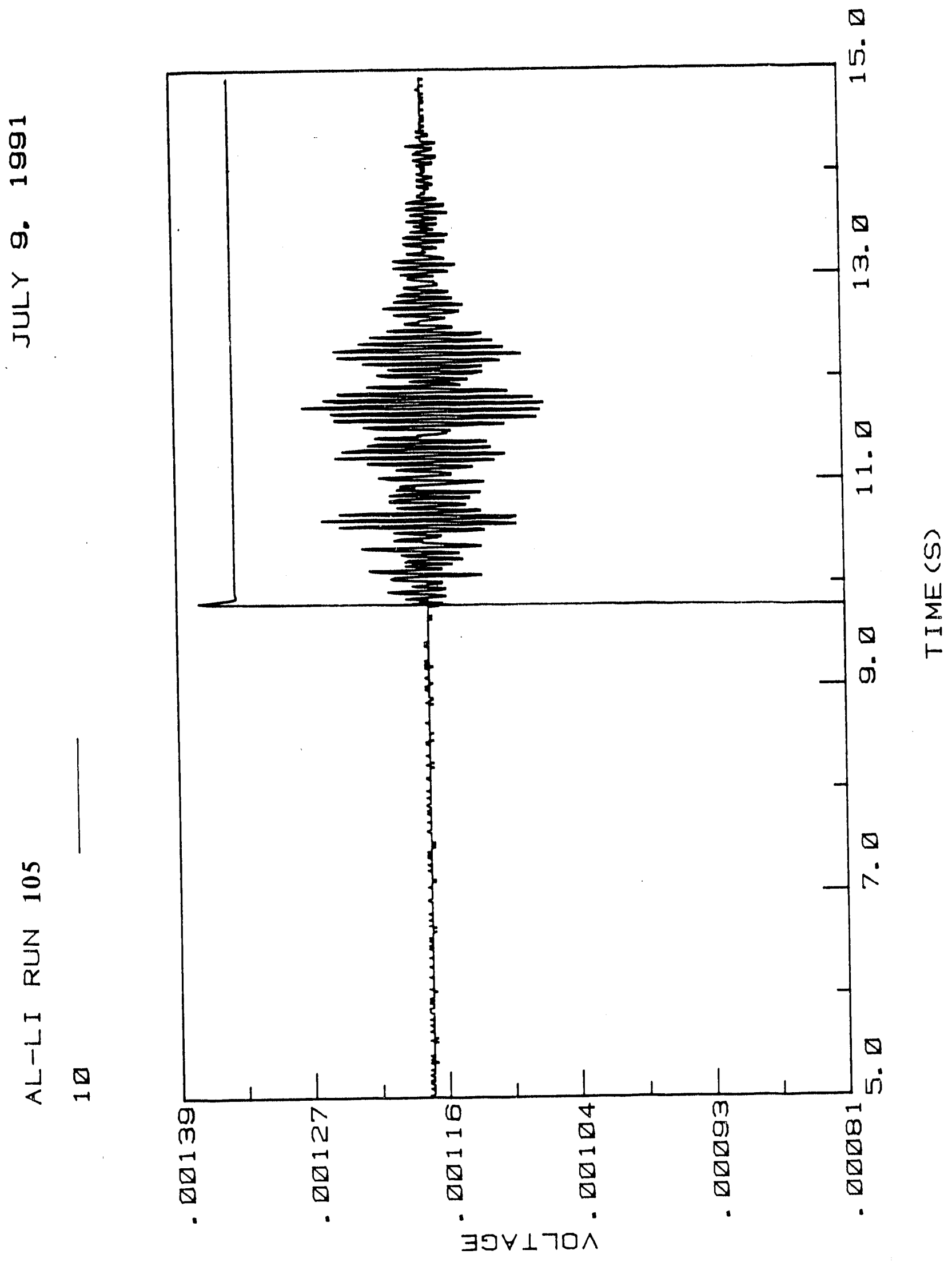




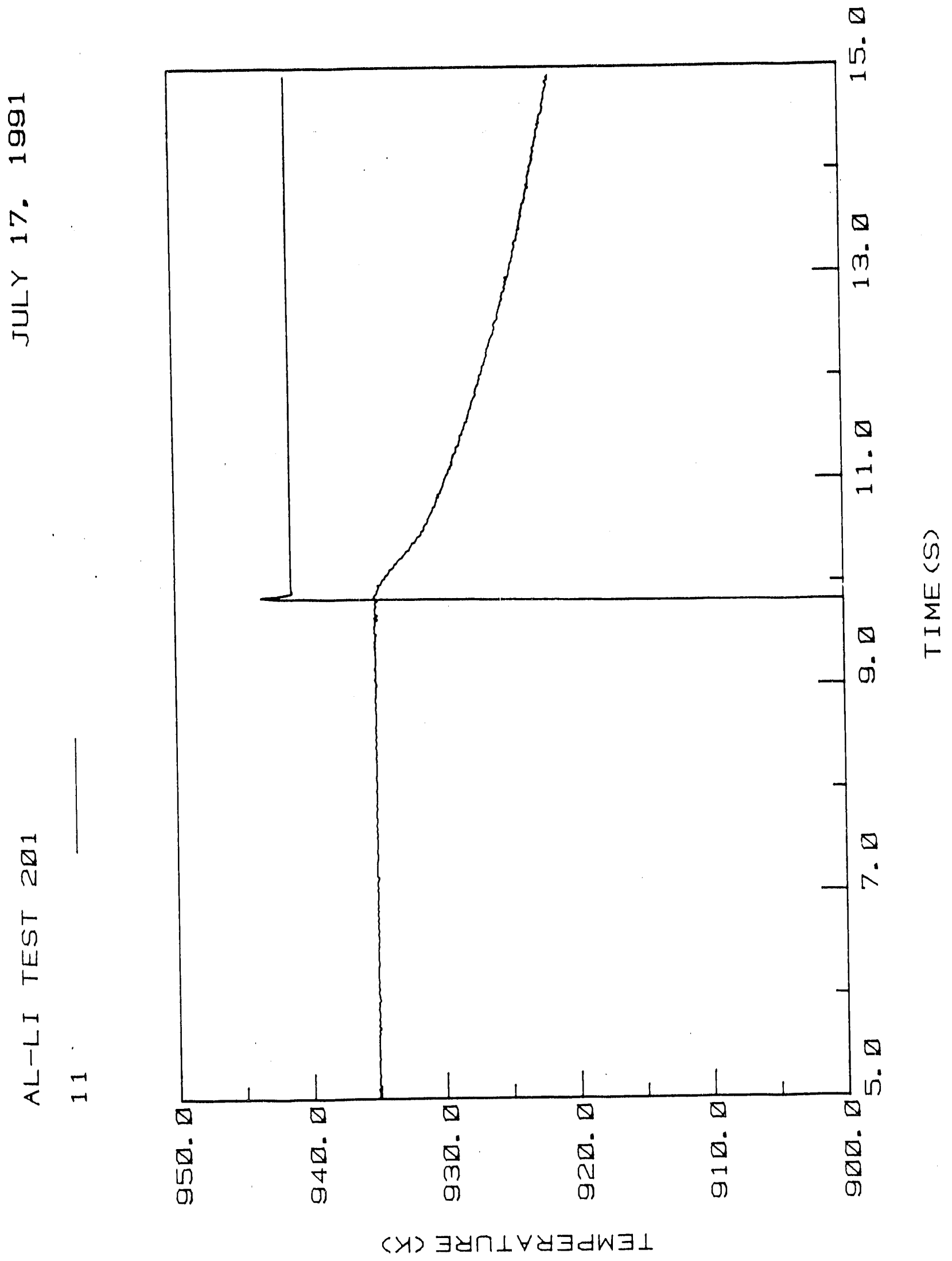




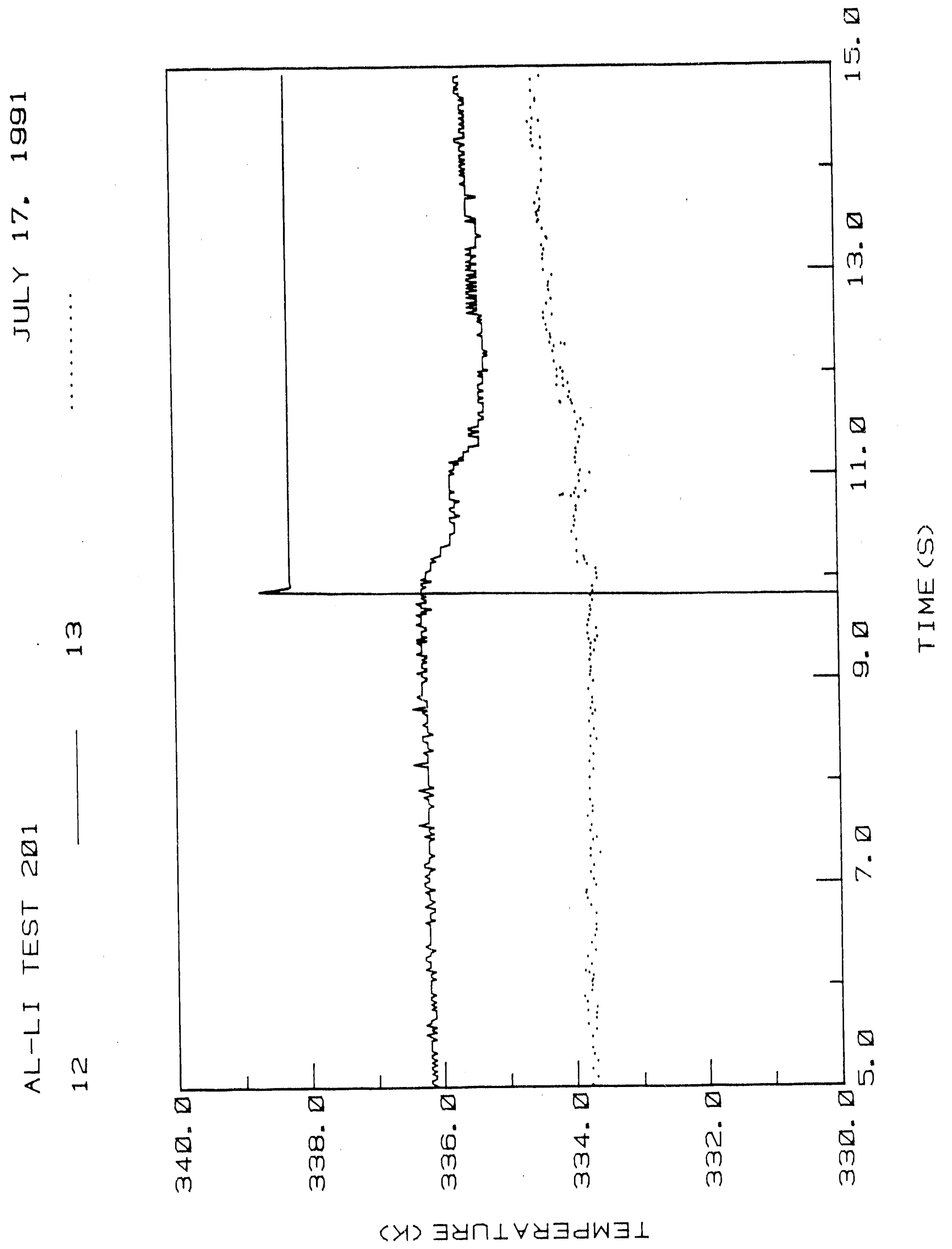




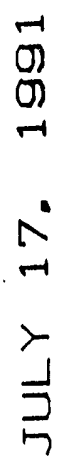

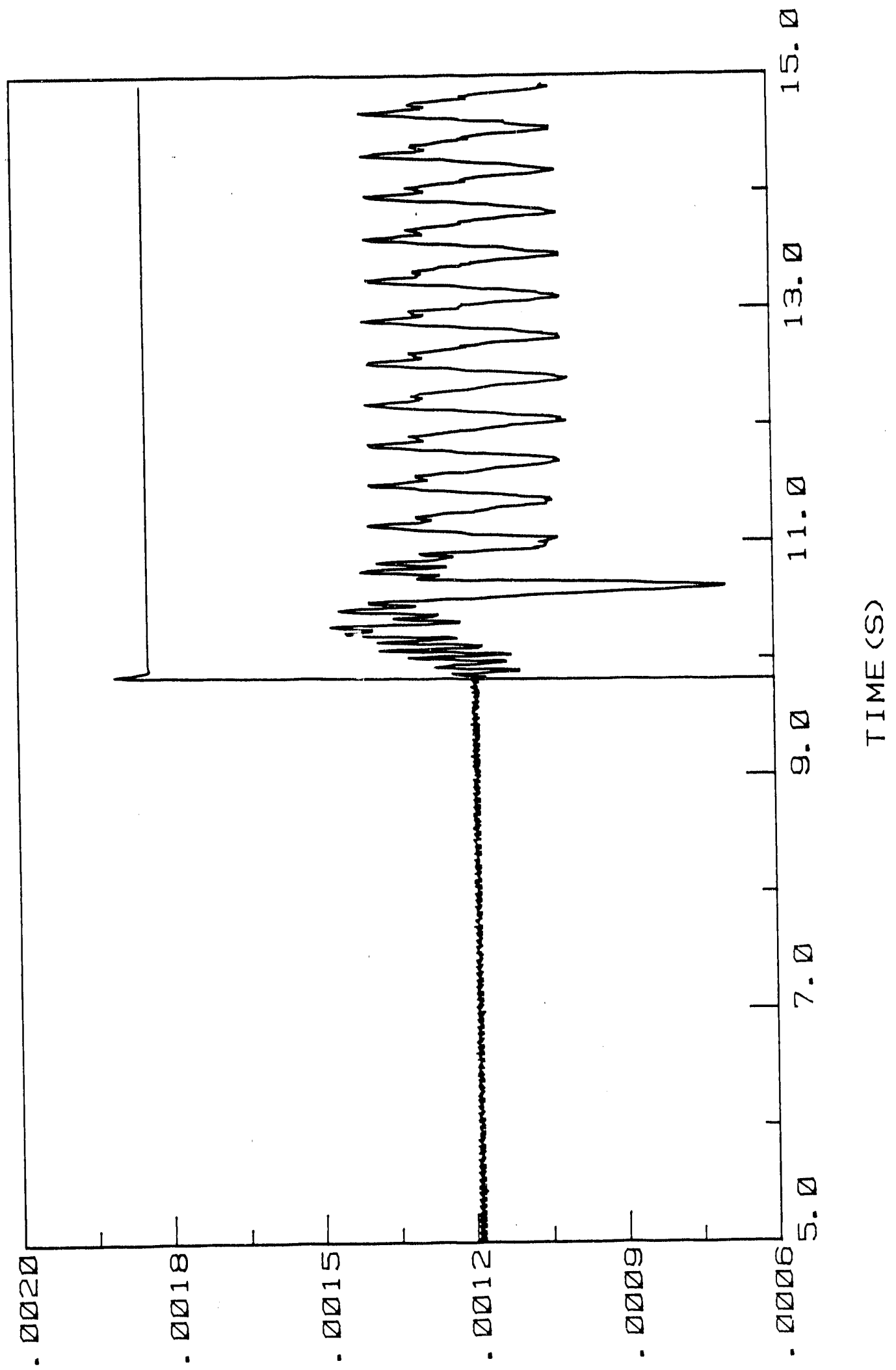

$\exists \Xi \forall \perp \neg 0 \wedge$ 


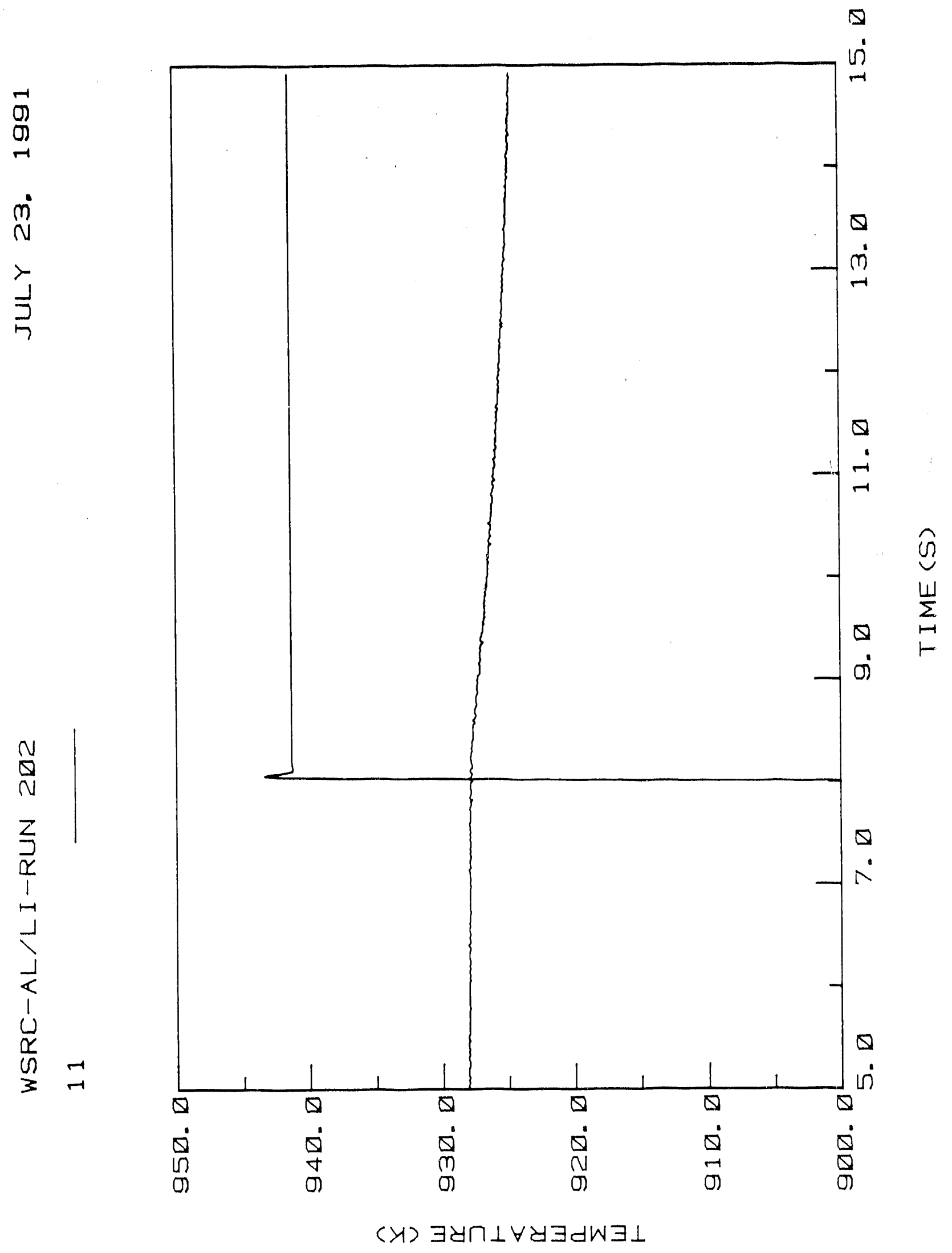




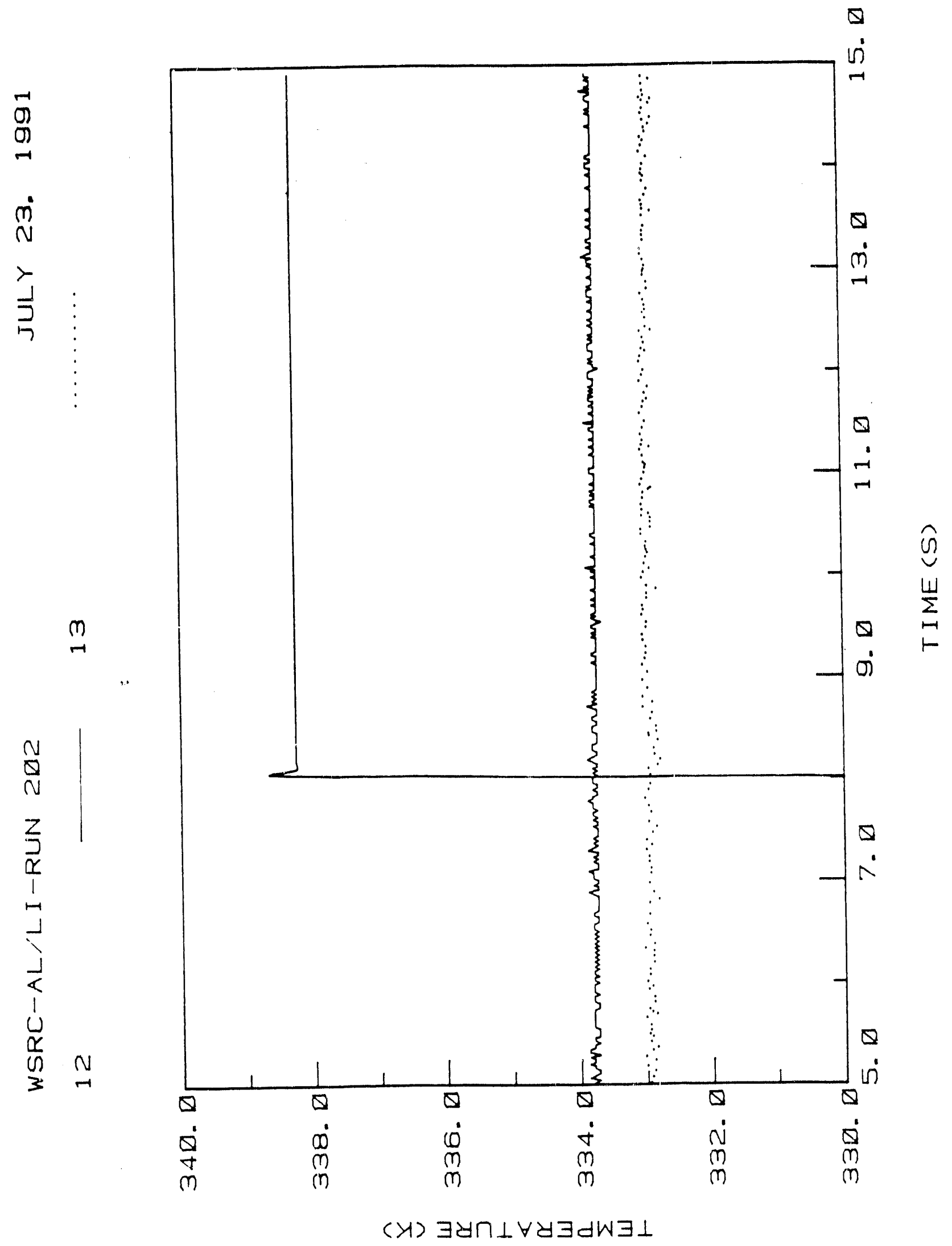




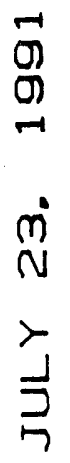

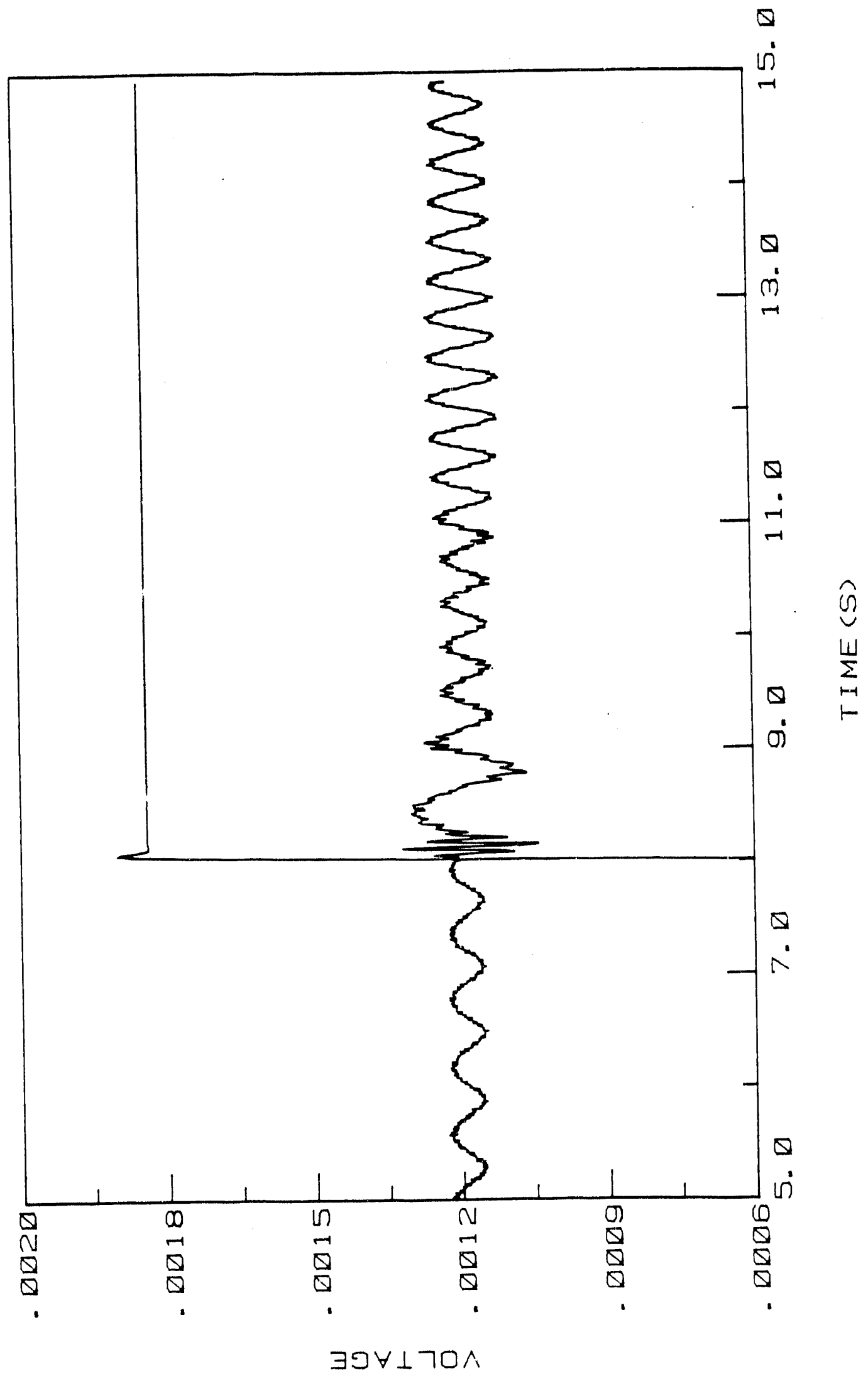




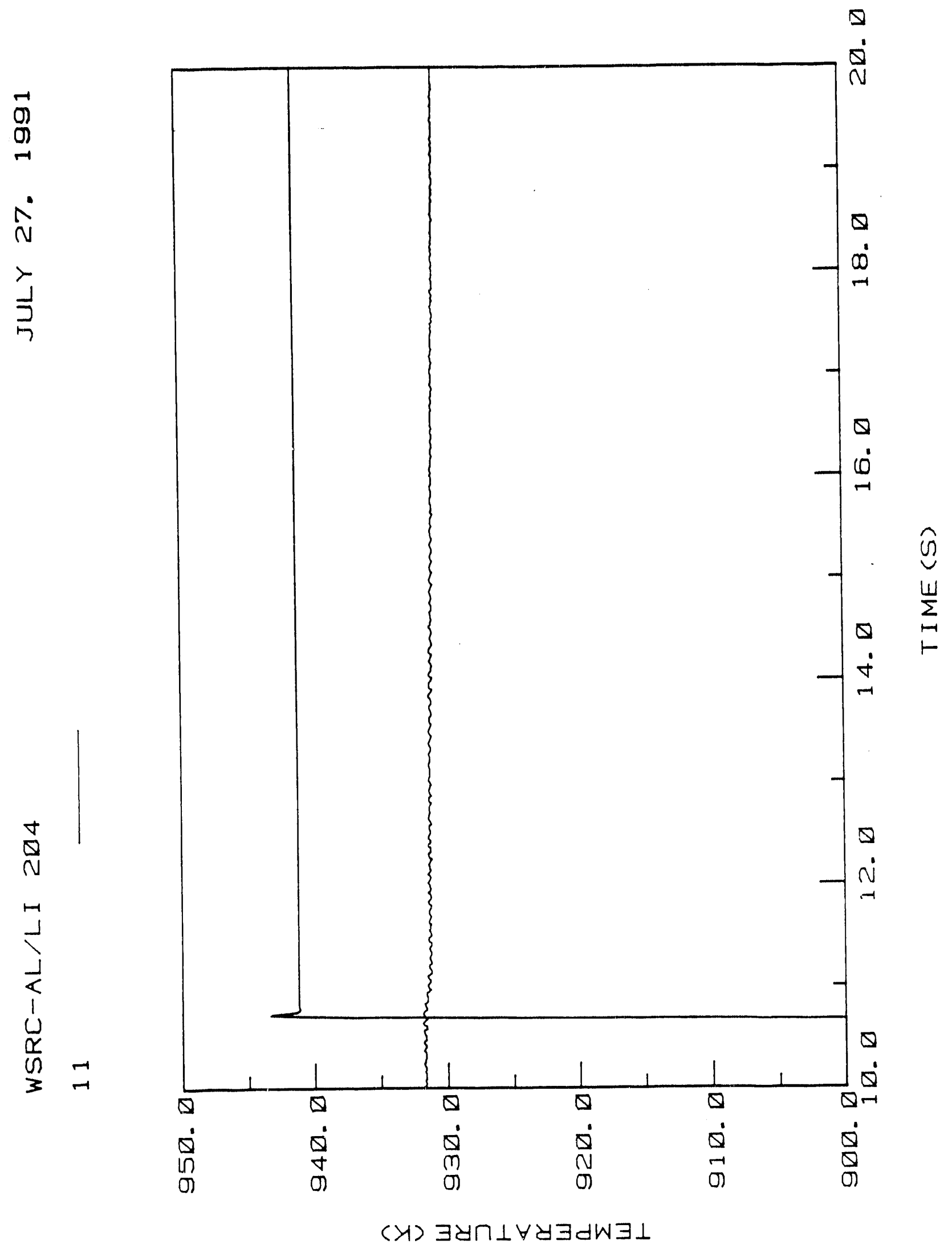




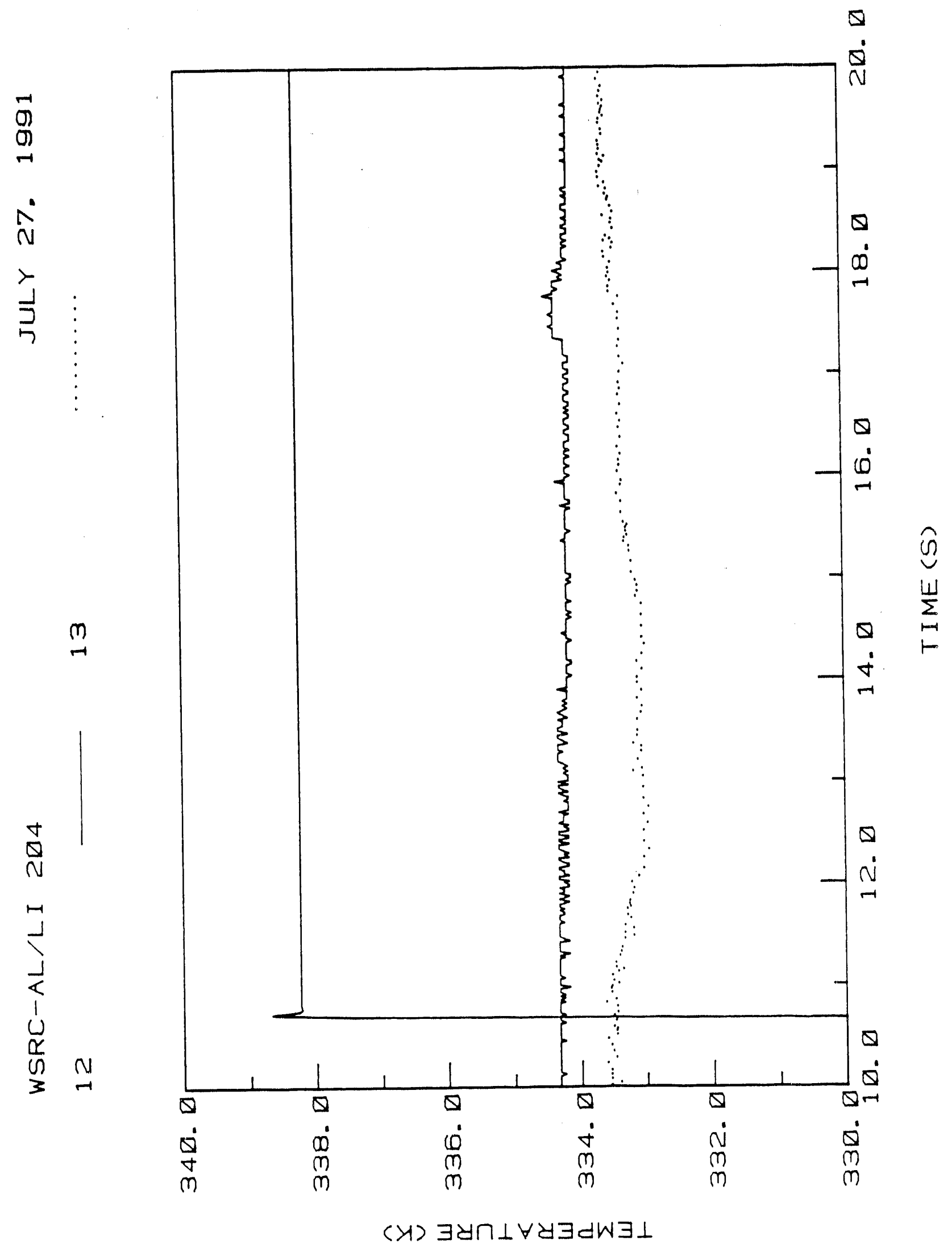




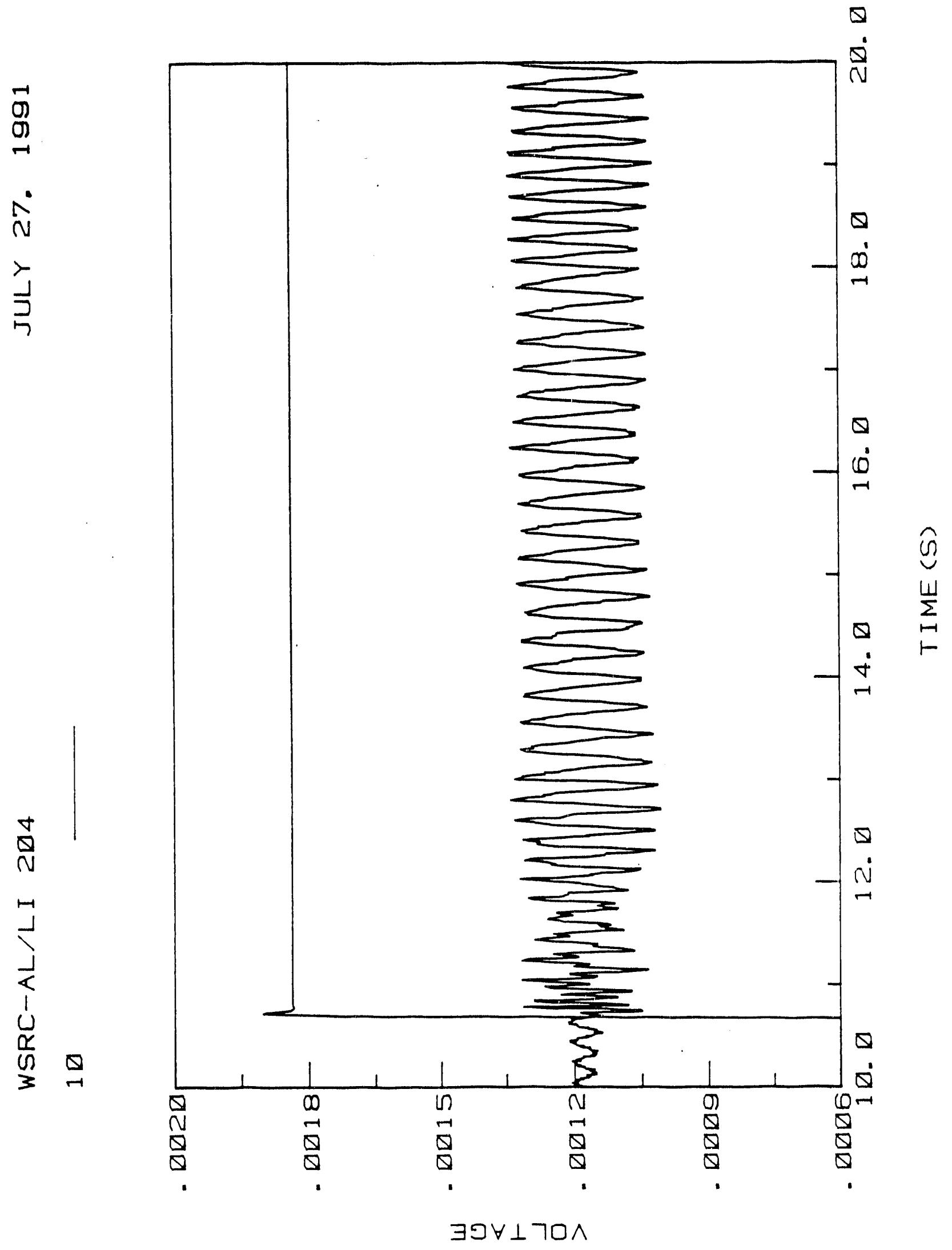




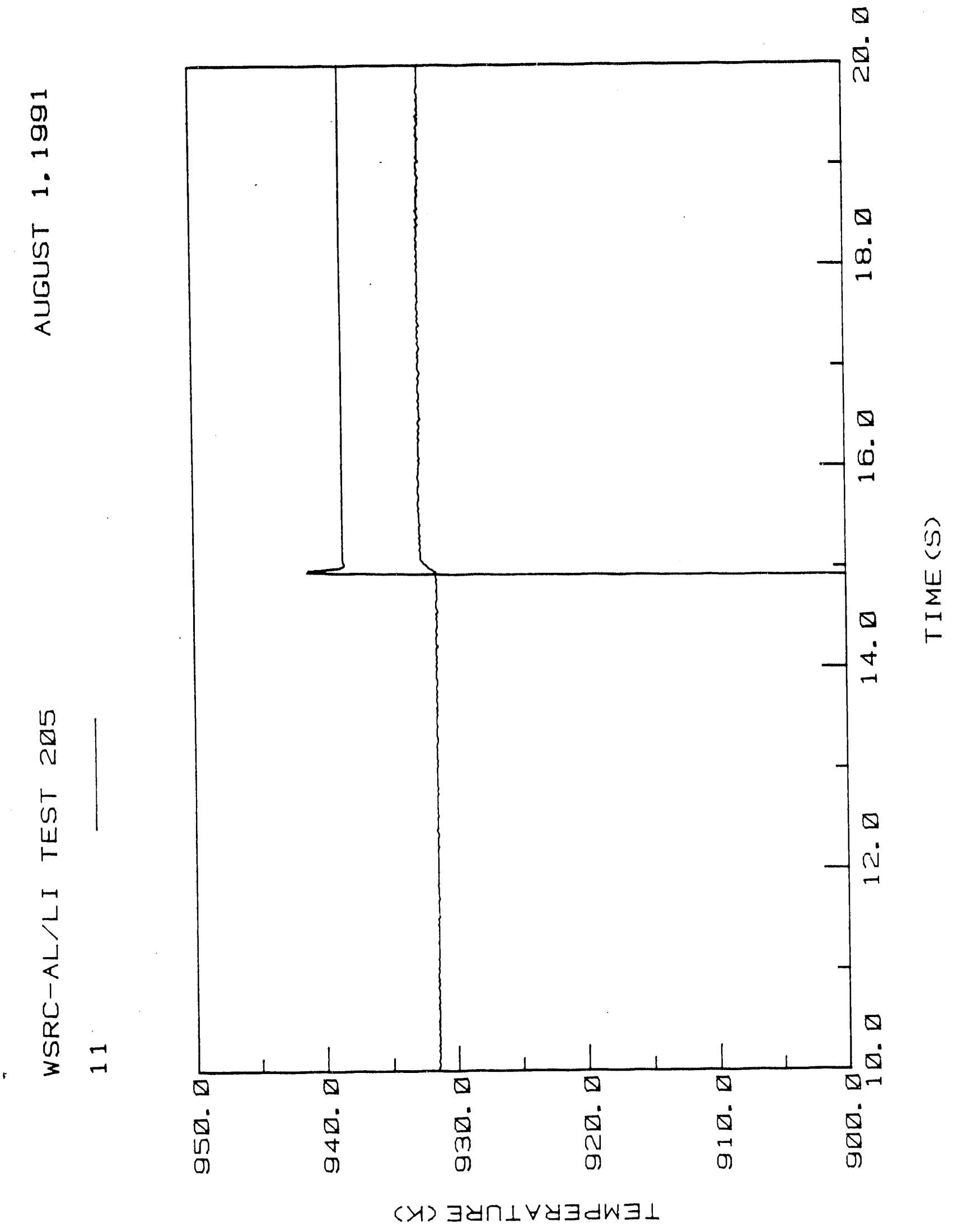




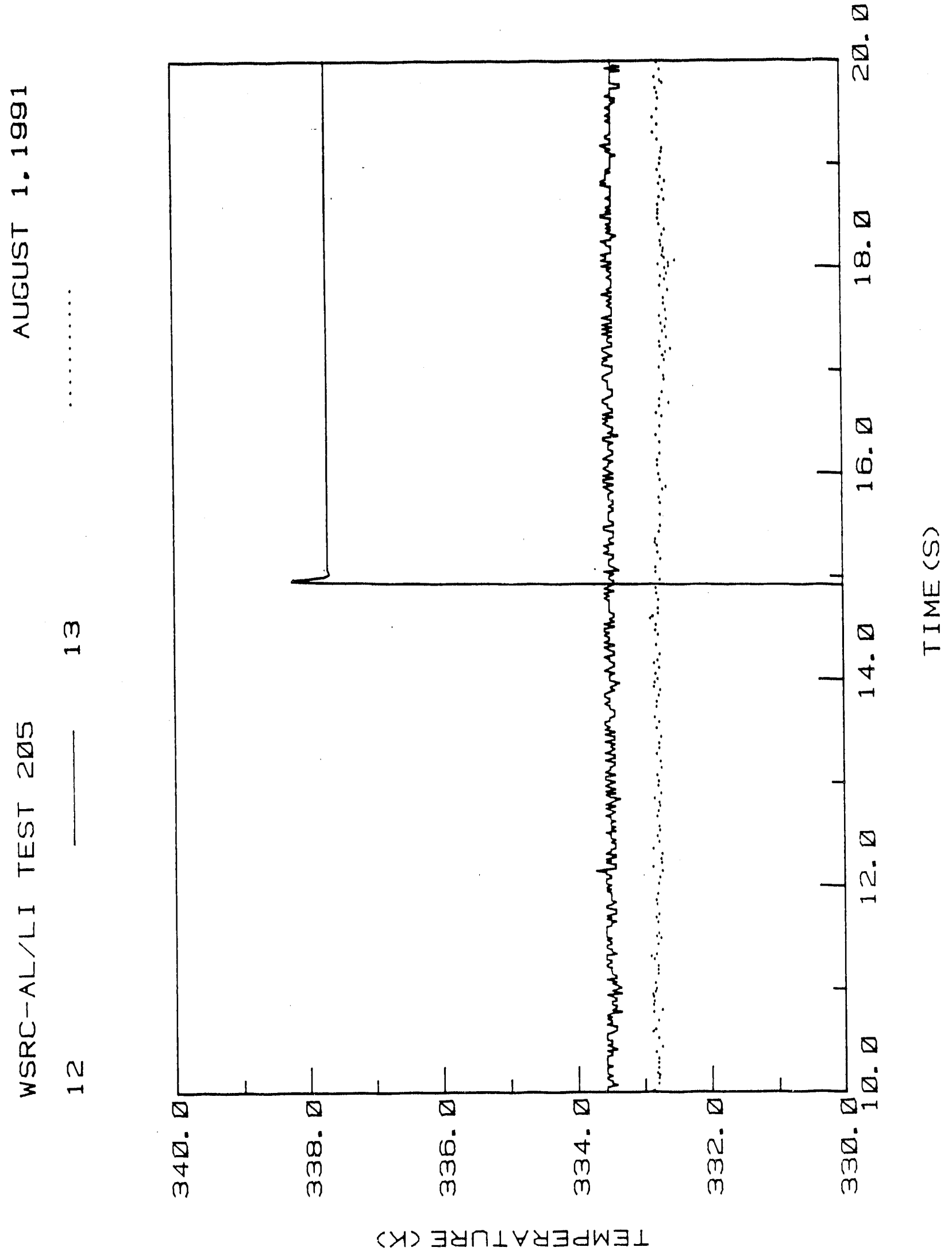




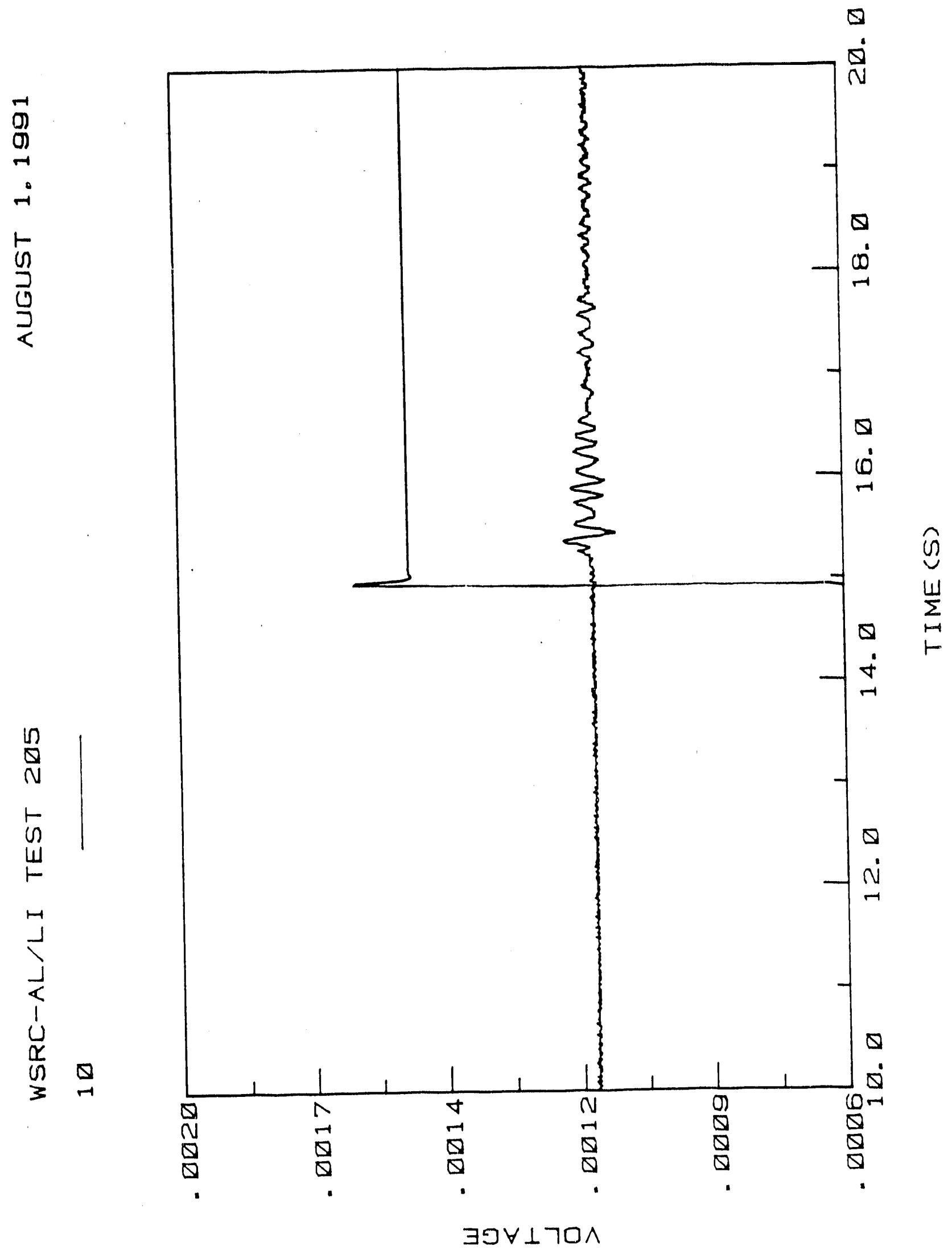




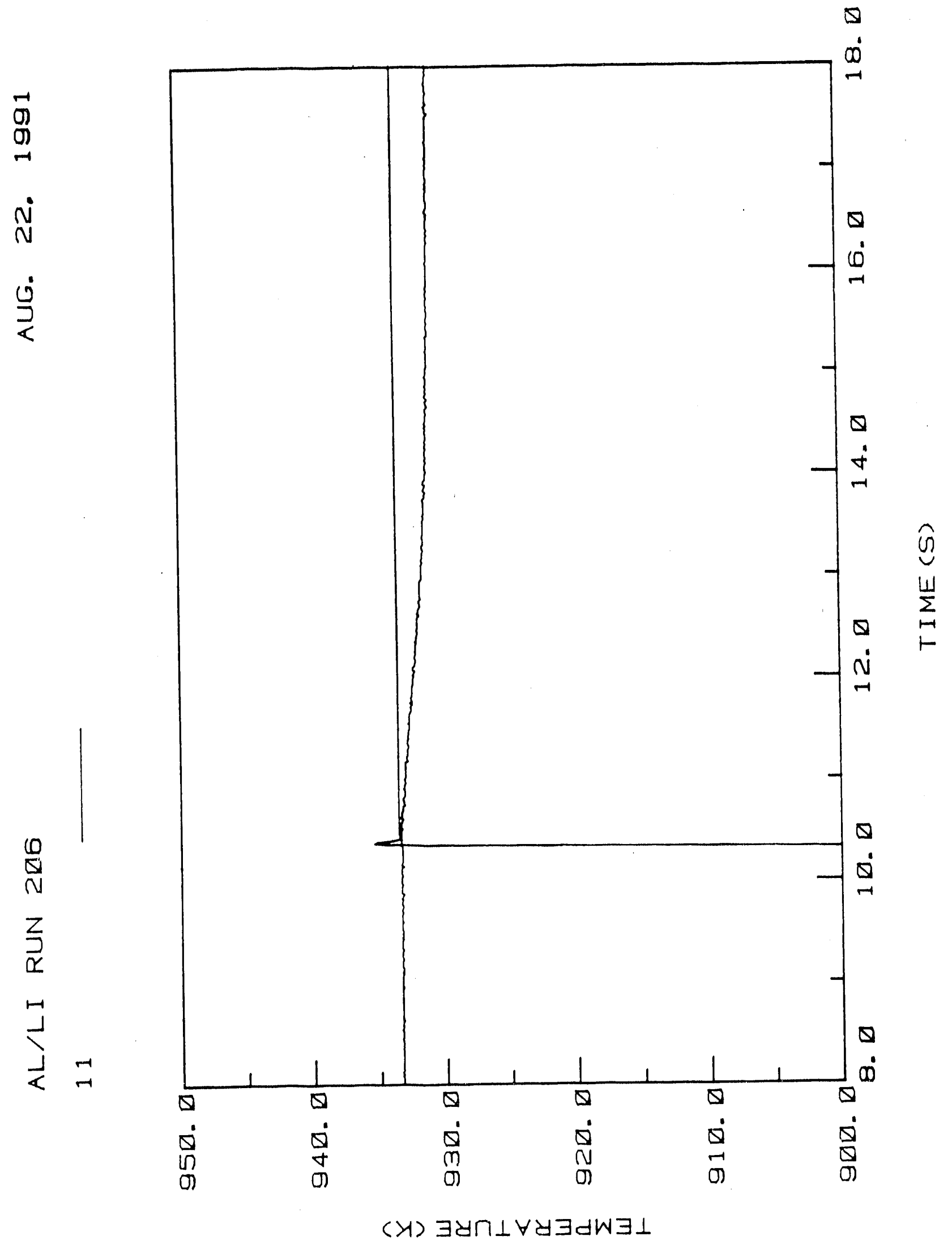




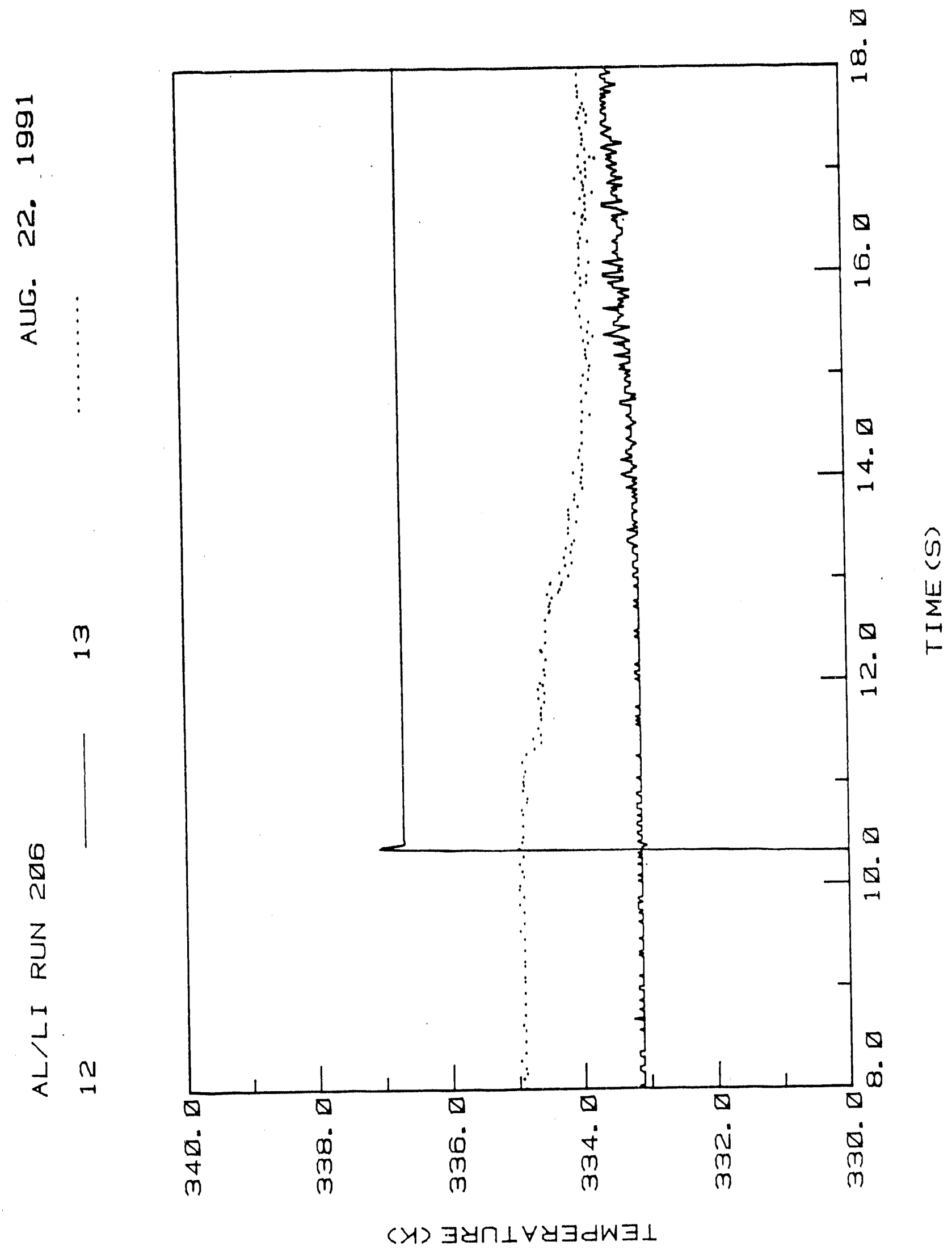




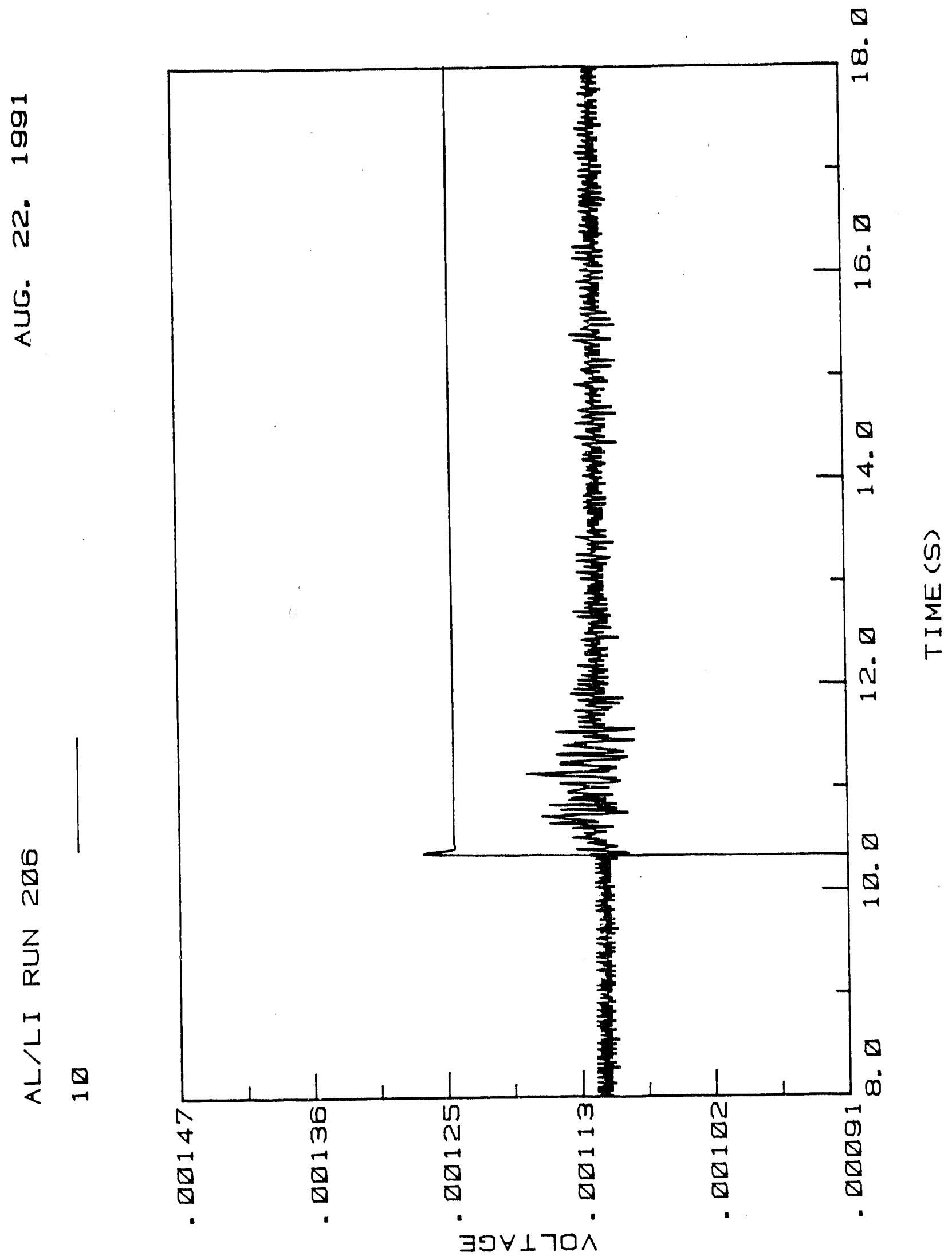




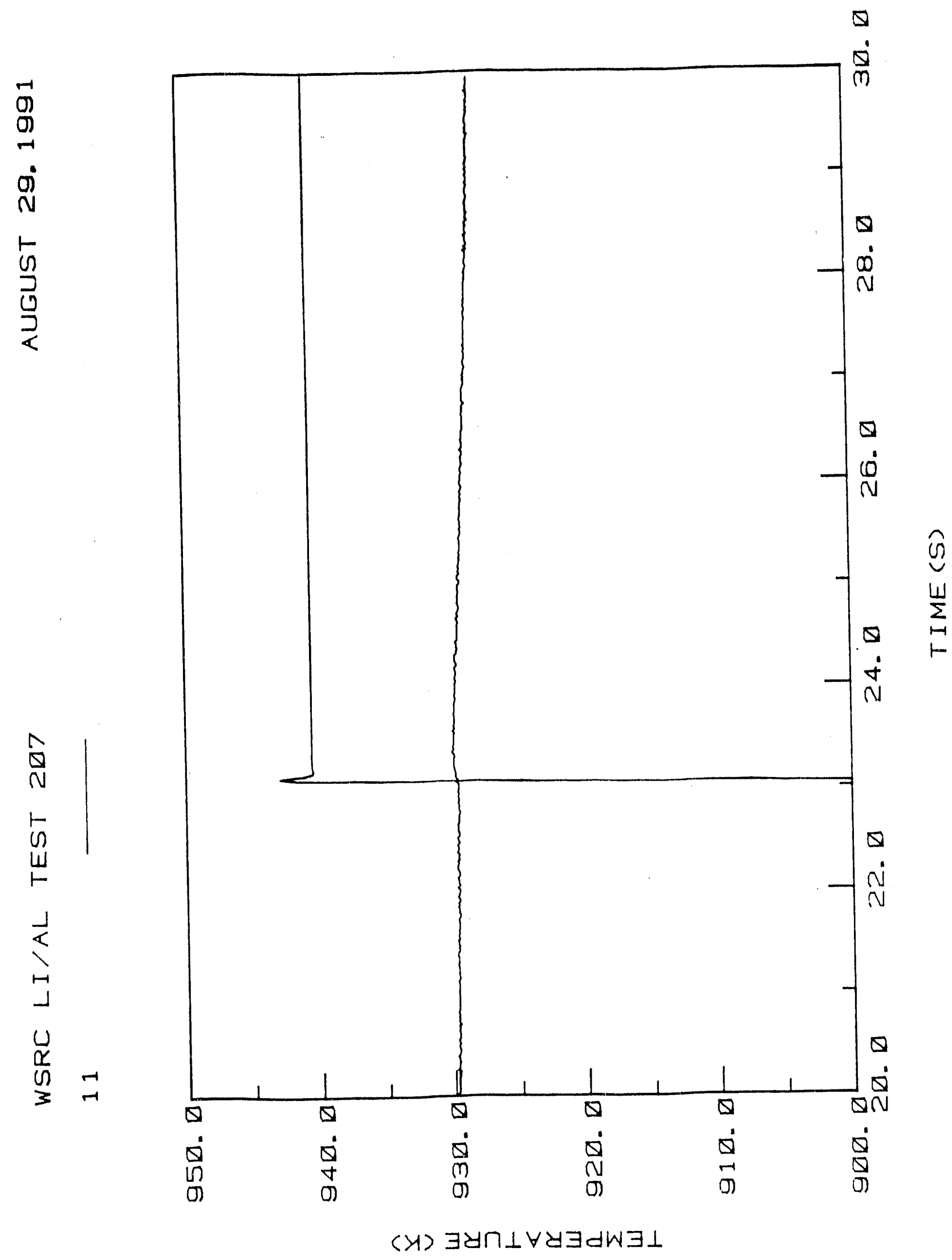




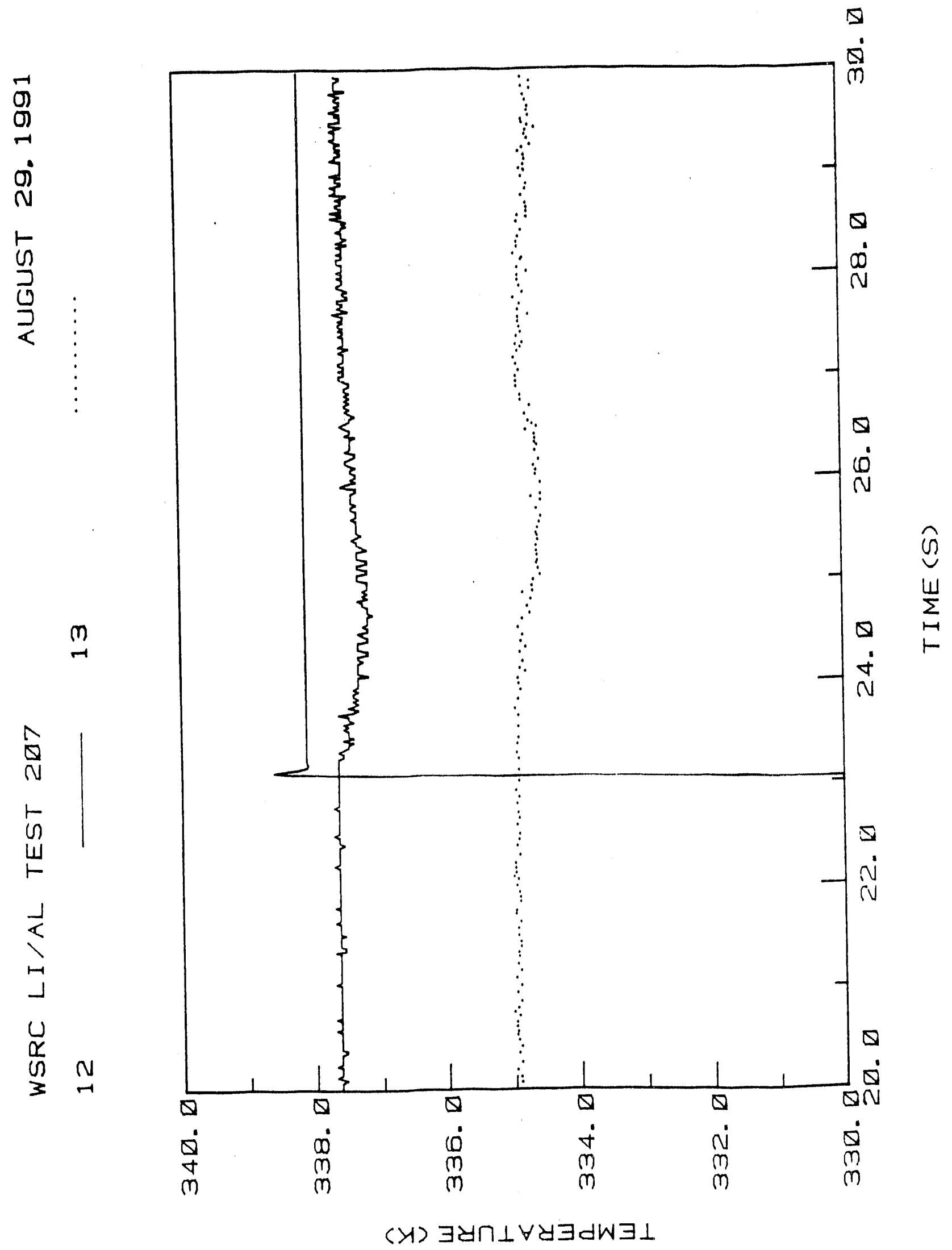




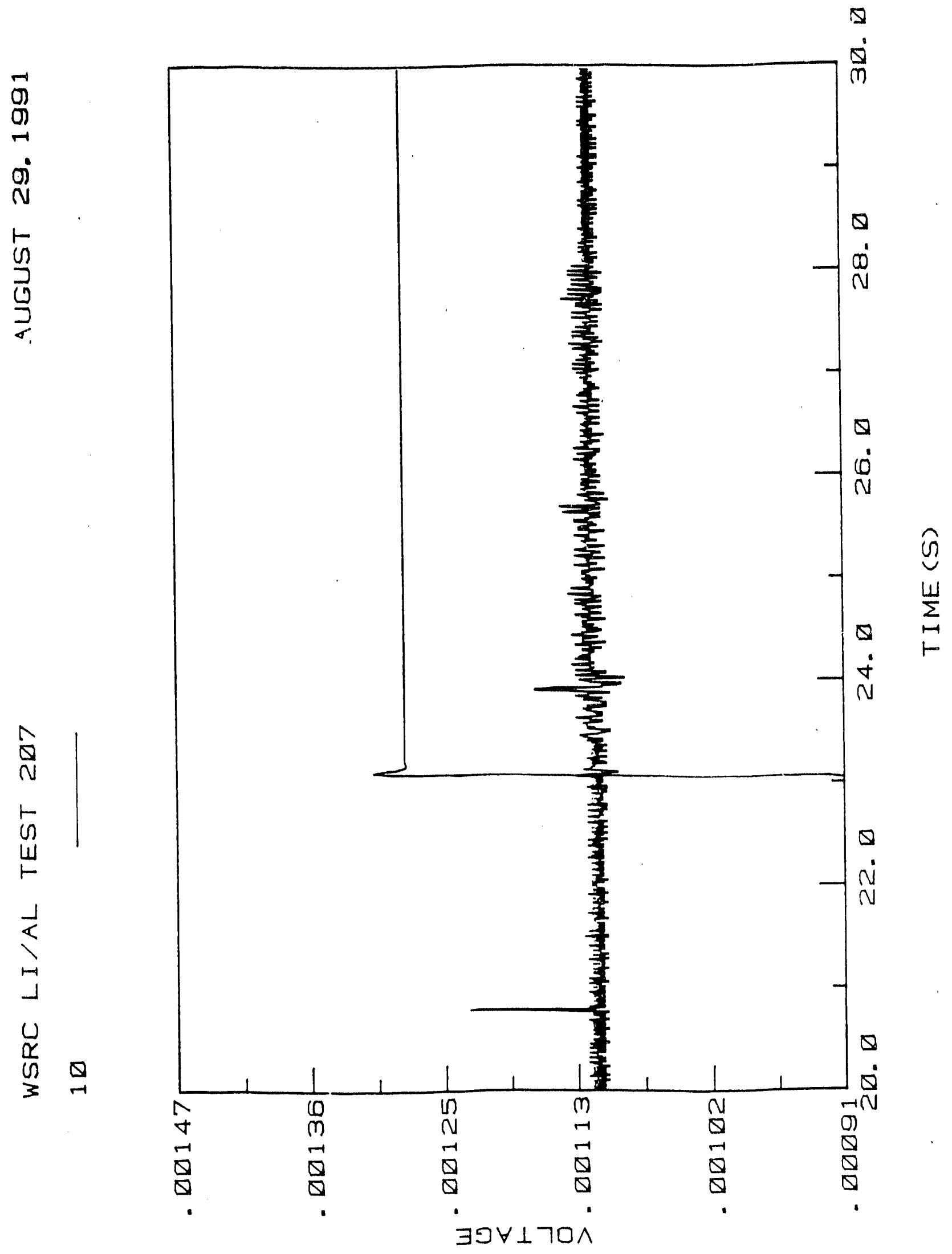




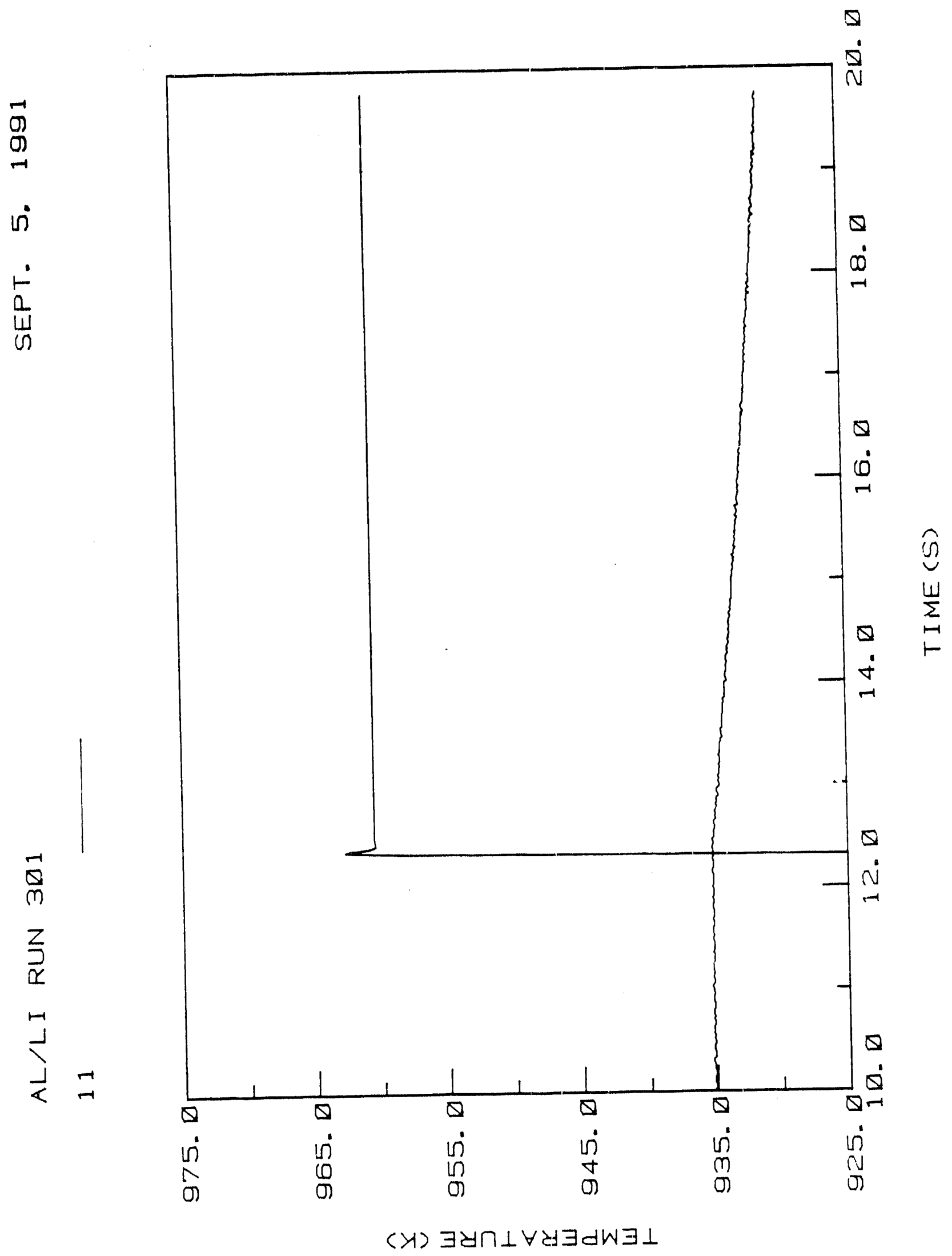




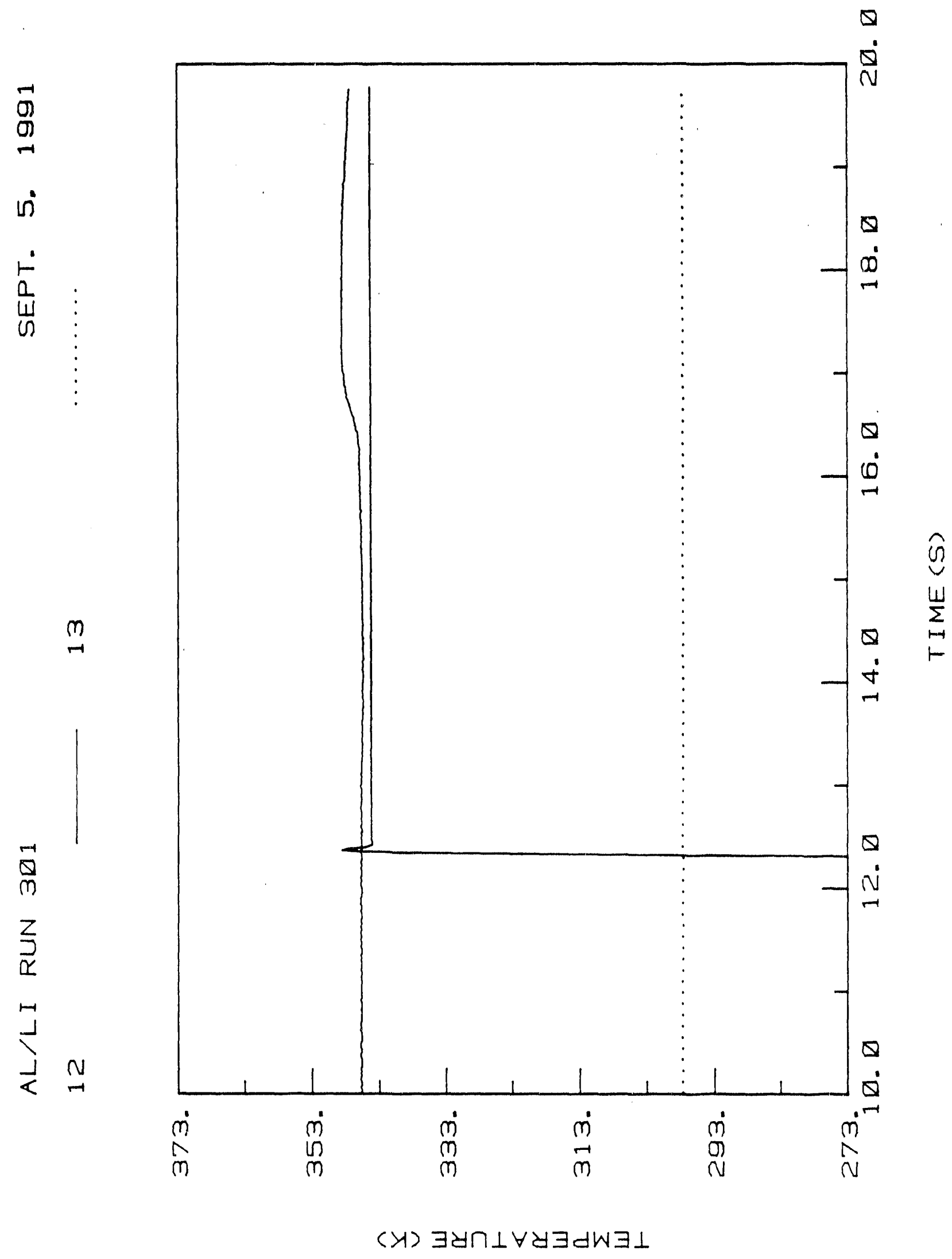




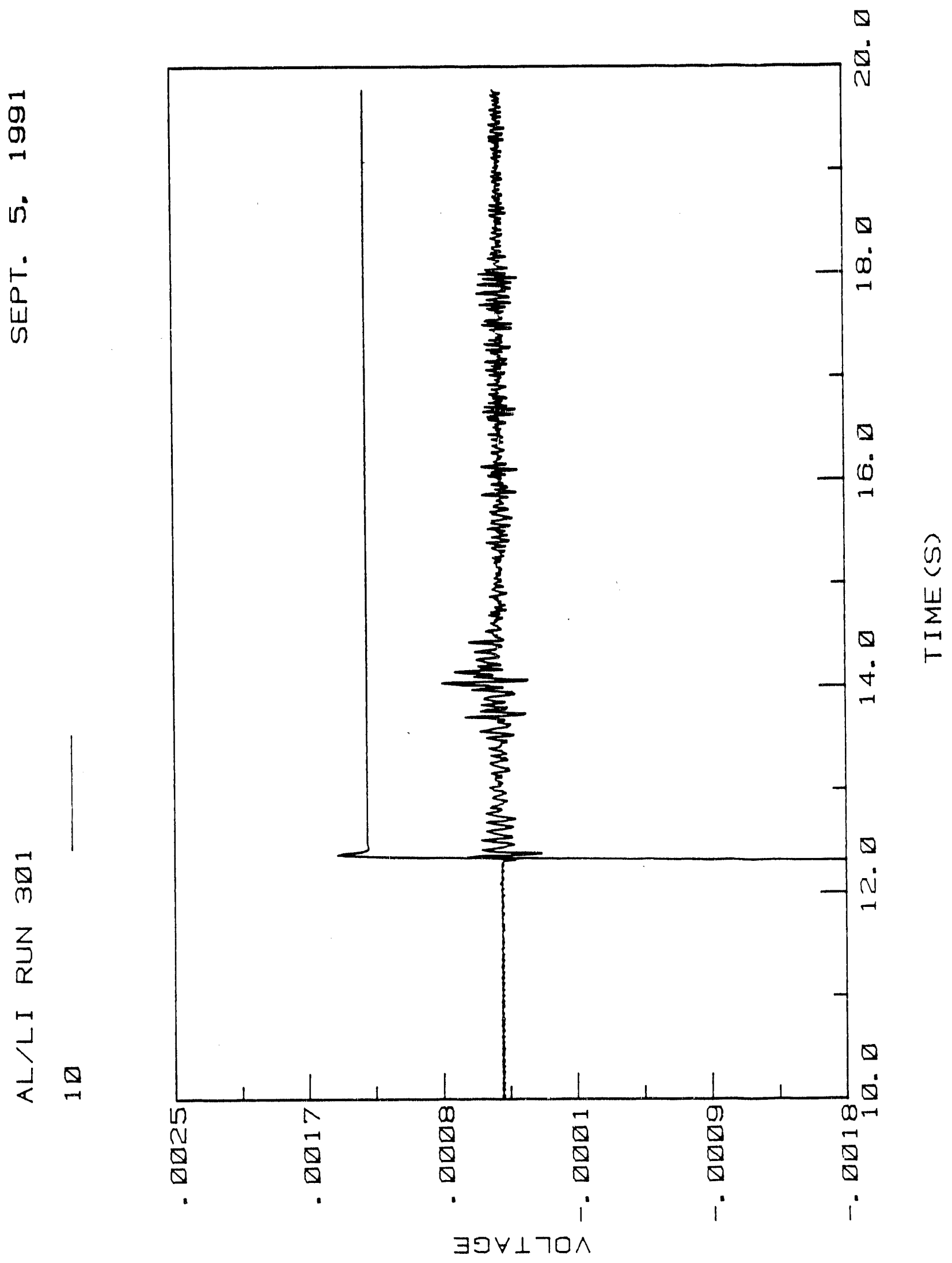




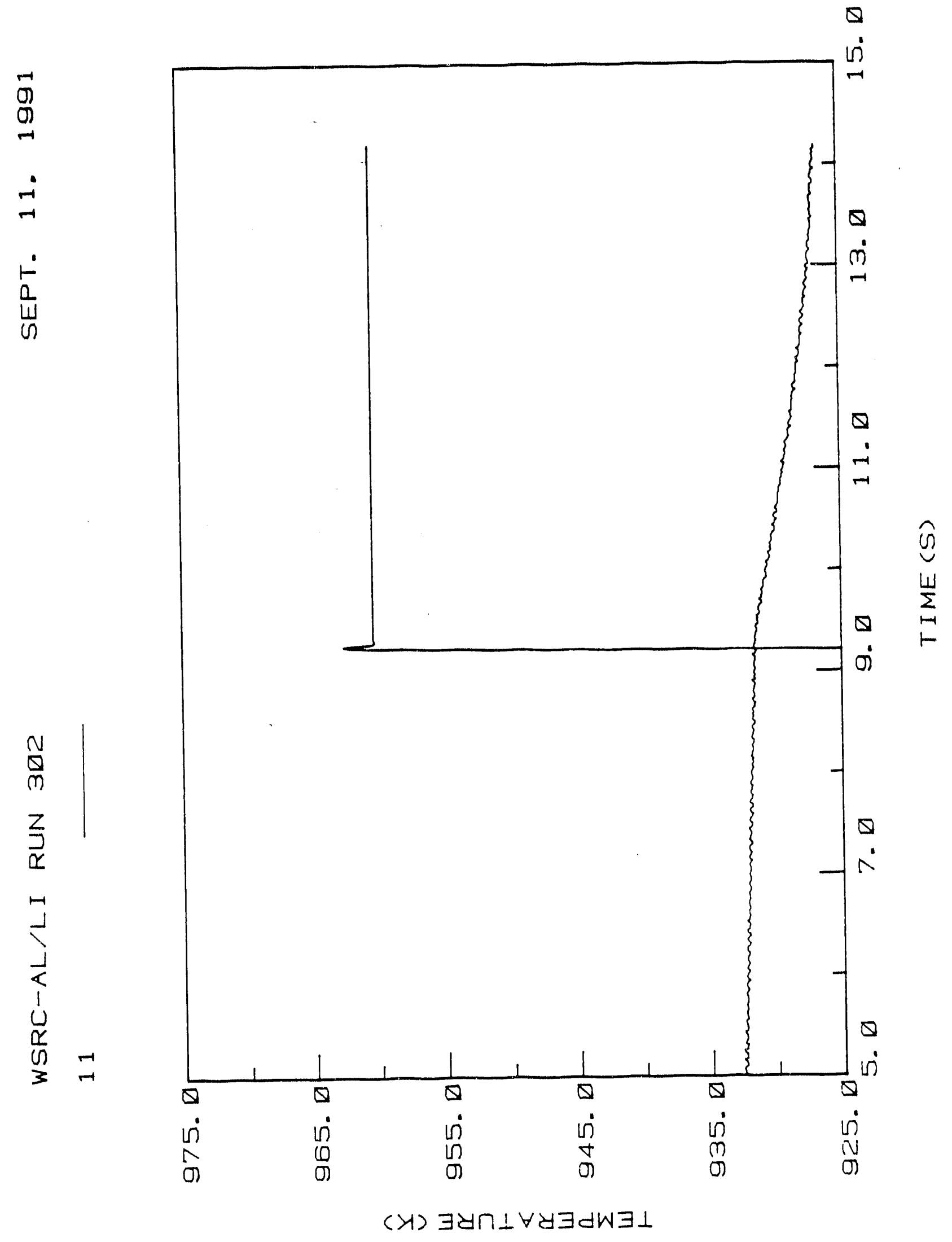




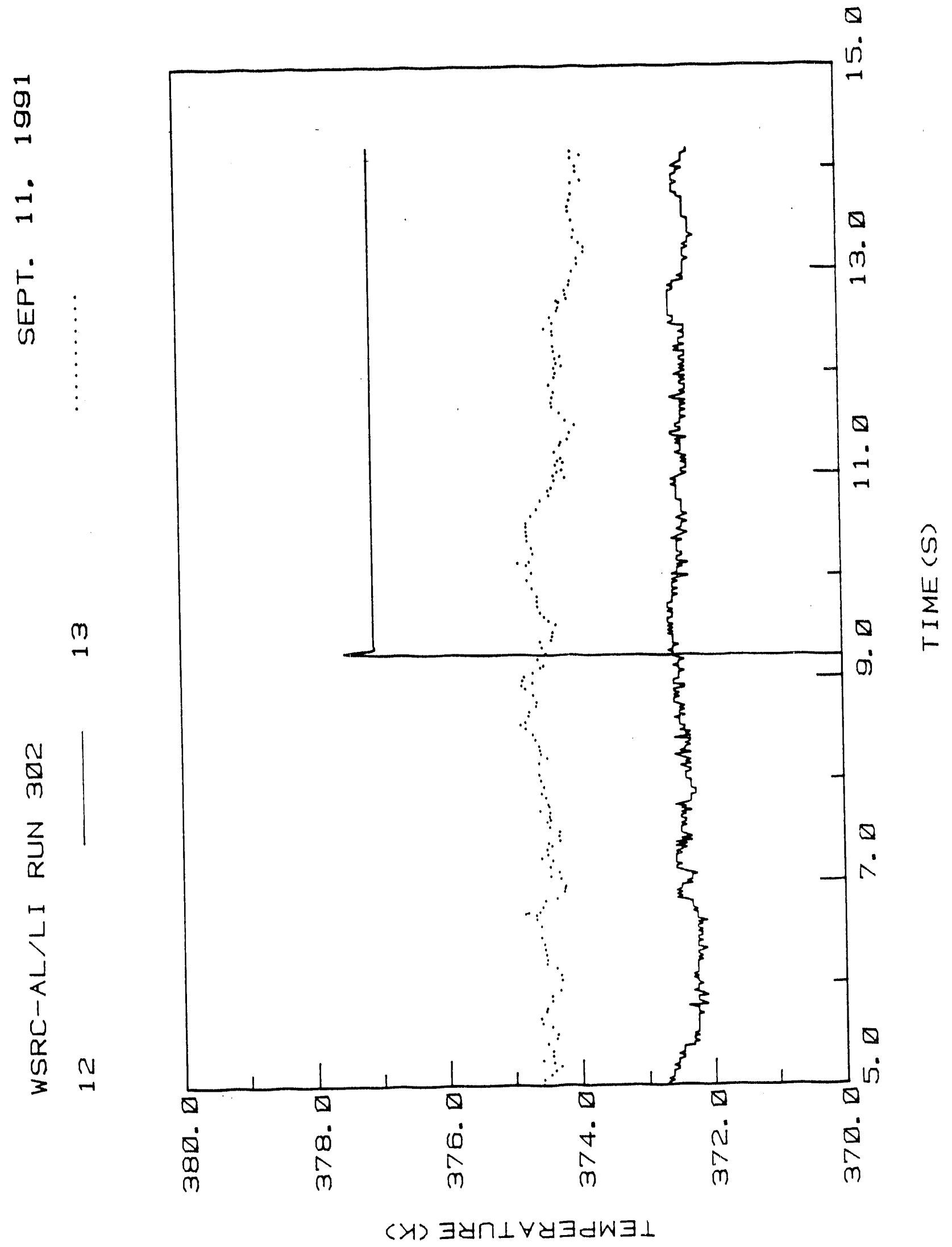




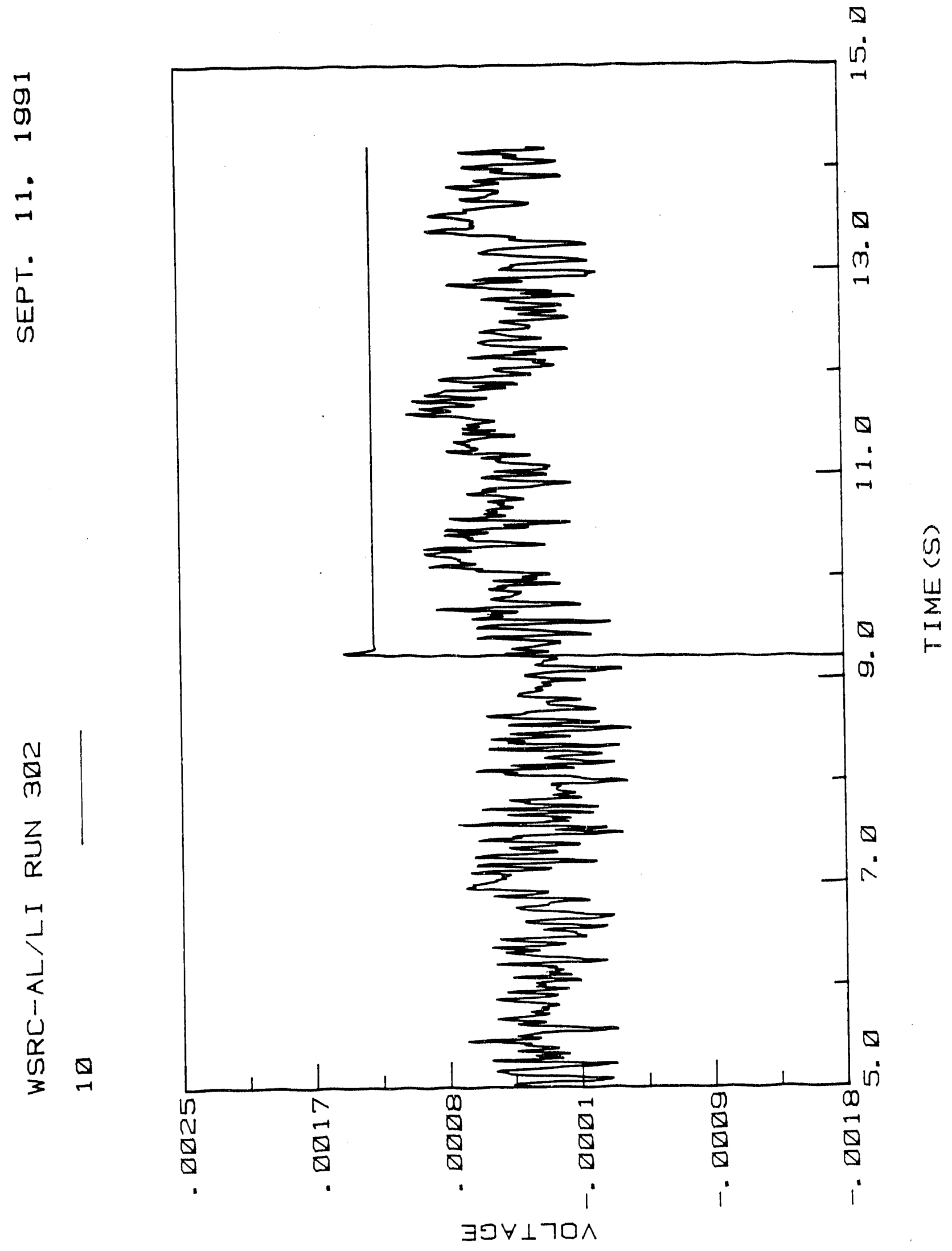




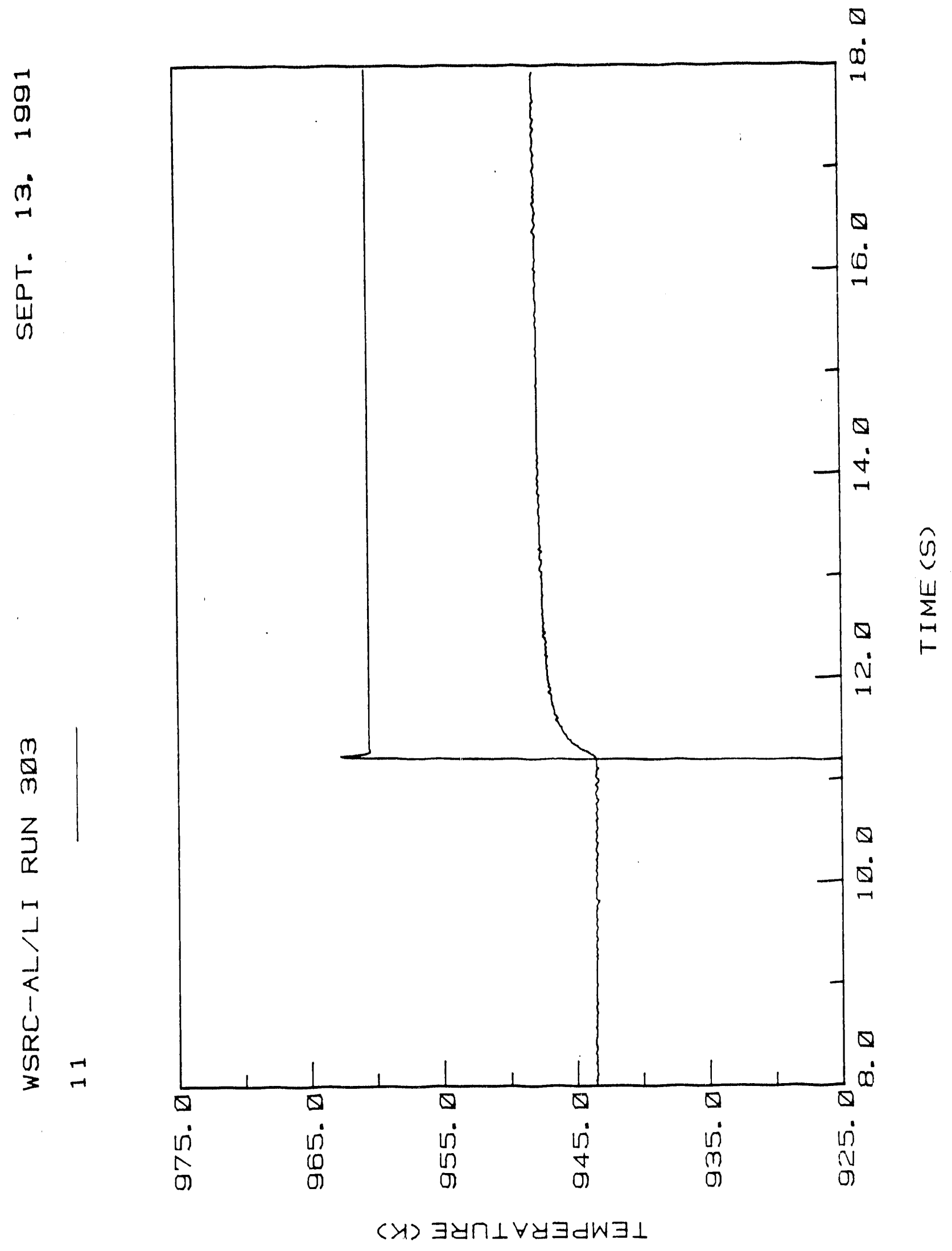




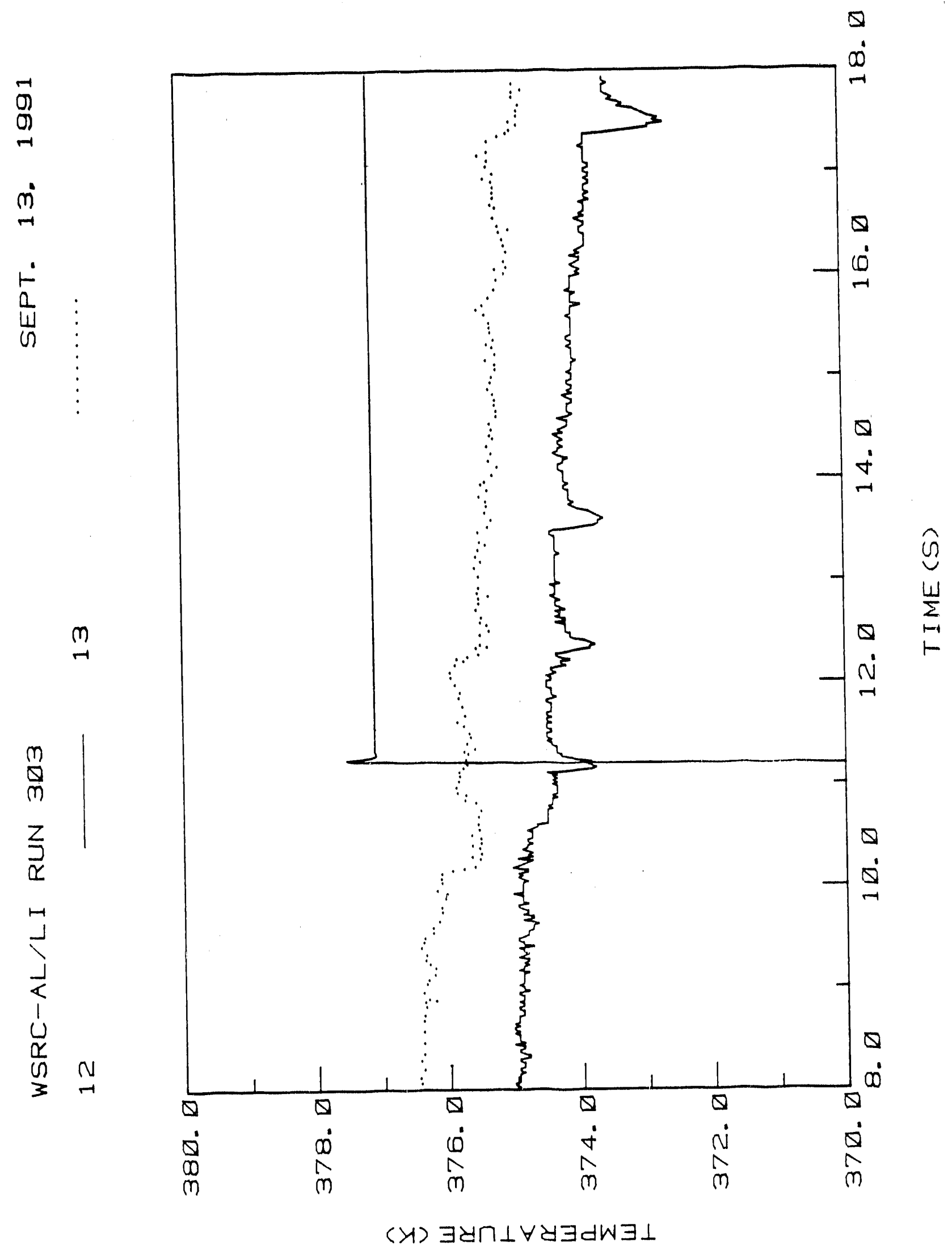




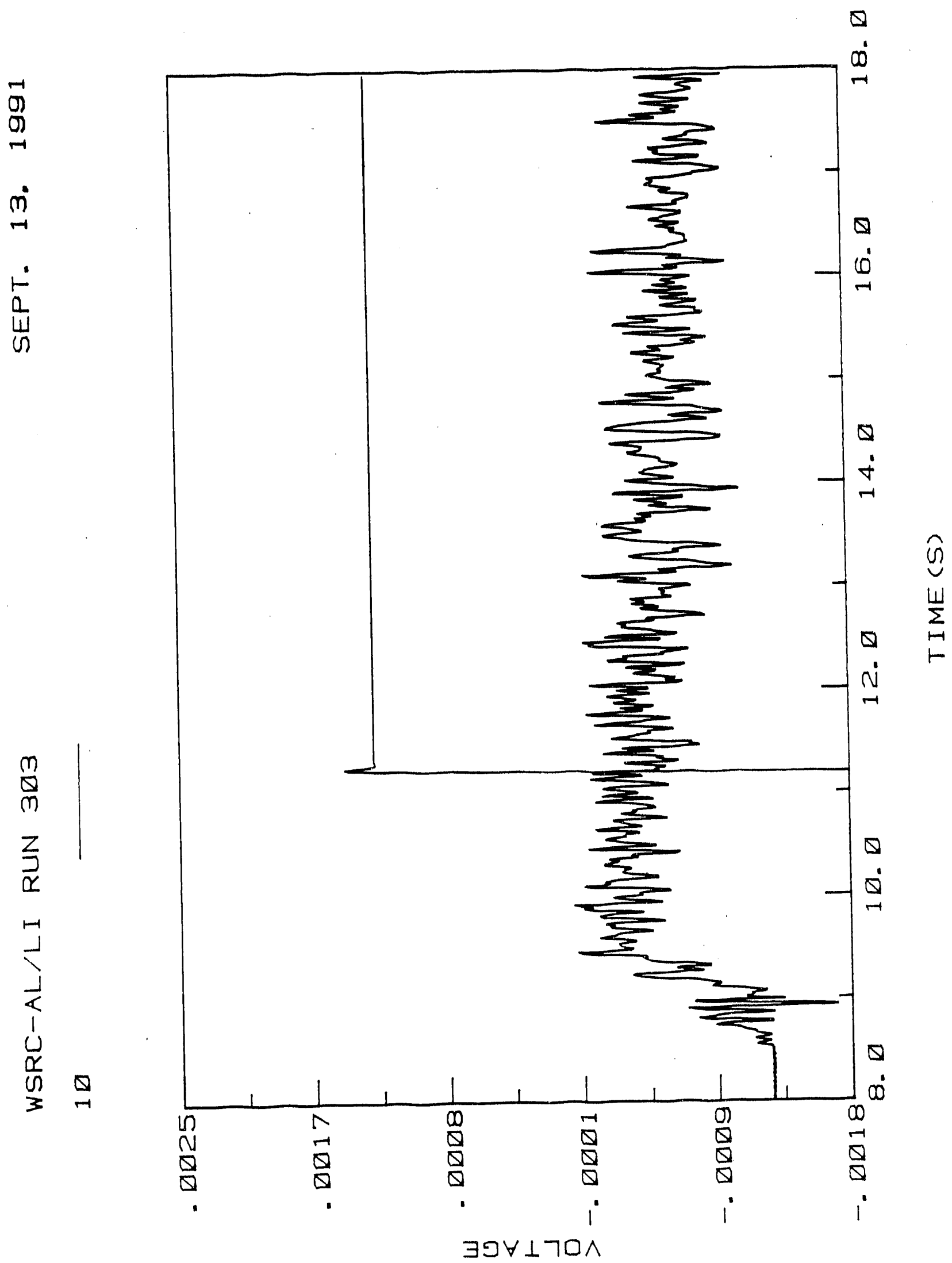




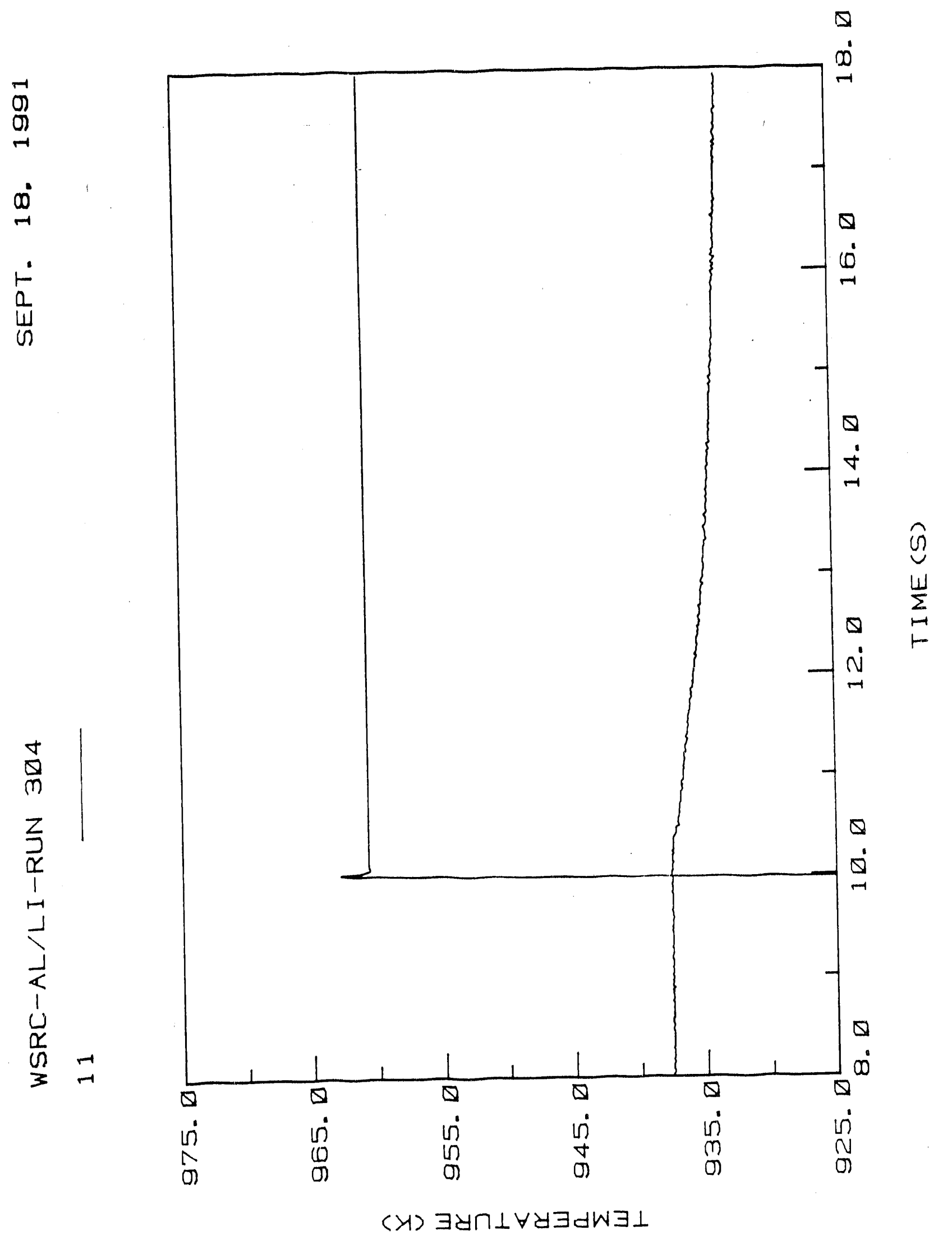




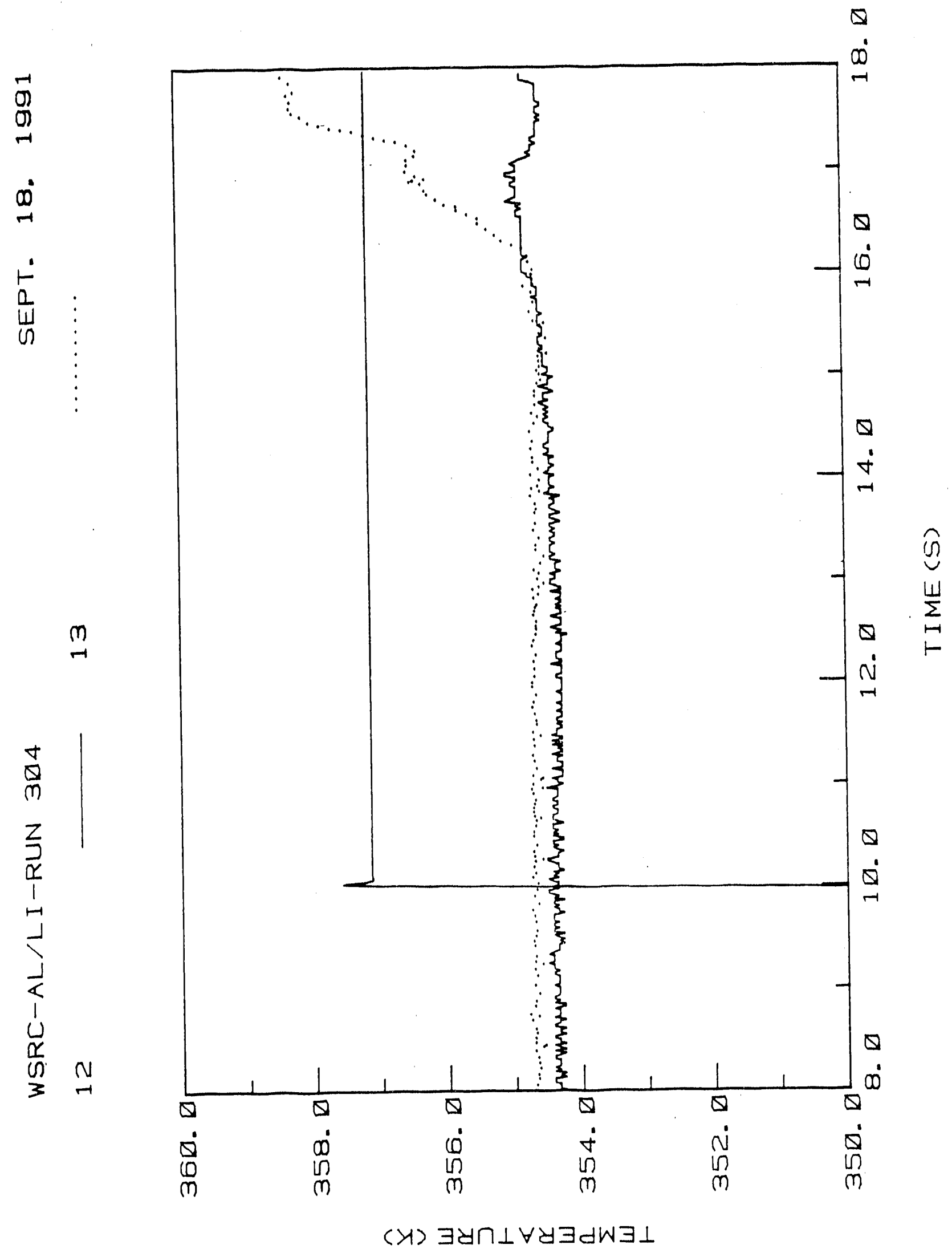




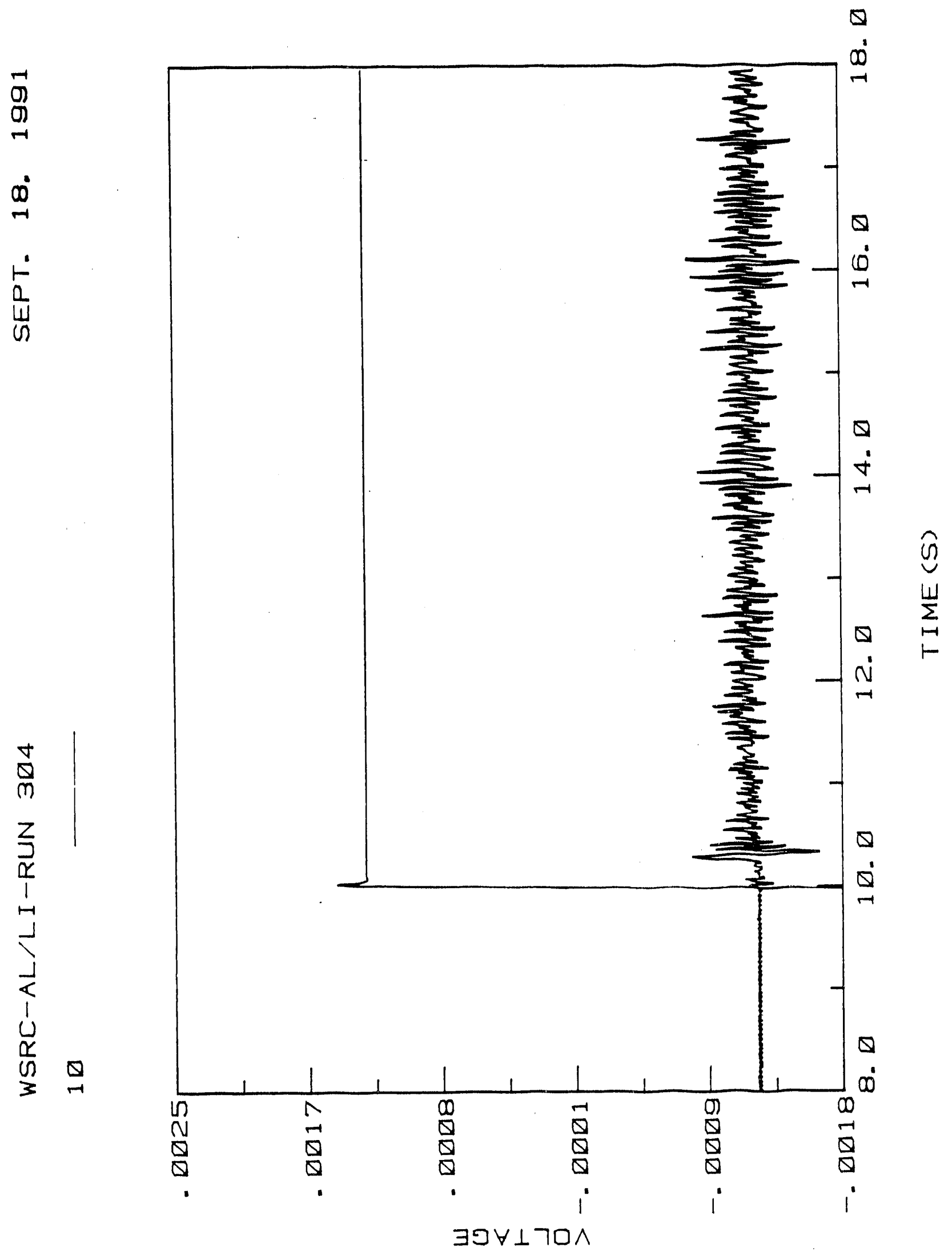




\section{APPENDIX B \\ REFLEX Spreadsheet Listing of Experimental \\ Parameters and Measurements}

This appendix includes a REFLEX spreadsheet listing of the experimental parameters and measurements. Some of the 85 fields are input fields (I) while others are calculated fields (C). An explanation of each field and its units are given below. All entries in a row are for the same run.

Field
RUN
MASSAL
RHOAL
DEPTHH2O
VOLAL
FLOWRATE
DJET
UBAR
TIME
RJET
HFALL
UJETCORR
DJETCORR
WEBER
LOVERDCORR
LSTARBREAK
LBREAKUP
JETTIME1
JETTIME2
RODDELAY
RODTOP
RODBOTTOM
LJETCORR
TPASSJET
JG
VOIDMEAS
DEBRISMASS
25MM
19MM
12.5MM
9.5MM
$6.7 M M$
4.75MM

\begin{tabular}{|c|c|}
\hline Description & I or $\mathrm{C}$ \\
\hline Run Number & 1 \\
\hline Mass of melt injected $(\mathrm{gm})$ & I \\
\hline Density of melt $\left(\mathrm{gm} / \mathrm{cm}^{3}\right)$ & I \\
\hline Water pool depth $(\mathrm{cm})$ & I \\
\hline Volume of melt $\left(\mathrm{cm}^{3)}\right.$ & $\mathrm{C}$ \\
\hline Flowrate of melt $(\mathrm{gm} / \mathrm{s})$ & $\mathrm{C}$ \\
\hline Initial melt jet diameter $(\mathrm{m})$ & I \\
\hline Average jet velocity at crucible $(\mathrm{cm} / \mathrm{s})$ & $\mathrm{C}$ \\
\hline Time for complete melt ejection(s) & $\mathrm{C}$ \\
\hline Initial melt jet radius (m) & $\mathrm{C}$ \\
\hline Jet fall distance to water surface $(\mathrm{cm})$ & I \\
\hline Jet velocity at water surface $(\mathrm{cm} / \mathrm{s})$ & $\mathrm{C}$ \\
\hline Jet diameter at water surface (m) & $\mathrm{C}$ \\
\hline Jet Weber number at water surface & $\mathrm{C}$ \\
\hline Jet breakup length $\div$ DJETCORR & $\mathrm{C}$ \\
\hline Dimensionless jet breakup length & $\mathrm{C}$ \\
\hline Dimensional jet breakup length $(\mathrm{cm})$ & $\mathrm{C}$ \\
\hline Time for jet to water surface(s) & I \\
\hline Time for jet to water bottom(s) & I \\
\hline Delay time after jet initiation till rod drops(s) & 1 \\
\hline Time for rod to water surface(s) & I \\
\hline Time for rod to water bottom(s) & I \\
\hline Length of jet at water surface $(\mathrm{cm})$ & $\mathrm{C}$ \\
\hline Time for jet to pass any interface(s) & $\mathrm{C}$ \\
\hline Superficial velocity of gas injection $(\mathrm{cm} / \mathrm{s})$ & 1 \\
\hline Measured void fraction in septifoil & I \\
\hline Total mass of debris sieved ( $\mathrm{gm}$ ) & I \\
\hline Mass of debris GT $25 \mathrm{~mm}(\mathrm{gm})$ & I \\
\hline Mass of debris GT $19 \mathrm{~mm}$, LT $25 \mathrm{~mm}(\mathrm{gm})$ & I \\
\hline Mass of debris GT $12.5 \mathrm{~mm}, \mathrm{LT} 19 \mathrm{~mm}(\mathrm{gm})$ & I \\
\hline Mass of debris GT $9.5 \mathrm{~mm}, \mathrm{LT} 12.5 \mathrm{~mm}(\mathrm{gm})$ & I \\
\hline Mass of debris GT $6.7 \mathrm{~mm}, \mathrm{LT} 9.5 \mathrm{~mm}(\mathrm{gm})$ & I \\
\hline Mass of debris GT $4.75 \mathrm{~mm}, \mathrm{LT} 6.7 \mathrm{~mm}(\mathrm{gm})$ & I \\
\hline
\end{tabular}




3.35MM
2.36MM
2.00MM
1.19MM
833UM
600UM
500UM
300UM
212UM
150UM
106UM
75UM
53UM
45UM
LT45UM
CUM\%LT75UM
CUM\%LT106UM
CUM\%LT150UM
CUM\%LT212UM
CUM\%LT300UM
CUM\%LT500UM
CUM\%LT600UM
CUM\%LT833UM
CUM\%LT1.19MM
CUM\%LT2.00MM
CUM\%LT2.36MM
CUM\%LT3.35MM
CUM\%LT4.75MM
CUM\%LT6.70MM
CUM\%LT9.50MM
CUM\%LT12.5MM
CUM\%LT19.0MM
CUM\%LT25.0MM
CUM\%GT25.0MM
PDF64UM
PDF90.5UM
PDF128UM
PDF181UM
PDF256UM
PDF400UM
PDF550UM
PDF716.5UM
PDF1.012MM
PDF1.60MM

Mass of debris GT $3.35 \mathrm{~mm}$, LT $4.75 \mathrm{~mm}(\mathrm{gm})$ Mass of debris GT $2.36 \mathrm{~mm}$, LT $3.35 \mathrm{~mm}$ (gm) Mass of debris GT $2.00 \mathrm{~mm}$, LT $2.36 \mathrm{~mm}(\mathrm{gm})$ Mass of debris GT $1.19 \mathrm{~mm}, \mathrm{LT} 2.00 \mathrm{~mm}(\mathrm{gm})$ Mass of debris GT $833 \mu \mathrm{m}, \mathrm{LT} 1.19 \mathrm{~mm}(\mathrm{gm})$ Mass of debris GT $600 \mu \mathrm{m}, \mathrm{LT} 833 \mu \mathrm{m}(\mathrm{gm})$ Mass of debris GT $500 \mu \mathrm{m}, \mathrm{LT} 600 \mu \mathrm{m}(\mathrm{gm})$ Mass of debris GT $300 \mu \mathrm{m}$, LT $500 \mu \mathrm{m}(\mathrm{gm})$ Mass of debris GT $212 \mu \mathrm{m}, \mathrm{LT} 300 \mu \mathrm{m}(\mathrm{gm})$ Mass of debris GT $150 \mu \mathrm{m}, \mathrm{LT} 212 \mu \mathrm{m}(\mathrm{gm})$ Mass of debris GT $106 \mu \mathrm{m}$, LT $150 \mu \mathrm{m}(\mathrm{gm})$ Mass of debris GT $75 \mu \mathrm{m}, \mathrm{LT} 106 \mu \mathrm{m}(\mathrm{gm})$ Mass of debris GT $53 \mu \mathrm{m}$, LT $75 \mu \mathrm{m}(\mathrm{gm})$ Mass of debris GT $45 \mu \mathrm{m}$, LT $53 \mu \mathrm{m}(\mathrm{gm})$ Mass of debris less than $45 \mu \mathrm{m}(\mathrm{gm})$ Cumulative \% of Debris LT $75 \mu \mathrm{m}$ Cumulative \% of Debris LT $106 \mu \mathrm{m}$ Cumulative \% of Debris LT $150 \mu \mathrm{m}$ Cumulative \% of Debris LT $212 \mu \mathrm{m}$ Cumulative \% of Debris LT $300 \mu \mathrm{m}$ Cumulative $\%$ of Debris LT $500 \mu \mathrm{m}$ Cumulative $\%$ of Debris LT $600 \mu \mathrm{m}$ Cumulative \% of Debris LT $833 \mu \mathrm{m}$ Cumulative \% of Debris LT $1.19 \mathrm{~mm}$ Cumulative \% of Debris LT $2.00 \mathrm{~mm}$ Cumulative \% of Debris LT $2.36 \mathrm{~mm}$ Cumulative \% of Debris LT $3.35 \mathrm{~mm}$ Cumulative \% of Debris LT $4.75 \mathrm{~mm}$ Cumulative \% of Debris LT $6.70 \mathrm{~mm}$ Cumulative \% of Debris LT $9.50 \mathrm{~mm}$ Cumulative \% of Debris LT $12.5 \mathrm{~mm}$ Cumulative $\%$ of Debris LT $19.0 \mathrm{~mm}$ Cumulative \% of Debris LT $25.0 \mathrm{~mm}$ Cumulative \% of Debris GT $25.0 \mathrm{~mm}$ Debris Size PDF at $64 \mu \mathrm{m}$ Debris Size PDF at $90.5 \mu \mathrm{m}$ Debris Size PDF at $128 \mu \mathrm{m}$ Debris Size PDF at $181 \mu \mathrm{m}$ Debris Size PDF at $256 \mu \mathrm{m}$ Debris Size PDF at $400 \mu \mathrm{m}$ Debris Size PDF at $550 \mu \mathrm{m}$ Debris Size PDF at $716.5 \mu \mathrm{m}$ Debris Size PDF at $1.012 \mathrm{~mm}$ Debris Size PDF at $1.60 \mathrm{~mm}$ 
PDF2.18MM PDF 2.86MM PDF4.05MM PDF5.73MM PDF8.10MM PDF11.0MM PDF15.75MM PDF22.0MM
Debris Size PDF at $2.18 \mathrm{~mm}$ Debris Size PDF at $2.86 \mathrm{~mm}$ Debris Size PDF at $4.05 \mathrm{~mm}$ Debris Size PDF at $5.73 \mathrm{~mm}$ Debris Size PDF at $8.10 \mathrm{~mm}$ Debris Size PDF at $11.0 \mathrm{~mm}$ Debris Size PDF at $15.75 \mathrm{~mm}$ Debris Size PDF at $22.0 \mathrm{mrn}$
C

C

C

C

C

C

C

C 
WSRC LI/AL-WATER RAPID STEAM GENERATION JANUARY 1992

\begin{tabular}{|c|c|c|c|c|c|c|c|c|}
\hline UN & MASSAL & DEPTHH 20 & RHOAL & VOLAL & FLOWRATE & DJET & UBAR & ITME \\
\hline 101 & 97.5 & 100 & 2.36 & 41.31 & 163.866 & 0.00635 & 219.36 & 0.6 \\
\hline 02 & 7 & 86 & 36 & & 162.766 & 0.00635 & 217.89 & \\
\hline 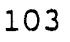 & 74.9 & 86.4 & 2.36 & 31.74 & 162.826 & 0.00635 & 217.97 & 6 \\
\hline 04 & & 86.4 & 2.36 & 5 & .278 & 0.0 & $2: 4.56$ & \\
\hline 05 & 80 . & 86.4 & 2.5 & 3 & 16 & 0. & 216.06 & 3 \\
\hline 201 & 100.8 & 30.5 & 2.36 & 42.71 & 162.581 & 0.0 & 217.64 & .62 \\
\hline 202 & & 305 & & & & & .45 & \\
\hline 204 & 10 & 30.5 & 2.36 & & 63 & 0. & 216.95 & .0 \\
\hline 205 & 110.3 & 30.5 & 2.36 & 46.74 & 162.206 & 0.00 & 217.14 & .68 \\
\hline 206 & 109 & 30.5 & 2.36 & 46.19 & 162.687 & 0.0 & 217.78 & .67 \\
\hline 207 & & 30 . & 2.36 & & & & 217.89 & .4 \\
\hline 301 & 98.4 & 91.4 & 2.36 & 41.69 & 161.311 & 0.00635 & 215.94 & .61 \\
\hline 302 & 23 & 77.5 & 2.36 & 9.75 & 164.286 & 0.00635 & 219.92 & .14 \\
\hline 0 & & 41.9 & 2.36 & & 164.571 & 0.0 & 220.31 & \\
\hline 30 & 91.4 & 30.5 & 2.36 & 38.73 & 163.214 & 0.00635 & 218.49 & 0.56 \\
\hline
\end{tabular}




\begin{tabular}{lrrrrrrr} 
RJET & LBREAKUP & HFALL & UJETCORR & DJETCORR & WEBER & LOVERDCORR & LSTARBREAK \\
\hline 0.00318 & -11.26 & 8.20 & 253.36 & 0.00591 & 102.88 & 19.06 & 12.41 \\
0.00318 & 8.86 & 21.80 & 300.34 & 0.00541 & 132.34 & 16.39 & 10.67 \\
0.00318 & 8.86 & 21.80 & 300.40 & 0.00541 & 132.41 & 16.38 & 10.66 \\
0.00318 & 8.94 & 21.80 & 297.93 & 0.00539 & 129.75 & 16.58 & 10.79 \\
0.00318 & 8.90 & 21.80 & 299.01 & 0.00540 & 130.92 & 16.49 & 10.74 \\
0.00318 & 5.08 & 77.70 & 446.83 & 0.00443 & 240.02 & 11.46 & 7.46 \\
0.00318 & 5.08 & 77.70 & 447.23 & 0.00444 & 240.78 & 11.44 & 7.45 \\
0.00318 & 5.08 & 77.70 & 446.50 & 0.00443 & 239.37 & 11.48 & 7.47 \\
0.00318 & 5.08 & 77.70 & 446.59 & 0.00443 & 239.55 & 11.48 & 7.47 \\
0.00318 & 5.08 & 77.70 & 446.90 & 0.00443 & 240.16 & 11.46 & 7.46 \\
0.00318 & 5.08 & 77.70 & 446.95 & 0.00443 & 240.26 & 11.46 & 7.46 \\
0.00318 & 9.66 & 16.80 & 282.06 & 0.00556 & 119.91 & 17.39 & 11.32 \\
0.00318 & 7.80 & 30.70 & 329.45 & 0.00519 & 152.75 & 15.03 & 9.79 \\
0.00318 & 5.51 & 66.30 & 422.47 & 0.00459 & 222.01 & 12.01 & 7.82 \\
0.00318 & 5.08 & 77.70 & 447.25 & 0.00444 & 240.82 & 11.44 & 7.45
\end{tabular}




\begin{tabular}{|c|c|c|c|c|c|c|c|}
\hline JETTIME I & JETTIME2 & RODDELAY & RODTOP & RODBOTTOM & LJETCORR & TPASSJET & JG \\
\hline----- & $-\cdots-$ & $-\cdots-\infty$ & ----- & ------- & $---150--\overline{75}$ & $---\overline{0}-\overline{0}$ & - \\
\hline $\begin{array}{l}0.03 \\
0.08\end{array}$ & 0.43 & & & & & $\begin{array}{l}0.60 \\
0.47\end{array}$ & \\
\hline $\begin{array}{l}0.08 \\
0.08\end{array}$ & $\begin{array}{l}0.37 \\
0.37\end{array}$ & & - & & $\begin{array}{l}141.16 \\
138.18\end{array}$ & 0.46 & \\
\hline 0.09 & 0.38 & & & & 107.26 & 0.36 & \\
\hline 0.08 & 0.37 & & & & 149.51 & 0.50 & \\
\hline 0.23 & 0.30 & & & & 277.04 & $0 . \in 2$ & \\
\hline 0.23 & 0.30 & & & & 196.78 & 0.41 & \\
\hline 0.23 & 0.30 & 0.06 & 0.32 & 0.42 & 281.29 & 0.63 & \\
\hline 0.23 & 0.30 & 0.06 & 0.32 & 0.42 & 303.68 & 0.68 & \\
\hline 0.23 & 0.30 & 0.06 & 0.32 & 0.42 & 299.42 & 0.67 & \\
\hline 0.23 & 0.30 & 0.16 & 0.41 & 0.51 & 210.07 & 0.47 & \\
\hline 0.07 & 0.39 & & & & 172.06 & 0.61 & \\
\hline 0.11 & 0.35 & & & & 46.12 & 0.14 & 15.30 \\
\hline 0.21 & 0.31 & & & & 147.87 & 0.35 & 15.30 \\
\hline 0.23 & 0.30 & 0.07 & 0.32 & 0.42 & 250.46 & 0.56 & \\
\hline
\end{tabular}




\begin{tabular}{rrrrrrrr} 
VOIDMEAS & DEBRISMASS & $25 \mathrm{MM}$ & $19 \mathrm{MM}$ & $12.5 \mathrm{MM}$ & $9.5 \mathrm{MM}$ & $6.7 \mathrm{MM}$ & $4.75 \mathrm{MM}$ \\
\hline & 36.0267 & 0 & 0 & 6.7635 & 12.8641 & 4.9176 & 5.6821 \\
& 76.3743 & 0 & 0 & 12.9945 & 11.2337 & 10.0113 & 11.3617 \\
& 74.6599 & 0 & 0 & 24.6611 & 11.4534 & 5.0216 & 4.6565 \\
& 57.6115 & 0 & 0 & 19.8639 & 17.4265 & 8.8417 & 4.9386 \\
& 80.8811 & 16.2454 & 24.1857 & 22.9776 & 8.4593 & 5.9166 & 2.3326 \\
& 98.2045 & 0 & 0 & 8.4384 & 14.3286 & 19.6 & 24.5099 \\
& 71.7907 & 0 & 0 & 7.0707 & 16.3787 & 17.8154 & 17.0221 \\
& 102.0846 & 0 & 32.1676 & 38.6696 & 13.1786 & 7.5375 & 6.8995 \\
& 110.1377 & 0 & 39.7173 & 42.5266 & 12.7383 & 8.6217 & 3.0591 \\
& 108.8788 & 0 & 25.154 & 43.6246 & 17.6339 & 10.8966 & 7.5799 \\
0.21 & 76.5797 & 0 & 7.0349 & 20.4411 & 26.9906 & 10.5321 & 8.1515 \\
0.27 & 98.4641 & 23.7382 & 37.4323 & 19.2466 & 10.2082 & 3.0349 & 2.5833 \\
& 22.8888 & 0 & 0 & 0 & 0 & 6.7109 & 12.9554 \\
& 57.5376 & 0 & 0 & 0 & 9.9591 & 20.3636 & 18.8129 \\
& 91.4534 & 0 & 0 & 17.623 & 29.1154 & 27.6775 & 13.265
\end{tabular}




\begin{tabular}{rrrrrrrrr}
$3.35 \mathrm{MM}$ & $2.36 \mathrm{MM}$ & $2.00 \mathrm{MM}$ & $1.19 \mathrm{MM}$ & $833 \mathrm{UM}$ & $600 \mathrm{UM}$ & $500 \mathrm{UM}$ & $300 \mathrm{UM}$ & $212 \mathrm{UM}$ \\
\hdashline 1.1544 & 1.6707 & 0.4409 & 1.2104 & 0.4646 & 0.3821 & 0.0776 & 0.2701 & 0.0561 \\
2.1135 & 4.4389 & 1.09 & 5.4437 & 3.7077 & 3.9403 & 1.028 & 4.9128 & 1.4657 \\
1.9703 & 4.1299 & 1.7714 & 5.7204 & 3.1701 & 3.0253 & 0.826 & 3.8451 & 1.2919 \\
1.0818 & 1.5951 & 0.71 & 1.4253 & 0.5778 & 0.4354 & 0.0947 & 0.3556 & 0.1039 \\
0.0345 & 0.0779 & 0.0337 & 0.1587 & 0.0741 & 0.0311 & 0.0082 & 0.0341 & 0 \\
7.2365 & 8.3729 & 2.6365 & 6.1041 & 2.4932 & 1.7496 & 0.324 & 1.3974 & 0.3746 \\
4.9647 & 3.4331 & 1.22 & 2.1555 & 0.6821 & 0.4059 & 0.0931 & 0.297 & 0.0857 \\
1.2637 & 1.0011 & 0.4035 & 0.4828 & 0.178 & 0.1072 & 0.0246 & 0.0902 & 0.0246 \\
1.4486 & 0.9233 & 0.2199 & 0.4105 & 0.184 & 0.105 & 0.0325 & 0.1011 & 0.0254 \\
1.6703 & 0.9948 & 0.4248 & 0.5933 & 0.1387 & 0.0815 & 0.0168 & 0.0418 & 0.01 \\
1.7831 & 1.0696 & 0.17 & 0.2303 & 0.0696 & 0.029 & 0.0094 & 0.0304 & 0.0104 \\
0.7513 & 0.7145 & 0.1632 & 0.3658 & 0.1284 & 0.0433 & 0.0132 & 0.0271 & 0.0134 \\
1.6161 & 1.1208 & 0.0664 & 0.2806 & 0.0666 & 0.0393 & 0.003 & 0.0157 & 0.0034 \\
3.192 & 2.6259 & 0.7704 & 1.1926 & 0.2507 & 0.1413 & 0.0344 & 0.1141 & 0.0304 \\
1.6173 & 1.1733 & 0.2229 & 0.3719 & 0.1267 & 0.0664 & 0.0174 & 0.0454 & 0.0131
\end{tabular}




\begin{tabular}{rrrrrrrr}
$150 U M$ & lO6UM & \multicolumn{1}{l}{ 75UM } & 53UM & 45UM & LT45UM & CUM\&LT75UM & CUM\&LT106UM \\
\hline 0.042 & 0.0224 & 0.0083 & -0.0 & 0 & 0 & 0.000 & 0.023 \\
1.3479 & 0.6276 & 0.1771 & 0.0572 & 0 & 0 & 0.075 & 0.307 \\
1.4692 & 1.0504 & 0.4437 & 0.1513 & 0 & 0 & 0.203 & 0.797 \\
0.0942 & 0.0567 & 0.0369 & 0 & 0 & 0 & 0.000 & 0.064 \\
0 & 0 & 0 & 0 & 0 & 0 & 0.000 & 0.000 \\
0.3238 & 0.2016 & 0.114 & 0 & 0 & 0 & 0.000 & 0.116 \\
0.0743 & 0.053 & 0.0385 & 0 & 0 & 0 & 0.000 & 0.054 \\
0.0234 & 0.0324 & 0 & 0 & 0 & 0 & 0.000 & 0.000 \\
0.0217 & 0 & 0 & 0 & 0 & 0 & 0.000 & 0.000 \\
0.0168 & 0 & 0 & 0 & 0 & 0 & 0.000 & 0.000 \\
0.0269 & 0 & 0 & 0 & 0 & 0 & 0.000 & 0.000 \\
0 & 0 & 0 & 0 & 0 & 0 & 0.000 & 0.000 \\
0.0072 & 0 & 0 & 0 & 0 & 0 & 0.000 & 0.000 \\
0.0249 & 0.0223 & 0 & 0 & 0 & 0 & 0.000 & 0.000 \\
0.0142 & 0.0087 & 0.006 & 0 & 0 & 0 & 0.000 & 0.007
\end{tabular}




CUM\&LT150UM
0.085
1.129
2.204
0.162
0.000
0.321
0.127
0.032
0.000
0.000
0.000
0.000
0.000
0.039
0.016

\begin{tabular}{cr} 
CUMZLT212UM & CUM\&LT300UM \\
\hline 0.202 & 0.358 \\
2.893 & 4.812 \\
4.172 & 5.902 \\
0.326 & 0.506 \\
0.000 & 0.000 \\
0.651 & 1.033 \\
0.231 & 0.350 \\
0.055 & 0.079 \\
0.020 & 0.043 \\
0.015 & 0.025 \\
0.035 & 0.049 \\
0.000 & 0.014 \\
0.031 & 0.046 \\
0.082 & 0.135 \\
0.032 & 0.046
\end{tabular}

CUMZIT500UM
11.107
11.052
1.0524
0.042
2.455
0.764
0.167
0.135
0.063
0.088
0.041
0.115
0.333
0.096

\begin{tabular}{rr} 
CUM\&LT600UM & CUMVLT833UM \\
\hline 1.323 & 2.383 \\
12.591 & 17.750 \\
12.159 & 16.211 \\
1.288 & 2.044 \\
0.052 & 0.091 \\
2.785 & 4.567 \\
0.894 & 1.459 \\
0.191 & 0.296 \\
0.164 & 0.259 \\
0.078 & 0.153 \\
0.101 & 0.139 \\
0.055 & 0.099 \\
0.128 & 0.300 \\
0.393 & 0.639 \\
0.115 & 0.187
\end{tabular}




\begin{tabular}{rrrrr} 
CUM\&L1.19MM & CUM\&LT2.00MM & CUMqLT2.36MM & CUM\&LT3.35MM & CUM\&LT4.75MM \\
\hline 3.67 & 7.03 & 8.26 & 12.89 & 16.10 \\
22.60 & 29.73 & 31.71 & 37.52 & 40.29 \\
20.46 & 28.12 & 30.49 & 36.02 & 38.66 \\
3.05 & 5.52 & 6.75 & 9.52 & 11.40 \\
0.18 & 0.38 & 0.42 & 0.52 & 0.56 \\
7.11 & 13.32 & 16.01 & 24.53 & 31.90 \\
2.41 & 5.41 & 7.11 & 11.89 & 18.81 \\
0.47 & 0.94 & 1.34 & 2.32 & 3.56 \\
0.43 & 0.80 & 1.00 & 1.84 & 3.15 \\
0.28 & 0.83 & 1.22 & 2.13 & 3.66 \\
0.23 & 0.53 & 0.75 & 2.15 & 4.48 \\
0.23 & 0.60 & 0.77 & 1.49 & 2.25 \\
0.59 & 1.82 & 2.11 & 7.00 & 14.06 \\
1.07 & 3.15 & 4.49 & 9.05 & 14.60 \\
0.33 & 0.73 & 0.98 & 2.26 & 4.03
\end{tabular}




\begin{tabular}{|c|c|c|c|c|}
\hline CUM\&LT6. $70 \mathrm{MM}$ & CUM\&LT9.5OMM & CUMFLT12.5MM & CUM\&LT19. OMM & CUMOLT25. OMM \\
\hline$----\overline{0}$ & $0-0-10-2$ & 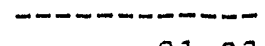 & 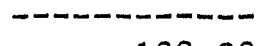 & n \\
\hline 31.87 & 45.52 & 81.23 & 100.00 & 100.00 \\
\hline 55.17 & 68.27 & 82.98 & 100.00 & 100.00 \\
\hline 44.90 & 51.62 & 66.97 & 100.00 & 100.00 \\
\hline 19.97 & 35.32 & 65.57 & 100.05 & 100.05 \\
\hline 3.44 & 10.76 & 21.22 & 49.63 & 79.53 \\
\hline .56 .86 & 76.82 & 91.41 & 100.00 & 100.00 \\
\hline 42.52 & 67.34 & 90.15 & 100.00 & 100.00 \\
\hline 10.32 & 17.70 & 30.61 & 68.49 & 100.00 \\
\hline 5.93 & 13.76 & 25.32 & 63.94 & 100.00 \\
\hline 10.63 & 20.63 & 36.83 & 76.90 & 100.00 \\
\hline 1.5 .12 & 28.87 & 64.12 & 90.81 & 100.00 \\
\hline 4.88 & 7.96 & 18.33 & 37.87 & 75.89 \\
\hline 70.67 & 99.99 & 99.99 & 99.99 & 99.99 \\
\hline 47.29 & 82.69 & 99.99 & 99.99 & 99.99 \\
\hline 18.53 & 48.80 & 80.63 & 99.90 & 99.90 \\
\hline
\end{tabular}




100.00
100.00
100.00
100.05
99.62
100.00
100.00
100.00
100.00
100.00
100.00
100.00
99.99
99.99
99.90

\begin{tabular}{rr} 
PDF64UM & PDF90.5UM \\
\hline 0.000 & 0.743 \\
3.404 & 7.480 \\
9.211 & 19.171 \\
0.000 & 2.066 \\
0.000 & 0.000 \\
0.000 & 3.745 \\
0.000 & 1.730 \\
0.000 & 0.000 \\
0.000 & 0.000 \\
0.000 & 0.000 \\
0.000 & 0.000 \\
0.000 & 0.000 \\
0.000 & 0.000 \\
0.000 & 0.000 \\
0.000 & 0.212
\end{tabular}

PDF128UM
1.413
18.676
31.975
2.237
0.000
4.666
1.678
0.721
0.000
0.000
0.000
0.000
0.000
0.881
0.216

\begin{tabular}{rrr} 
PDF181UM & PDF256UM & PDF400UM \\
\hline 1.880 & 1.770 & 3.749 \\
28.465 & 21.808 & 32.1 .63 \\
31.740 & 19.663 & 25.751 \\
2.637 & 2.049 & 3.086 \\
0.000 & 0.000 & 0.211 \\
5.318 & 4.335 & 7.115 \\
1.669 & 1.357 & 2.069 \\
0.370 & 0.274 & 0.442 \\
0.318 & 0.262 & 0.459 \\
0.249 & 0.104 & 0.192 \\
0.567 & 0.154 & 0.198 \\
0.000 & 0.155 & 0.138 \\
0.507 & 0.169 & 0.343 \\
0.698 & 0.600 & 0.992 \\
0.250 & 0.163 & 0.248
\end{tabular}




\begin{tabular}{|c|c|c|c|c|c|c|}
\hline PDF550UM & PDF716.5UM & PDF $1.012 \mathrm{MM}$ & PDF1.60MM & PDF2.18MM & PDF2.86MM & PDF 4.0EMM \\
\hline- & $\cdots$ & $\ldots$ & -- & $---\infty$ & $---\infty-$ & -- \\
\hline 2.154 & 4.552 & 3.612 & 4.148 & 3.399 & 4.684 & 2.28 \\
\hline 13.460 & 22.142 & 13.598 & 8.800 & 5.495 & 5.871 & 1.97 \\
\hline 11.064 & 17.391 & 11.894 & 9.459 & 6.591 & 5.587 & 1.885 \\
\hline 1.644 & 3.244 & 2.809 & 3.054 & 3.423 & 2.797 & 1.341 \\
\hline 0.101 & 0.165 & 0.257 & 0.242 & 0.116 & 0.097 & 0.030 \\
\hline 3.299 & 7.646 & 7.111 & 7.674 & 7.458 & 8.612 & 5.263 \\
\hline 1.297 & 2.427 & 2.661 & 3.707 & 4.72 .1 & 4.830 & 4.940 \\
\hline 0.241 & 0.451 & 0.488 & 0.584 & 1.098 & 0.991 & 0.884 \\
\hline 0.295 & 0.409 & 0.468 & 0.460 & 0.555 & 0.847 & 0.939 \\
\hline 0.154 & 0.321 & 0.357 & 0.673 & 1.084 & 0.923 & 1.096 \\
\hline 0.123 & 0.163 & 0.255 & 0.371 & 0.617 & 1.411 & 1.663 \\
\hline 0.134 & 0.189 & 0.365 & 0.459 & 0.460 & 0.733 & 0.545 \\
\hline 0.131 & 0.737 & 0.815 & 1.513 & 0.806 & 4.946 & 5.043 \\
\hline 0.598 & 1.054 & 1.220 & 2.559 & 3.719 & 4.610 & 3.963 \\
\hline 0.190 & 0.312 & 0.388 & 0.502 & 0.677 & 1.296 & 1.263 \\
\hline
\end{tabular}




\begin{tabular}{rrrrr} 
PDF5.73MM & PDF8.1OMM & PDF11.0MM & PDF15.75MM & PDF22.0MM \\
\hline 8.088 & 4.875 & 11.902 & 2.888 & 0.000 \\
7.629 & 4.682 & 4.903 & 2.618 & 0.000 \\
3.198 & 2.402 & 5.114 & 5.082 & 0.000 \\
4.396 & 5.481 & 10.083 & 5.304 & 0.000 \\
1.479 & 2.613 & 3.486 & 4.371 & 4.984 \\
12.799 & 7.128 & 4.864 & 1.322 & 0.000 \\
12.159 & 8.863 & 7.605 & 1.515 & 0.000 \\
3.466 & 2.637 & 4.303 & 5.828 & 5.252 \\
1.424 & 2.796 & 3.855 & 5.940 & 6.010 \\
3.570 & 3.574 & 5.399 & 6.164 & 3.850 \\
5.459 & 4.912 & 11.748 & 4.107 & 1.531 \\
1.345 & 1.101 & 3.456 & 3.007 & 6.336 \\
29.026 & 10.471 & 0.000 & 0.000 & 0.000 \\
16.768 & 12.640 & 5.770 & 0.000 & 0.000 \\
7.438 & 10.809 & 10.612 & 2.965 & 0.000
\end{tabular}




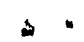
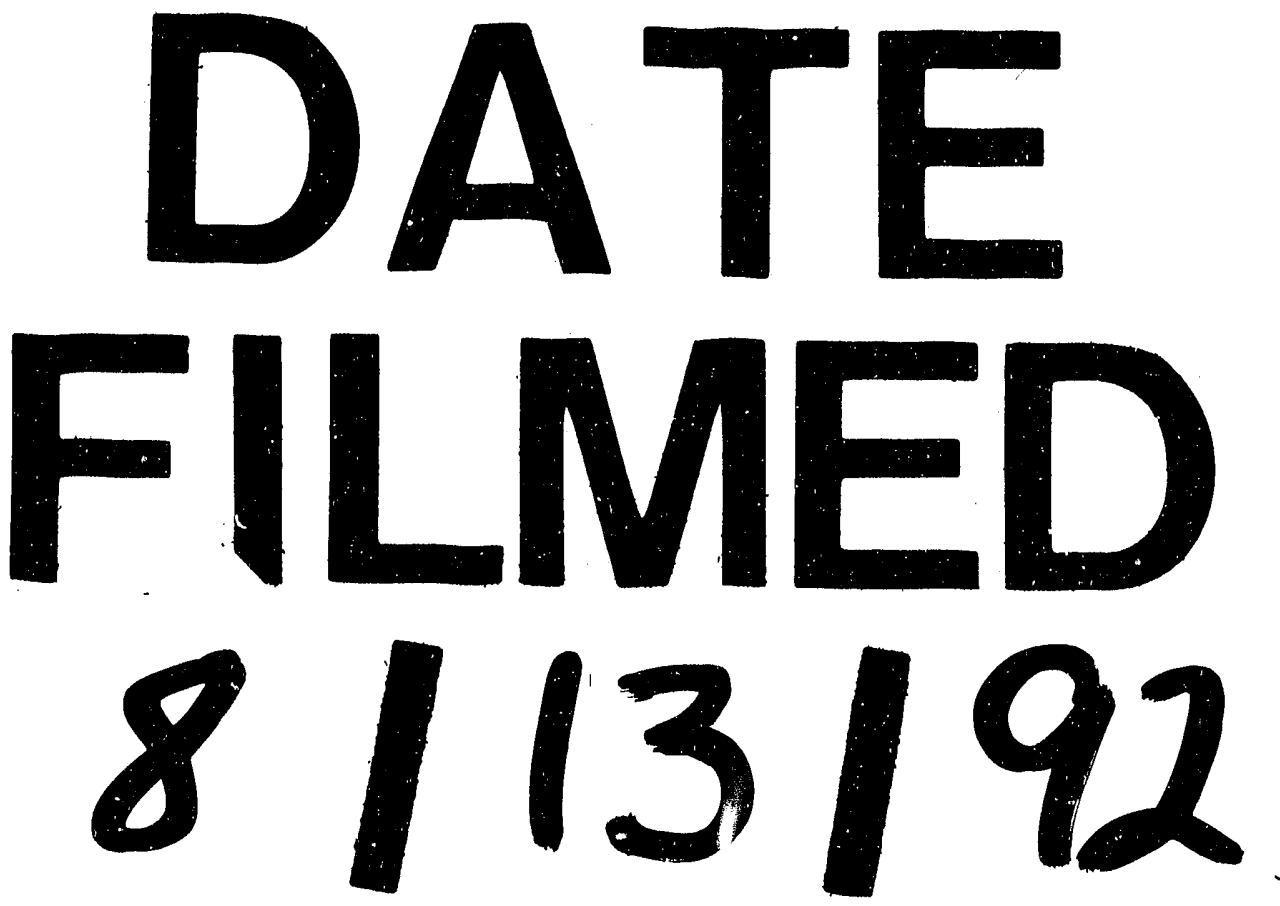